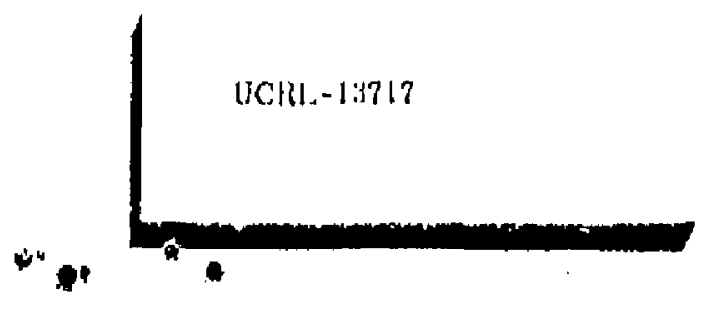

PJISH' I RL'PULI'

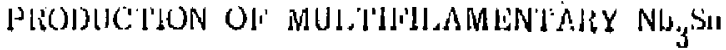

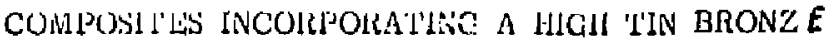

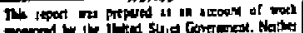

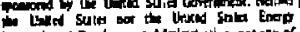

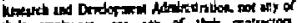

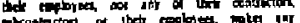

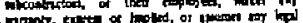

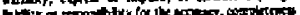

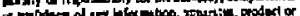

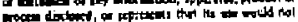

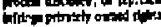

Conlracl No, 1695603
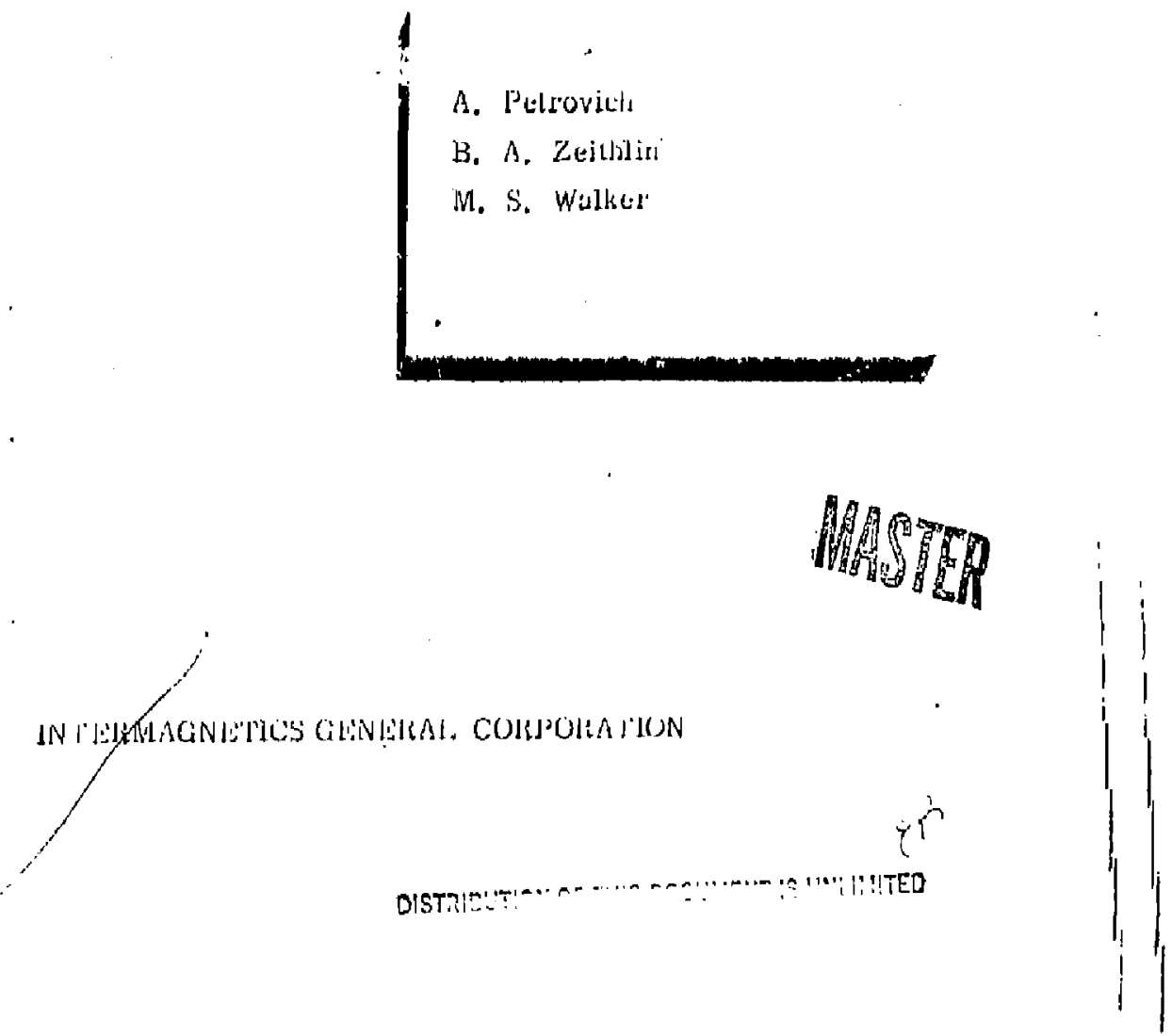


\title{
PHASE I REPORT
}

\section{PRONUCTION OF MULTIEILAMENTARY $\mathrm{Nb}_{3} \mathrm{Sn}$ COMPOSITES INCORPORATING A HIGH TIN BRONZE}

\author{
A. Petrovich \\ B. A. Zeitlin \\ H. S. Walker
}

Contract No. 1695603

\section{Study Commissioned By: Lawrence Livermore Laboratory Iivermore, California}
Study Rerformed By: Intermagnetics General Corp. Guilderland, New York

\section{August 20,1976}

(Revised 12/17/76)

IGC Report No. 876-6 


\section{ABSTRACT}

The economics and processing methods have been examfined for the fabrication of multifllamentary $\mathrm{No}_{3} \mathrm{Sin}$ using a high tin bronze reactive matrix. Four conductor configurations utilizlng the high tin bronze were compared with a conventional $\mathrm{Cu}_{\mathrm{u}}-13$ wt $\% \mathrm{sn}$ bronze. The most promising of these desigas 1s potentially 40\% lower in cost per ampere peter than the conventional composite. Large hydrostatic extrusion facillties, whtch are required for the high tin processing, are not presently avallable in this country but can be made by conversion of conventional presses. They exist in Europe.

Bxpertoents were conducted to Investigate the applicability of hydrostatic extruston, and billet components were successfully prepared using the hydrostatic extrusion technique. We have concluded that the economics, avallabllity of facilities and inttial fabrication results are favorable for this type of conductor and that the next stage in this progran of scale up ti) extrusion and drawing of $2^{\prime \prime}-3^{\prime \prime}$ dianeter composite billets chould be tmdertaken. 
TABLE OP CONTENTS

Section

Page

1.0 INTRODUCTION

1.1 Purpose of the Present Study

1.2 Description of the Proposed Method of Fabricating Mult Ifilamentary $\mathrm{Nb}_{3} \mathrm{Sn}$

\subsection{BACKGROUND}

2.1 Hydrostatic Extruston

2.1.1 The Capabilities of Hydrostatic Extrusion

2.1.2 Existing Commerclal Facilitles

2.1.3 Facturs Affecting Pressures Necessary for $2-6$ Bydrostatic Extrusion

2.2 Hest Generation During Extrusion

2.3 The Nature of Alloys in Tin-Copper Systems and the Reaction of Such Alloys with Niobium

2.4 Previous Work on Muitifilamentary $\mathrm{Nb}_{3} \mathrm{Sn}$ Composites Including TIn Rich Copper-Tin Alloys

3.0 ANALYSIS OF CONDUCTOR AND PROCESS DESIGN

3.1 Drawing of Composites Including Tin or a Tin Rich Copper-Tin Alloy

3.2 Itterdiffusion of Tin at: Cu, per During

Homogenization of the Tin kicik Constituent

$\begin{array}{lll}\text { 3.2.1 Dlfusion In Experimental Composices } & 3-9 \\ \text { 3.2.2 Implications of Three Diffusion Studies } & 3-11\end{array}$ on Composite Design

3.3 Btllet Construction

3.4 Extriston of Composite Billets Containfing the Tin Alloy

4.0 MODEL CONDUCTOR AND ECONOMIC CONSIDERATIONS

4.1 Design of a 10,000 Anpere (12 Tesla) Conductor Using the Proposed Technique 
TABLE OR CONTENTS

(continued)

Section

4.3 Kodel Conduçtor 2

4.4 Hodel Conductor $3 \quad 4-5$

4.5 Model Conductor $4 \quad 4-6$

4.6 Processing of Conductors 4-6

4.7 Economle Comparioon with Conductors Produced by 4-7 the Convent1onal Process

5.0 ECONOMTC CONSIDERATIONS

5.1 Quantity of Reactive Hatrly Necessary to React the 5-1 Nlabium Filaments

5.2 Cost Differences Resulting From Modifications of the 5-2 Processing

5.3 Other Factors Affecting Conductor Cost $5-2$

6.0 SLMMARY \& CONCLUSIONS 6-1

7.0 RCOHENDATIONS 7-1

8.0 REFELENCES 8-1

APPENDIX A

APPENDIX B 
1 Schematic representation of the hydrostatic and conventional extrusfon processes.

2 Uod III Endless Chamber Extruder: a continuous hydrostatic extruder under development at Westerm Electrlc Compeny (reproduced from "Westem Electric Company ContInuous Hydrostatic W1re lxtrusion", Paul Andrus and Glenn Schmehl, Manufacturing of Hire Seminar, Society of Manufacturing Englneers, Feb. 11, 1976, Phtladelphia, Pennsylvania.

3 Examples of the reduction obtainable by hydrostatic extrusion through a single die. (Reproduced from Anon.", "tiydrostatic Extrusion - A Viable Method of Metal Forning", Metallugria end Metal Forming, October, 1973, p. 325).

a) Example of the piping defect occurring during the conventional extrusion of a composite billet.

b) Distortion of fllament pattern occurring near the ends of the extruded rod.

Calculated curves of the temperature varlation over the cross section of the extrusion product at the die extt for several values of coefficient of friction and billet velocity. (From Guha, R. M., LengyeI, B., Vol. 54, p. 117, Jan. 1974).

Calcilated curves of temperature rise of the extruded Laterlat as a function of the progress of the extrusion. (From Guha, R. K., Lengye1, B., Vol. 54, p. 117, Jart, 1974).

7 The rise in emergent temperature as a function of ram travel for lead as measured by Singer, Al-Samarral, Jourmal Institute of Netals, Vol. 69, p. 225.

8 Experimentally determined rise in emergent temperature as a function of ram travel for tin billets subjected to varlous reduction ratios. (From Singer Al-Samarral, Joural Institute of Metals, Vol. 89, p. 225.

9 Schematic representation of the extrusion die, billet and die and position coordinates referred to by equations 2.2 through 2.5. 
LIST OF ILIDSTRATIONS

(continued)

Elgure

Page

11 Experimental composite used in diffusion studies consisting

of a core of Sn-16,77 Cu within a jacket of pure copper

composite diameter is $0.015^{\prime \prime}(.38 \mathrm{mo}$ ). Kagnification: $300 \mathrm{~K}$

12 Same-experimental composite as shown In Figure 11 but drawn to a diameter of $\left.0.008^{\prime \prime}(.20 \mathrm{~mm})\right)$. Magnification: $500 x$

13 As cast atructure of the $\$ \mathrm{Sp}-16.7 \% \mathrm{Cu}$ allog used to produce the composite drawn in Figure 11 and 12. Magnification: 200K

14 Photomlcrograph of a longitudinal sectlon of the composite ohown in Figure 11. Magnfictation: 300X

15 Photonlerograph of a longidudinal section of the composite shown in Figure 11. Magnification: $90 \mathrm{X}$

16 Photomlcrograph showing the cross section of the composite wire after a heat treatment of $20 \mathrm{brs}$, at $400^{\circ} \mathrm{C}$.

17 Photomicrograph showing the cross section of the composite wre after a heat treatment of $68 \mathrm{hrs}$, at $400^{\circ} \mathrm{C}$.

18 Photomicrograph of a sample of the composite shown in Figure 11 after a heat treatment of $61 \mathrm{hirg}$. at $600^{\circ} \mathrm{C}$.

19 Cross section of the hexagonal elements used in packing the billets used in the study of hydrostatic extruston. The dimensions of this hexagonal rod is $9.177^{\mathrm{th}}(.450 \mathrm{~cm})$ side to side. The core, which is a Si-16.7\% Cu alloy, occuptes 707 of the cross section.

20 Cross section of the hexagonal elemeat having as its core pure tin. The dimenston of the hexagonal rod is $0.177^{\prime \prime}$ $(.450 \mathrm{~cm})$ side to stde. The core occuptes $70 \%$ of the composite.

21 Cross section of billet showing the stacking of elerents.

22 Drawing of the billet used in the hydrostatic extrusion experiments.

23 Photograph of weld at the tail section of the experimental billet.

24 Photograph of the weld at the nose section of the experimental billet. 


\section{LIST OF ILLUSTRATIONS \\ (continued)}

Figure

Page

25 Reglon temaining in die after interruption of the 4.7 to 1

extrusion ( $6 \mathrm{ft} /$ min billet velocity).

25 Region remalning in die after interruption of the 9.5 to 1

extrusion ( $3 \mathrm{ft} /$ win billet velocity).

27 Cross section of rod extruded with a 4.7 to 1 reduction ratio and $a$ billet speed of $6 \mathrm{ft}$ per minute.

28 Crose vection of rod extruded with a 9.5 to 1 reduction racio and a billet speed of $6 \mathrm{ft}$ per tolnute.

29 Adiabatic temperature rise anid extrusion fressure as a function of reduction ratio.

30 Temperature rise as a function of reduction ratlo for a composite billet extruded at a speed of $.13 \mathrm{ft} /$ min with water cooling of the exlsting rod.

31 Schematlc representation of the second stage of billet packing for Node1 Cooductor I.

32 Unit cell of bfllet stacking for the second stage extrusion of Model Conductor I.

33 Schematic representation of the first stage of billet packing for Model Conductor II.

34. Unit cell of the first stage of packing of Model Conductor II. 4-16

35 Schematic representation of the second stage billet of Model 4-17 Conductor II.

36 Untt cell of stacking of hexagonal elements in the second stage billet of Mode1 Conductor II.

37 Conductor \#3: First stage and second stage packing. 4-19

38 Conductor 14: Unit cell of first stage packing. 4-20

39 Conductor "14: Second stage blllet preparation. 4-21

B-1 Photomicrograph of a 0.015 " diameter copper/Sn $-16.7 \% \mathrm{Cu} \quad \mathrm{B}-2$

B-2 composite interdiffused at $600 \mathrm{C}$ for 60 hours B-2

B-3 B-3 


\section{LIST OF TABLES}

Table

Page

3-1 Sumary of Hydrostatfe Extrusion Experiments 3-28

$4-2$ Sumary of Bodel Conductor I $4-9$

4-2 Sumary of Hode1 Conductor II 4-10

4-3 Sumary of Model Conductor III 4-11

4-4 Sumary of tbdel Conductor IV 4-12

5-i vatrlx to Superconductor Ratlo for a 13.5 wt $5-4$ 7 Bronze Composite and the Four Kodel Conduceors

5-2 Processing Wodiffcations for the Model Conductots and the Resulting Percentage Change in Cost of Processing Per Pound of Matertal

A-1 Some Eydrostatic Extrugion Fachlities Existing A-2 In the United States 


\subsection{INTRODUCTION}

\subsection{Purpose of the Pregent Study}

The CTR program at Laurenct livermore Laboratory envisions a high fjeld version of FERF (Fusion Engineering Research Facility) Involving a multifilawentary No, $5 \mathrm{n}$ composice capable of carrying 10,000 Amperes in a field of 12 Tesla. A conceptual design of the Ying-lang type mirror tagaets which will be an essential part of this facllity involves of the order of $7 \times 30^{4} \mathrm{~kg}$ of multifilameatary superconductor. 1 In vlew of this quantity of miterial, the following factors in the fabrlcation of the conductor becone very important:

1. The cost of manufacturing a conductor in large quantities. This is determined by the quantity of matertals necessary to produce a given number of amp-metere of conductor, the cost of these materials and the cost of the fabricition steps such as: billet preparation, extrusion, drawing and heat treatment. The number and nature of these fabrication steps in turn depends on the material components of the conductor.

2. The maxdmum single length of conductor of a given current carrying capacity which may be produced. Because of the present limftation on rod dzawing factlities of about 60 meters, the weight of a single length of composite is limited to about $250 \mathrm{~kg}$. The construction of a wagnet such as that for FERF would necessarily involve joining of several iengths of conductor. Conductor joints add to the difficulty and expense of magaet construction as well as increase the ohmic disgipation which must be carried off by the cryogenic system. However, the problem of conductor foints can be witigated to some extenc by lncreasing the billet yleld in agp-meters by reducing the quanticy of reaction matrix (bronze or copper) recessary to produce a given quantity of $\mathrm{Nb}_{3} \mathrm{Sn}$.

The purpose of the present study is to exemine a new technique of conductor design and fabrication which has become commercially feasible because of the 
Increasing comercialization of cold hydrostatic extrusion. The present study will emphasize the design of the conductor and its fabrication. The two factors in the conductor's fabrication mentioned above will be criticaliy examined.

\subsection{Description of the Proposed Method of Fabricating Multifilame titary itb $3 n$} Mujaifllamentary $\mathrm{Nb}_{3} \mathrm{Sn}$ composites are presently produced by the reaction of nlobfum fllameats with an a-bronze matrix provider efther by codiawing bro:ze Wth ainbiun or by the diffusion of extemally apjlted tin to copper/niobstra composites. While tin bronziss of composition thout $13-15$ wt $z$ itn requite annes?s after each $40 \%$ to $90 \%$ reductino in area, copper and nlobfum are sufficiently ductile to whthstand almost unlimited drawing without interwedfate anneals. Consequently, composites involping the external application of tin to a drakis nlobium/copper/tantalum composite are potentlally more economical than drawn bronze/niobtum/tantalum composites. However, there is a Ieservation to the application in EERF of a 10,000 \& (12 T) MF $\mathrm{M}_{3} \mathrm{Sn}$ supercondu tor produced by the external diffugion of tin into a copper/niobicul composite (external diffusion method). Since a cypical diffuston distance of tin in a crpper conposite is only on the order of $0.020^{\prime \prime}(.051 \mathrm{~cm})$ at the reaction temperatures, a conductor of this current carrying capacity wust be produced by cabling epveral strards of composte. In viek of the tremendous crushing forces estimated for the proposed coll, cables are not preferred.

The present study has been conducted to develop a monolithic conductor having the fabrication advantages of a copper based composite. In pariticular, we will examine the potential of the proposed conilv.tor for reducirg cunductor costs and increasing the amp-meter ydeld of an extrusion unic length of r.nductor. 
The pxoposed conductor essentially involves the replacepent of the conventional a-bronze in a monolithic conductor with a matrix of pure copper ani fllawents of a tin rich copper tin alloy (0 to 20 w/o copper),$^{2}$ Reaction of the niobium filaments proceeds by the diffusion of tin from the tin allog filaments to form the a-sronze which sucronds the niobium filaments and provides a vehicle for their reaction. The technique has been used succesefully by Hashiomoto et $a^{3}$ to produce shurt length\% of multifilamentary $\mathrm{Nb}_{3} \mathrm{Sn}$. Several advantages of this technique over the conventional a-bronze (uf to 15 wt $\%$ tin)/niobium composite are readily apparent:

1. A greater quantity of tin may be included in the reaction matrix. in order to be workable copper :Ich branzes cannot exceed 15 wt $\%$ tin. Beyond this concerization bronze becomes a two phased alloy consisting of $a-b r o n z a$ and the very brittle $z$ phase ${ }^{2}$ The result of the increased matrix tin concentration resulting frow the $i$ roposed technique is an Increased overall composite currect density, a reducticr in the quantity of materfals necessary for a gjven ampere meters of conductor, and an increase in the ampere-meter yield of the tillet. These factors result in a reduction in the conductor fabrication cost as well as longer conductor lengths per billet.

2. As demonstrated by Hashimoto et $\mathrm{al}^{3}$, the composites consisting of pure copper, tin-20\% copper and niabium way be drawa to tirej.r final diameter without a single anneal, the replacement of the a-bronze watrix with such a two element ratrix would eliginati the costly and time-consuming annealing schedule necessary to reduce a-bronze composites to their final diameter. The net result would not only be a reduction in conduc:ur cost but also 3 decrease in the time from billet consticuction to final conductor.

3. Casting of a-bronze to form the elements for billet preparation would be replaced by the casting of the lower melting point tin rich alloys and fabrication of pure copper elements. Here as well there is a potenclal cost savings since OFHC coppez is more easiliy woriced and the cost of casting tin rich alloys is less than that for a-bronze. 
Although the work of Hashimoto et at ${ }^{3}$ has demonstrated the feasibility of drawing and reacting the proposed conduccor, several questfong must be answered regarding the large scale prodaction of such composites. Among these are:

1. The ability to extrude cumposites consisting of copper, nlobium, t.In rich alloy and tantalum. Pressures required for the conventional extrugion of copper based composites at room temperature are prohlbitively high. The billec preieating to at least $5,50^{\circ} \mathrm{C}$ which is generally applied to reduce these pressures is significantly above the melting point of $t \mathrm{In}\left(232^{\circ} \mathrm{C}\right)$ and would therefore distupt the composite, A reasonable altemative, may however be found in room temperature hydrostatic extrusion. Although reductions of $15 / 1$ in area ${ }^{4}$ have been accomplished on OFAC copper by cold hydzostatic extrustion, the effect of billet heating resulting from dissipation of the energy of plastic deformation durfing cold hydrostatic extrusion must be examined.

2. The feasibility and procedure for producing the elements for billet stacking. These elements include hexagonal rods of the tin tich alloy. The drawing of pure tin or the tin rieh alloy by itself is made difficult by the softness of pure $t \ln$ and the brittleness of the th-copper alloys. The amount of jacketing with copper and the sowndness of the drawn jacketed rods must be determined.

3. The soundness of the tin or tin alloy filaments after reduction to the final diameter must be established.

4. The size and distribution of the tin alloy filaments which will ensure a sound conductor acd uniform diffusion wust be decermined. Limitations on the size of these filaments may result fron developtrent of kirkendall voids which should not engulf groups of nioblum filaments. As tin and copper Interdiffuse prior to reaction, non a-bronze phases tin-copper alloys neceasarlly form. Previous investigations suggest that $\mathrm{Nb}_{3} \mathrm{Sn}$ is not formed when niobium filawents ate In contact with copper tin alloys other than $\alpha$-bronze. The extent of their growth is therefore an important consideration in the design of an opr.imal conductor. 
5. The cost and ayaliability of hydrostatic extrusion facilities and its imfact on overall conductor fabrication cost must be established.

The first fhase of this study is Intended to answer those fundamental questions. Eaving determined those essential features of the conductor fabrication, this report will describe viable conductor options, will provide an assessment of the production economles of the proposed approach, and will suggect the details of further derelopment of full conductor composites to be carried out in the secend phase of this program.

The remafnder of the report is divided tato five chapters which will deal with the following aspects of the atudy:

Chapter 2 will provide background Information on the construction of composites consisting of tin rich alloys and hydrostatic extrusion of copper.

Chapter 3 will describe the analysis and experimentation conducted to answer the critical questions mentioned above.

Chapter 4 includes descriptions of model conductor.

Chapter 5 will provide an economic comparison between the proposed corductor desiges and a composite based on a 13.5 wt $\%$ bronze matrix.

Chapter 6 will provide conclustons on the present study and recommendation for further development. 


\subsection{BACKGROUND}

In this chapter we will priritie a background to digcussions presented in subequent chapters. Pertinent aspects of hydrnstatic extrusion such as the status of exfoting facilities, the alature of che process and heat generation during extrusion are diseussed. In connection with the design of a $\mathrm{Mr} \mathrm{Nb}_{3} \mathrm{Sn}$ composite Including a high tha bronze we will not only discuss prevlous successes th the area but also some aspects of the diffusion of tin in thi-copper alloys and the growth of alloy phases. Provious studles on the mechanical ptoperties of tincopper alloys are also summarized in this chapter.

\subsection{Hydrostatic Extrusion}

\subsubsection{The Capabilities of Hydrostatic Extrusion}

The fundamental difference between hydrostatic and conveational direct extrusion 1s illustrated in Figurs 1 . Instead of being in contact with $t i$ a container walls as in conventional extrusion, the blllet in hyd"ostatlc extrusion is gupported by a flutd over all surfaces except that in contact with the die. The extrusion driving force in hydrostatic extrusion is not provided directly to the end of the billet as in conventional extrusion. Instead the force is applied to the billet as a pressure applled over all surfaces exposed to the hydrostatic fluld. This mode of applying the extrusion driving force has at least three fundamentai advantages:

1. The hydrostatic pressure considerably enhances the ductility of the material befng extruded. Ihis aspect of netals which has been extensively Investigated by Bridgenan ${ }^{5}$ and others, results from the prevention of pores and microcracks which are involved in the mechanlsw of fracture. Consequently, a hydrostatic process permits the extruston of watertals which are too brittle to be extruded conventionally. There 1s, therefore, wuch greater assurance of producting a sound extrustion of copper or copper alloy composites at room temperature by hydrostatic extrusion than conventional extrusion. 


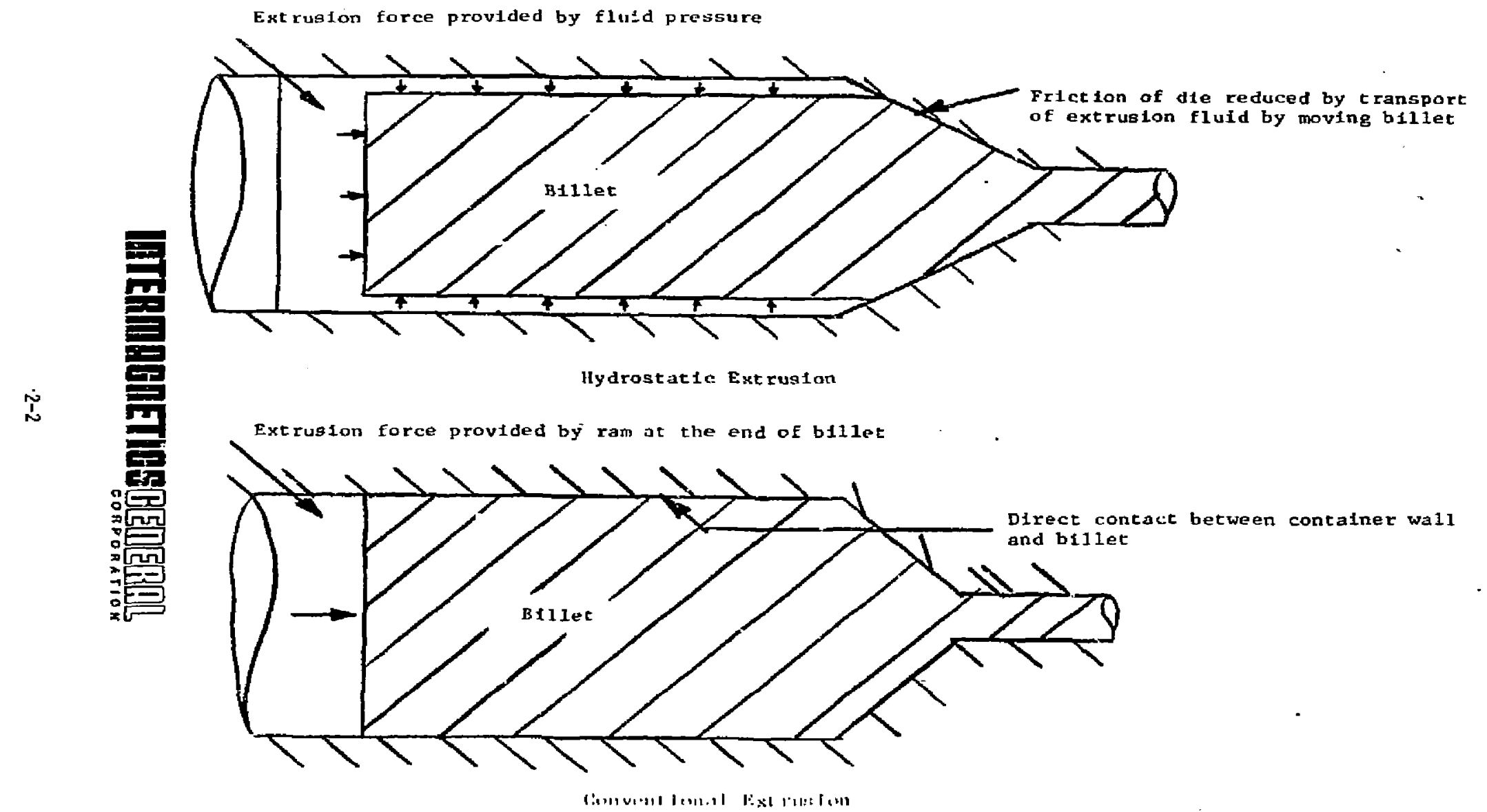

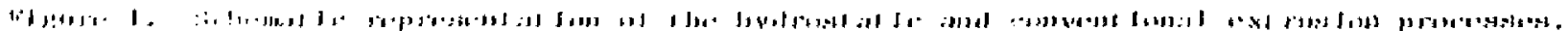


2. The fact that the billet is supported by a fluid in the extruston contalner rather than a container wall eliminates an iquortant component of friction and thereby considerably zeduce the extrusion pressure necessary for a given conductor. This fact is particulariy Important to the composites in question which contain low melting temperature alloys of $\mathrm{tin}$. The temperature rises occurring in these composites during extrusion re roughly proportional to the work exponded or pressures. The peak temperature will undoubtedly be the factor 11miting the perilssible reduction ratios.

3. When the fluid is continually in contact with the billet up to the die as it is in hydrostatic extrusion, there is a possibility of fluld being carried into the die when the billet velocity exceeds a critical value. This situation, iften referred to as hydrodynamic lubrication leads to a reduction in dfe friction and consequently a reduction in extrusion pressures. As wLll be discussed later, the existence of a lubricating film in the die allows a greater range of die angle and therefore greacer possibilities for reducing undegirable effect observed in conventional extrusion such as the pipiag defect and distortion. ${ }^{6}$

The ab11ity of hydrostatic extrusion to reduce copper at roim temperatures is essential to the proposed conductor because of the low melting point of tin rich copper-tin alloys (solidus: $227^{\circ} \mathrm{C}$ ). Bowever, eved with hydrostatic extrusion there is ccncern over billet heating occurring as a rasult of dissipation of the work of deformation. If the reduction rate is high enough, the thn phase may acquire the latent heat necessary to cause melting. The reduciton ratio necessary to bring about melting and the effect of such welting on the 1ategrity of the composite will be established in this study. If the limiting reduction Is that whirh melting occurs, such a factor w112 be Important to es'sti2shing the economles of the process. 


\section{- 2.1.2 Existing Compercial Facilities}

W1th the Increasing awareness of j.ts unlque capabilities cold hydrostatic extrusion has become a fully commerical method of reducing production size billets to cod and wire. ASEA (Ainanna Svenska Elect riska Akulebolaget) now offera a range of prodiction hydrostatic extrustion presses extending up to a capability of 290,000 psi with a container wich may accommodate a billet $71 / 8^{\prime \prime}$ daameter and $47^{\prime \prime}$ Iong (1900 cu ID). ${ }^{7,8}$ With the capability of 20 cycles per hour, this hydrostatic extrusion press is comparable in production rate to a conventional extrusion press. A major production application of hydrostatic extrusion of large billets is in the manufacture of copper clad aluninum wire. For example, the NatLonal Standard Company in Scotland is Involved in the production of such wire using a 4000 ton extrusion press bulle by ASEA of Sweden. ${ }^{8}$ In addition to this, there are other large ASEA hydrostatic extrusion presse. in Japan, Holtand and Sweden.

In addition to the extrusion of large dlameter billets, there are several schemes for the rediction of rod and wire either by a purely hydrostatic extrusion or a combination of hydrostatic extrusion and tenstle forces on the exiting wice (augmented hydrostatic extrusion) ${ }^{9010}$ an example of a tecinique for wire drawing Which relle:; on continuous hydrostatic extrusion is that presently under deveiopment at Westem Electric' Company. 11 Shown in Figure 2, their machine provides a cont inuous track loop. As shown in che diagram, the four continuous tracks provlde four chamber segments through which the rod is extruded. Rather than gripping the rod directiy, a viscous liquid $(e+g$, polyethylene) transfers pressure from the chamber aegments to the rod. With traction also provided in this manner, the rod is drawn fnto a higher pressure region further in the machine where diameter reduction is accomplished on the rod. Conventional wire drawing techniques involving tensile forces pulling the wire through the die is i:apable 


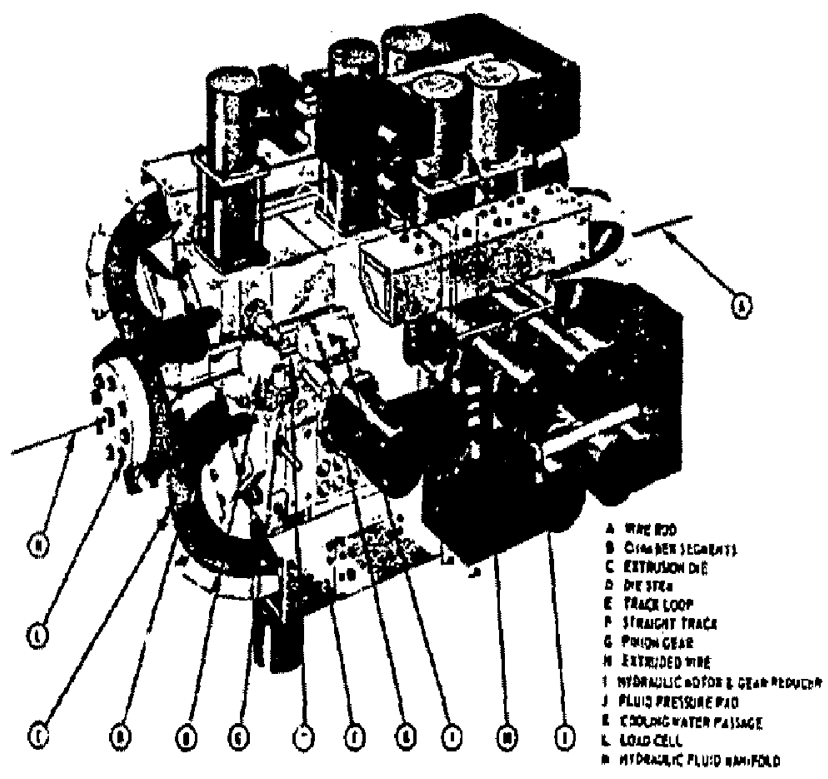

MateI

Yod III Endless Chamber Extruder: a continuous hydrostatic extruder under development at Western Electric Company (reproduced from "Hestern Electric Company Continuous hydrostatic Wire Extrusion", Paul Andrus and glenn Scimehl, Manufacturing Engineers, February 11, 1976, Philadelphia, Penusyl vania). 
of only 10 to $30 \%$ reduction in area because of tine iffited tensile strength of metals. This mechlne at Western Electric on the other hand reduces aluminum rod to whe with a reduction ratlo of 325 and a rod speed of 3 feet yer minute. 11 Having only a $5 / 16^{\prime \prime}(.79 \mathrm{~cm})$ bore in the pressure chamber, this machine cannot be used for either billete or the rod resultigg from the extrusion of an $8^{\prime \prime}$ to $10^{\prime \prime}$ $(20-25 \mathrm{~cm})$ diamter billet.

Large extrusion presses such as those produced by ASEA represent a signiftcant capital investment of on the order of tens of mllifions of dollars. To our knowledge there ts no Americen company contemplating the purchase of such a press In the near Future. Battelle Laboratorles, however, have developed a weans of converting conventional extrusion presses to a hydrostatic extrusion facility and have applied this wodification to theli own 2500 ton press. Costing on the ordez of $\$ 100,000$ for the conversion of an appropriate conventional press to one capable of extruding $7 "$ diaveter copper composite billets, this procedure is the most feasible alternative for the relatively small scale requirement of EERF.

In addition to thege facilities there are many small experimental extruston preases in this coutry. These facilities will be enumerated along with ayallable production size facllitieg in Appendix $\Lambda$.

\subsubsection{Pactors Affect 2ng Pressures Necessary for Hydrostatic Extrus Ion}

The cold hydrostatic extrusion of copper, aluminum and other matertals has bekn extensively studied. Figure 3 shows the necessary extrusion pressure as a furction of reduction ratio for copper and several other qatertals. In a manner analogous to conventional extrusion the analyt fe expression relating extrusion pressure to reduction ratio for hydrostacic extruston is: 


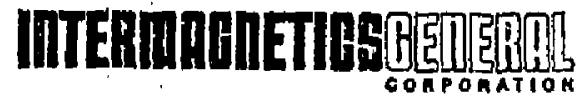

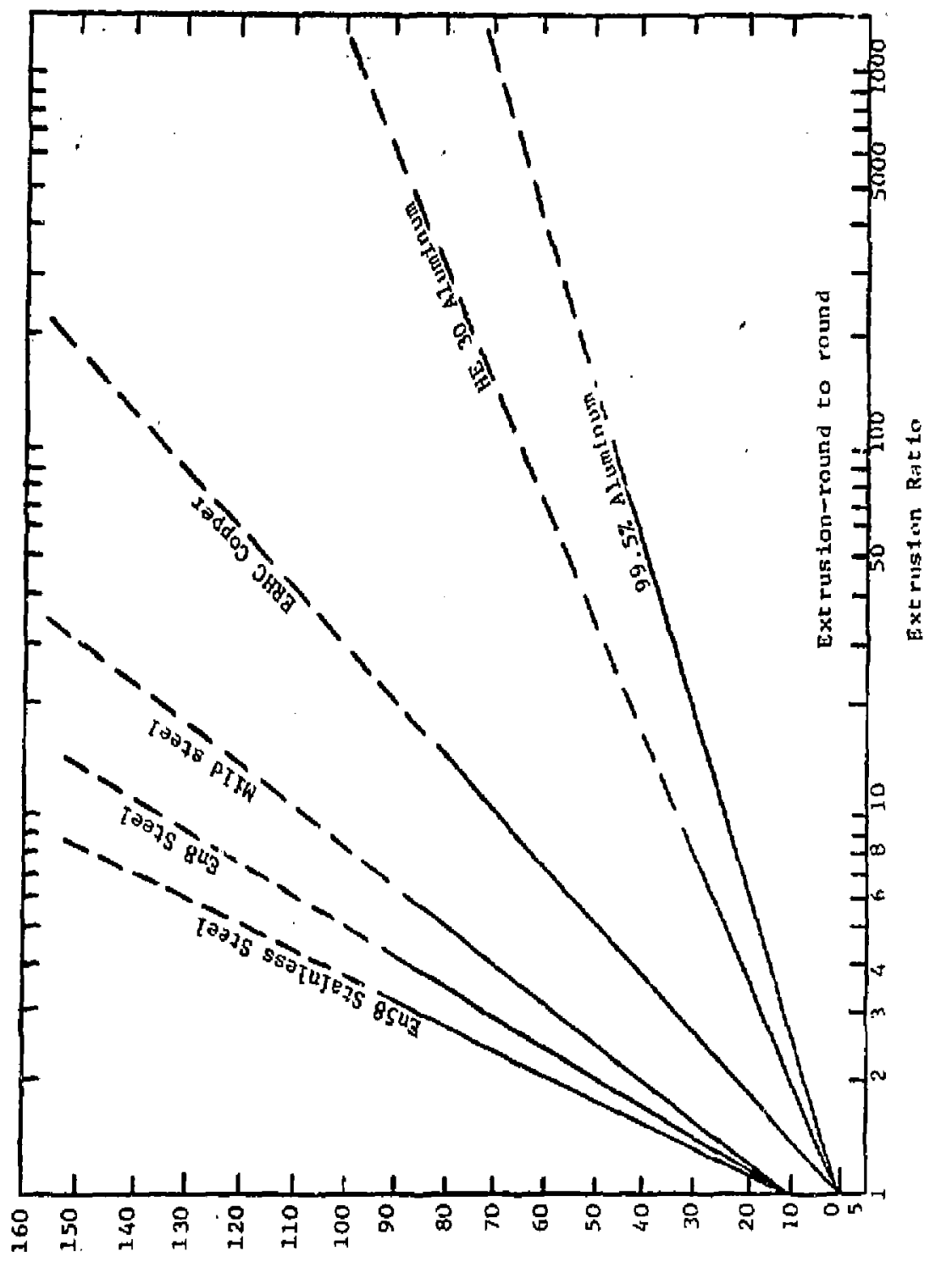

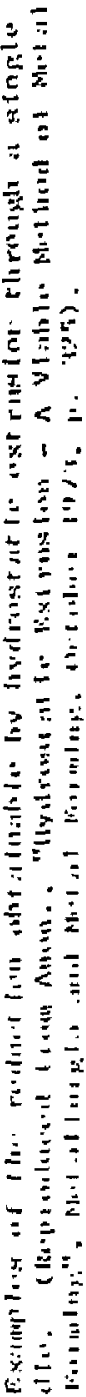

$$
\tau^{\text {LT/J 40.1 }}
$$

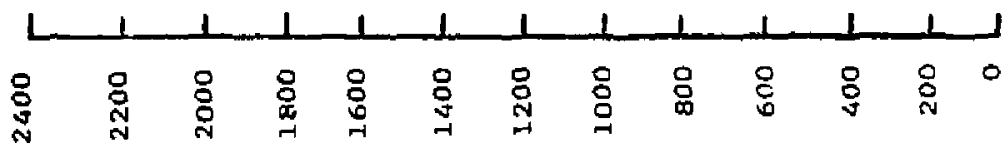

$\stackrel{-}{5}$ 
where $P$ is the pressure, $R$ is the reduction ratio and the constant $A, B$ depend on such facturs or die angle, condition of friction in the die and billet dlameter. 6

An important factor determining the extrusion pressure is the die design. Dies commonly used in practice are conical in shape with a cone angle chosen according to the material properties, the reduction ratio and the condicion of friction prevalling at the die. For given set of conditions such as coefficient of friction at the die, matertal yicld stress and zeduct lon ratio there is a die angle tivish corresponds to a winimum in the extrusion force. In conventional extrusion the optimal dfe angle usually increases with increasing extiusion ratio and coefficient of friction. This feature has in fact been demonstrated analytically in the text of Aviczur ${ }^{6}$ and is expressed in a formula ralating driving stress to reduction ratio, die angle and coefficient of friction. Another factor determini:g extrusion force is the stralu rate of the material being deformed. Even without straln hardening, deformation stresses generally Increase with Increasing strain rate. A thind factor in detemining extrusion force which is particularly important to the process of hydrostatic extrusion is the possibilfty of hydrodynamic lubrication. This phenomenon, which is characterfzed by a continuous filn of lubricant separating the billet from the die, will occur when the Iubricant is sufficiently viscous, the velocity of material at the dle is sufficlently high, and the extruded rod diameter is sufficlently 6mall.

Hydrodynanic lubrication is more rcadlly maintalned in cold hydrostatic extrusion than io conventional warm or hot extrusion because of the scability of the lubricant at lower temperatures ar. the greater availability of the 


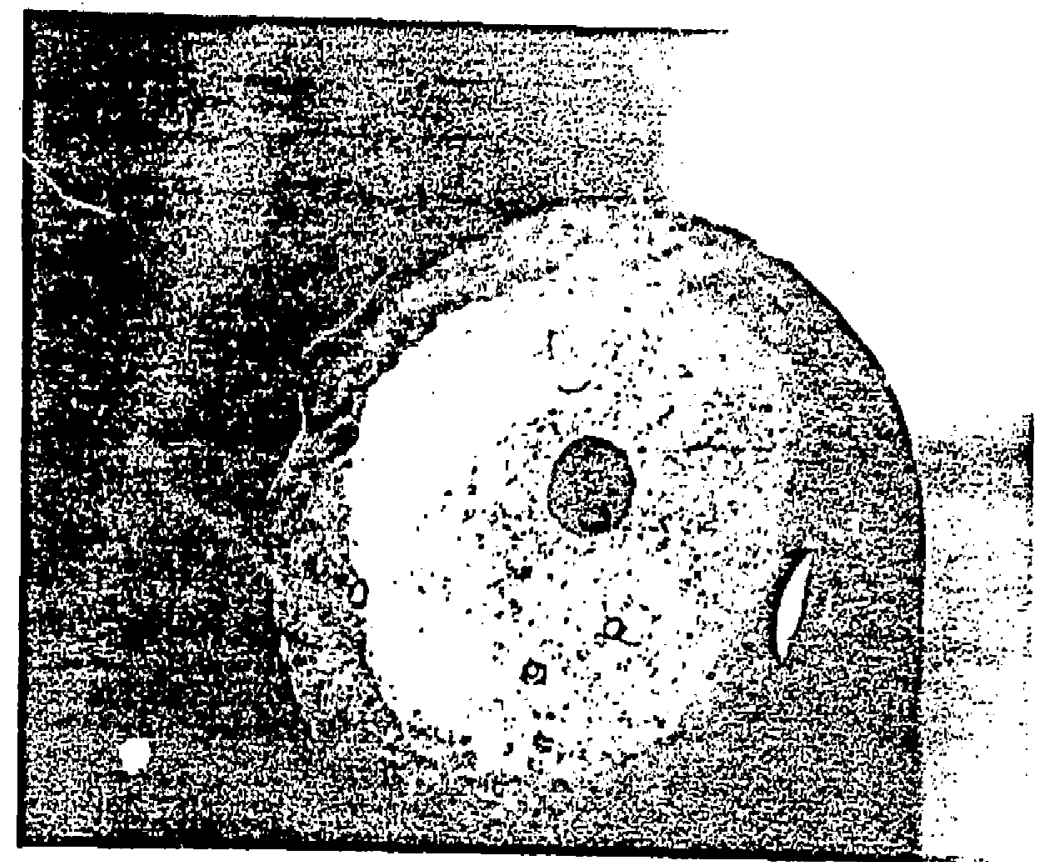

Figure 4a. Esample of the piping defect occurcing during the conventional extruston of a composite billet.

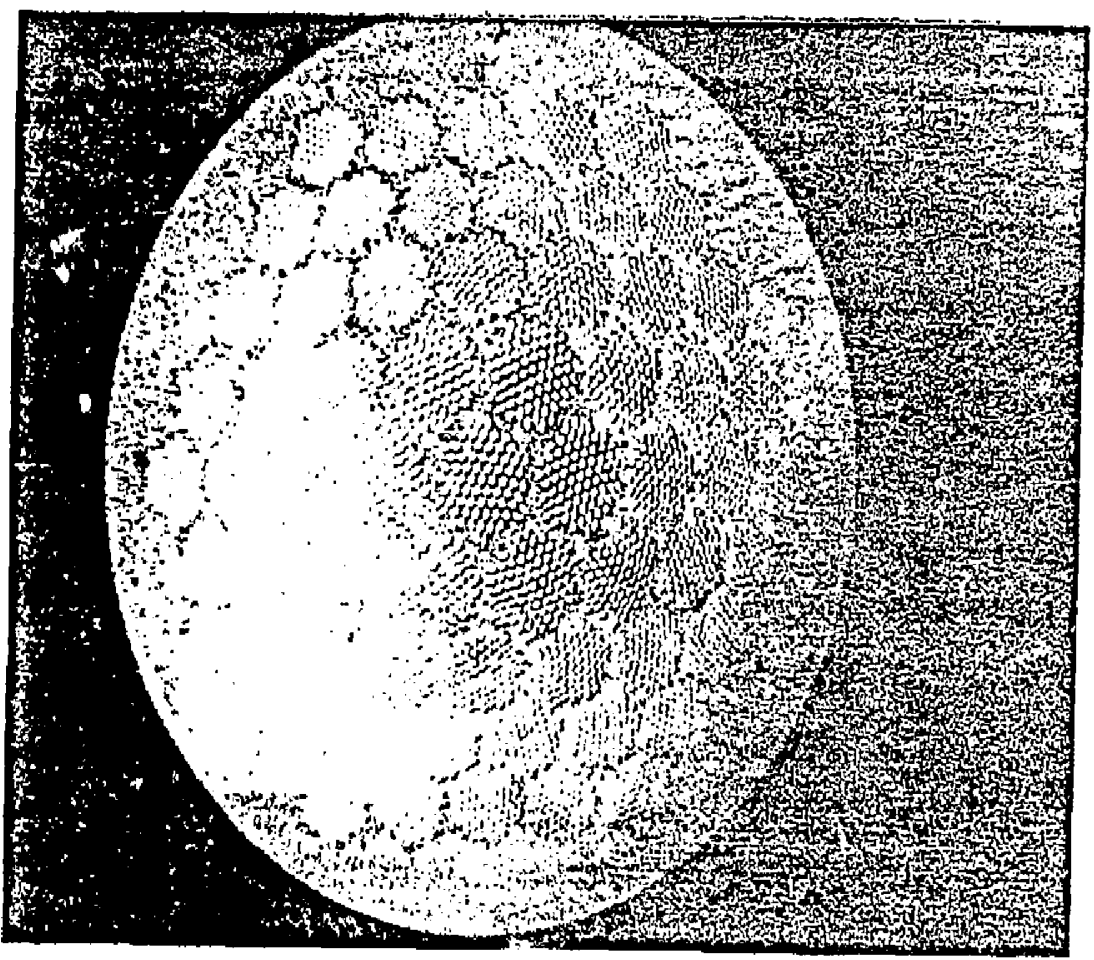

Figure 4b. Distortion of filinent patem ocruring near the ends of the extruded rod. 
extruston fluld under pressure as a die lubricant. Since the velocity of the materlal at the dle generally increases with decreasing die angle for a given reduction ratio and since a minimum velocity is necessary to maintain bydrodynamlc lubrlcation, the phenomenon is more likely associated with smaller die angles. 6

Hydrodynamlc lubrication provides an inortant benefit ro the extrusion of superconducting composites. As mentioned earlier, the optimal die angle Increases with increasing friction and extrusion ratio. At higher reduction ratios (e.g. 20/1) the extrusion force increases rapidly as one reduces die angle from the optimal value. However, the defects which occur near the ends of the extruded rod such as distortion of the fllament pattern and the piping defect (see Higure 4) are more severe as one lncreases the die angle. In conventional extrustun, we are therefore forced by the necessity of reducing extrugion force to choose a die anglw? which results in: a pore extensive Iegion of the extruded rod characterized by defects. In a typical extrusion of a bronze/nlobium composite up to $20 \%$ of the extruded rod must be aiscarded because of these defects. The existence of hydrodynamle lubrication during hydrostatic extrusion results in a reduction of friction and therefore a reduction in the optital de cone angle. We therefore have good reason to believe that billet discard will be reduced when conventional warm extrusion 1s replaced by cold hydrostatic extruston of copper based composite billets.

\subsection{Heac Generation During Extrusion}

Because of the existence of a low melting temerature materials in the composite billets of the proposed approach there is concern over tempera rises resulting frow the dissipation of the work of deformation. We must therefore understand the effect of extrusion rate, heat conductinn, and billet slze on 
the peak temperature reached. by the billet. The analysis of the thermal probiem during extrusion is complicated by the simultaneous processes of heat generatirn, transport of heat by moving material ard conduction of heal: by therwal diffusion. However, several Investigatious have made progress in estimating heating effects during conventional and hy i-ostatic extrusion through conical dies, By using a finite element technique for the calculation of temperature and determining the velocity and strain flelds determined from a visioplasticf.ty experiment, Altan and Kobayashi ${ }^{12}$ were able to calculate non-steady state teiperature along the length and eross section of the billet at particular stages of the extruston. Using a similar maans of analysis Guha and Lengyel $1^{13}$ calculated the temperature distribution occurring in a blllet duriag hydcostatic extrusionidrawing. Carrying out theit calculations by assuming properties of higil coniuctivity copper, they theoretically established some Interesting aspecis of temperature distribution during the extrusion process. Figure 5 is a reproduction of their curves showing the varlation of temperature over the crose section of tice extrustion proaisct at the die exit for stveral values of coefificient of friction and billet velocity. As one would expect, there fs peaking in the temperature at the surface of the extruded rod, However, rodusing the ex:-rusion spetd not only reduces the average temperature achieved $t \cdot 1$ also tends to eliminate the peak in temperature at the surface resulting from friction. Figure 6 showing their curves of temperature rise of the material as a function of the progresu of the extrudions indicates that a steady state temperature is rapidly arhieved during the extrusion process. Temperature measurements of Singer and Al-Samartiit on materials exiting an extrusion die conflrms the qualitative to perature variation theoretically predicted by Guha and Lengyel ${ }^{13}$. Figure 7 showing their measurements of the rise fn emergent temperature as a function of ram travel for lead dewonstrates the temperature plateau reached early in the extrusion. 
as well as the variation of this steady state temperature with extrusion speed. Figure 8 showe thetr curves for the rise in emergent temperature as a function of ram travel for tin billets subjected to various reduction ratios. The variation of temperature with extrusind ratio is rounhy proportional to the race of deformation energy jeneration as predicted by equation (1).

For the purpose of this study, decafled calculations of the temperature digtribution as car:ied out by the previously mentioned investigations would be excesstvely time-consuming and not particularly enlightening. In orter to control the temperature rise in the adtertal we must understand the effect of the following factors on peak tomperature achiered in the extrusion process:

\section{Billet speed}

2. Geat transferred from the extruded rod

3. Heat cosiduction from the deformation region

4. Reduction ratio

5. Billet diameter

6. All other factors determining the xtruston pressure

For this purpose we have constructed a mathemarical mode:. which neglects the temperature variation over the cross section and deals only with the ateady state temperature: As shown in Figures 5, 6, 7 and 8, these specifications are well fugtified at sufficlently low speeds and low coefficient of friction. Figcre 9 shows a schematic representation of the extrusion die and the positior. coordinates to which all of the foroulation will refer. He will start by writing the steady state heat balance for the billet and the excruded tod outside of the deformation zone. In the billet we have:

$$
\text { i. } \pi a_{B}^{2} \frac{d^{2} T}{b x^{2}}-\pi v_{B} c a_{B}^{2} \frac{d T}{d x}-2+a_{B} h_{B} T=0 \text {, }
$$

where $T$ is the terpe:ature of the billet at position $X$ along its length, $k$ is the average thermal conductivity of the billet aaterial, 




RELATIVE RADIUS

Figure 5. Calculated curves of the temperature variation over the cross section of the ext rusion product at the die exit for several values of coeffictent of friction and billet velocity. '(From Guha, R, M. . Lengyel, B., Vol. 54, p. 117, Jan, 1974). 
B11let Speed:

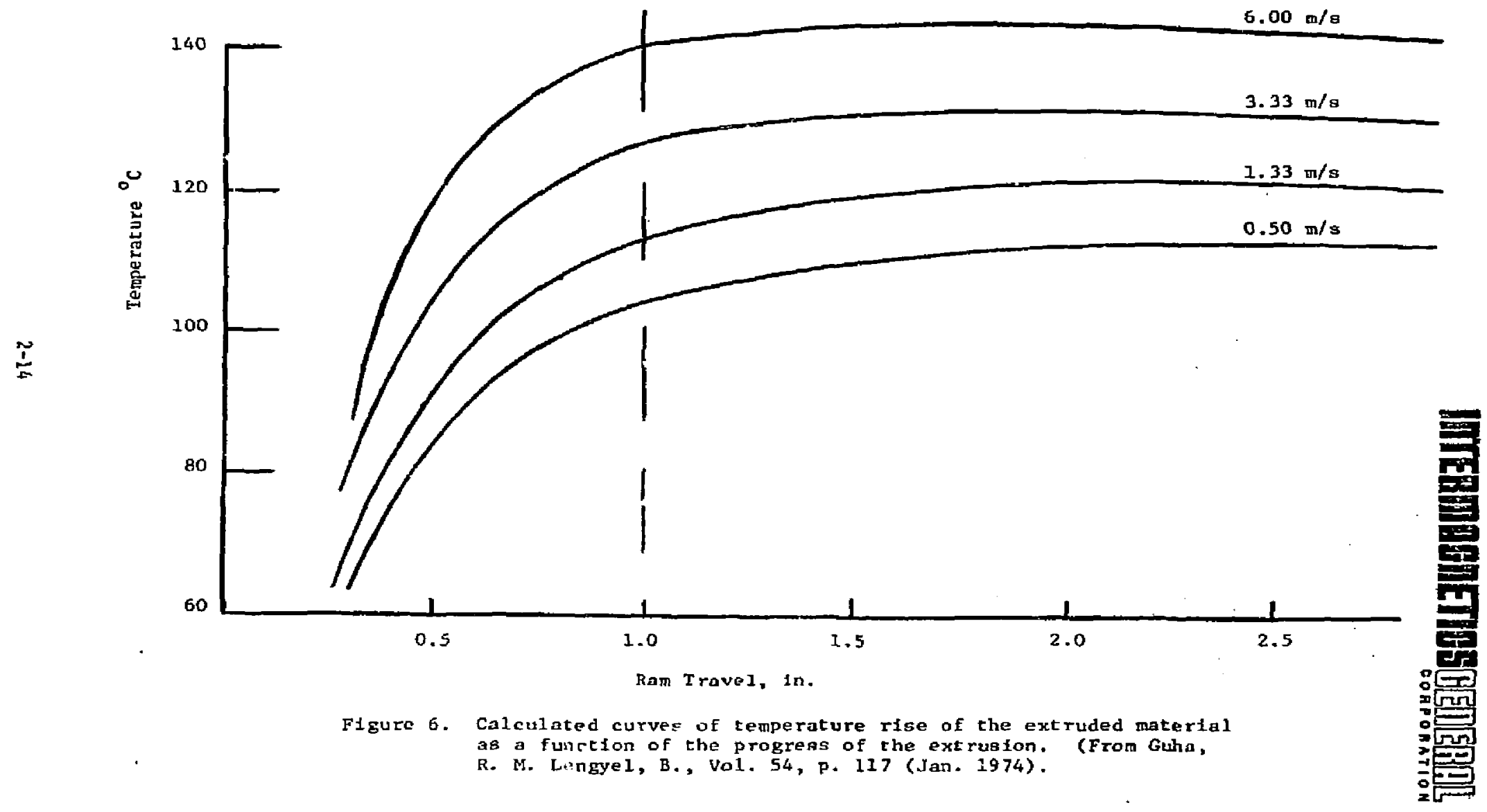




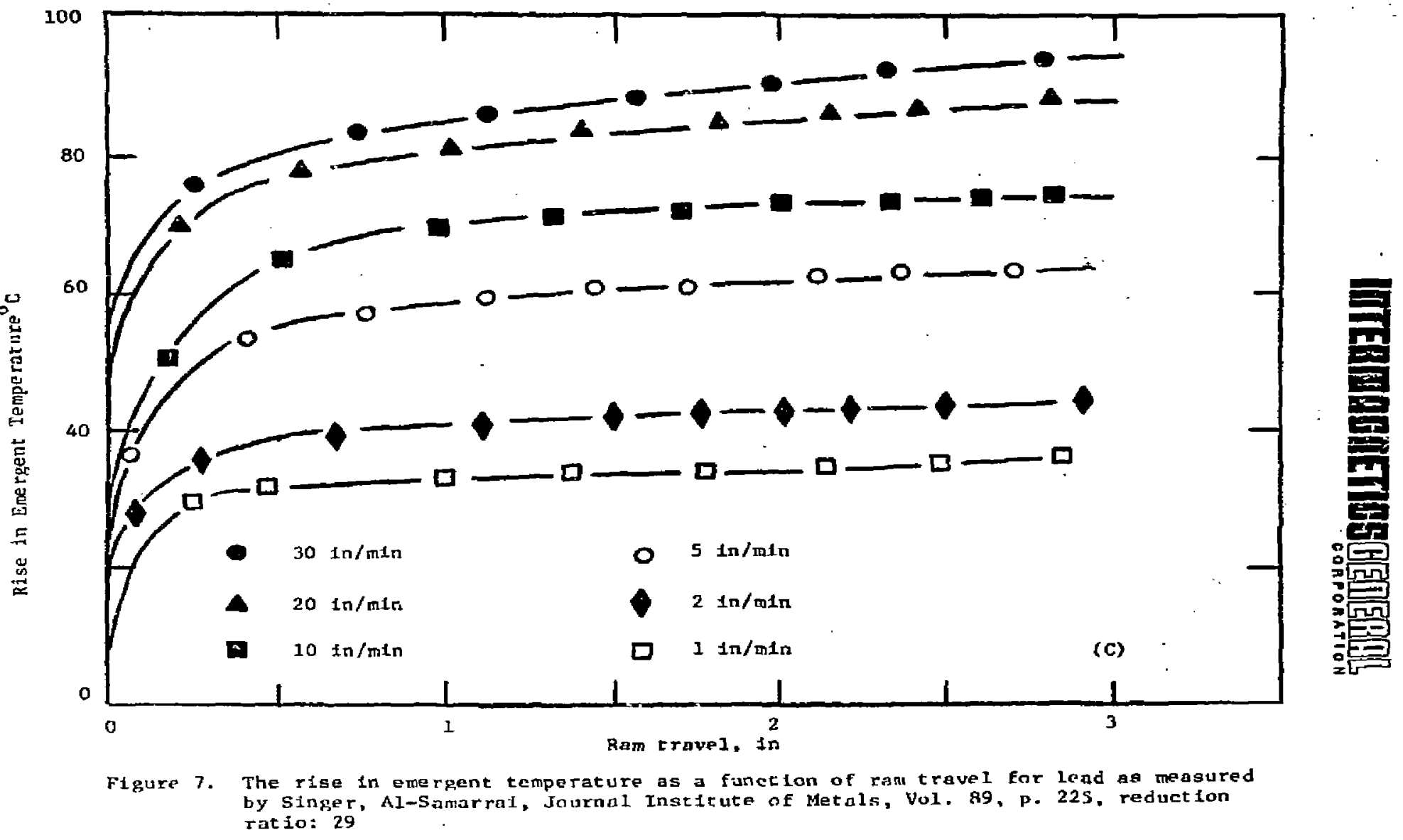




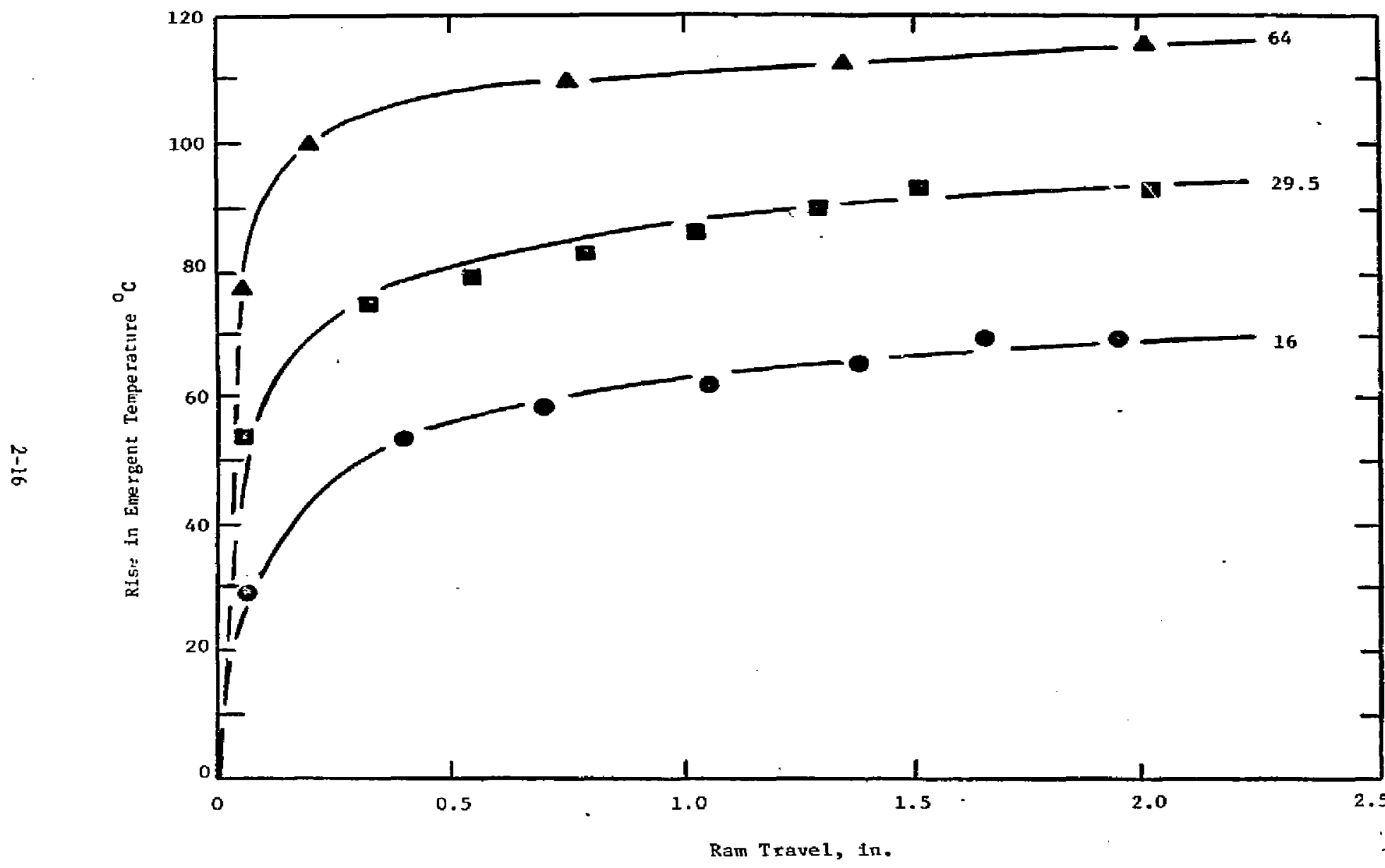

Figure 8. Experimentally determined rise in emergent tenperature as a function of ram travel for tin billers subjected to various reduction ratios. (From Singer Al-Samarral, Journal Institute of Metals, vol. 89, p. 225). 
$a_{B}$ is the radius of the billet,

$v_{B}$ 1s the speed of the billet,

C Is the heat capacity of the billet matertal,

and $b_{B}$ ts the coefficlent of surface heat transfer between the surface of the billet and the hydrostatic fludd medium.

A efmilar expression can be written for the extruded rod:

$$
k \pi a_{R}^{2} \frac{d^{2} T}{d x^{2}}-\pi v_{R} c a_{R}^{2} \frac{d T}{d x}-2 \pi a_{R} h_{a} T=0
$$

where now

$h_{0}$ is the coefficient of surface heat transfer between the rod and whatever uedian surrounds $t t$,

$a_{R}$ is the radius of the extruded rod,

and $v_{R}$ is the speed of the excruded rod.

In both of the above expressions we have assumed a miform temperature distribution over the cross section of the billet or rod. The first terw in the above expressions represent the process of heat conduction along the blllet or rod. The second represents the transport of heat by the moving rod or billet and the last term the heat transferred frow the surface. In the deformation zone the heat balance equation is more involved. Not only is the billet reducing in diameter as it passes through the die but also heat is being generated at a rate which is related to the rate of deformation at any point in the deformation region. The differential equation within the dia which occuples the length $\ell$ along the $x$ axis is:

$$
\begin{aligned}
& k \pi(\tan a)^{2}(b-x)^{2} \frac{d^{2} T}{d x^{2}}-v_{B} a_{B}{ }^{2} C \frac{d T}{d x} \\
& -2 \pi h_{0} \tan a(b-x) T+W(x)=0,
\end{aligned}
$$


where

d 10 the die seal cone angle,

$h_{0}$ is the surface heat transfer coeffictent between the billet and die surface,

$b$ is the constant equal to $a_{B} /$ tan $a$

and $W(x)$ is the deformation energy dissipated per unit length along the die.

To determine the steady state temperature as a function of position we must rolve the alfferential equations 2,3 and 4 and apoly the boundary conditions which are:

$$
\begin{aligned}
& T=0 \text { at }-\infty \text { and }+\infty \\
& T_{I}=T_{I I} \text { at } x=0 \\
& \frac{d T_{I}}{d x}=\frac{d T_{I I}}{d x} \text { at } x=0 \\
& T_{I I}=T_{I I I} \text { at } x=\ell \\
& \frac{d T_{I I}}{d x}=\frac{d I_{I I I}}{d x} \text { at } x=\ell
\end{aligned}
$$

Analytic expresston for $\mathrm{T}_{1}$ and $\mathrm{T}_{\text {III }}$ are eastly obtained for the corres;mding homogeneous differential equations. However, an expression for $I_{I I}$ is constd ably nore difficult.

For the sake of establishing the effectiveness of cooling the extruded rod in reducing the peak temperature experlenced by the composite, an expression will be derlved from these equations relating peak billet temperature to billet speed and reduction ratio. 


\subsection{The Nature of Alioys in the Tin-Copper System and the Reaction of Such Alloys with Niobium}

In anticipation of our analygis and design of conductors including pure $t$ in or high tin copper tin alloys we will discuss pertinent aspects of the diffugion and growth of phases in the tin-copper system, the composition dependence of the rate of $\mathrm{Nb}_{3} \mathrm{Sn}$ farmation and the mechanical properties of the varlous $t \mathrm{In}$ copper alloys.

The dependence of the rate of $\mathrm{Nb}_{3} \mathrm{St}$ fortuation on the composition of the matrix In solld state reaction in bronze has been clearly established by Suenaga et al. $\$ 5$ Up to 13 wt $\%$ tin in copper, the bronze matrix remains a homogeneous a phase throughout the processing of multiftlamentary composites and generally the rate of $\mathrm{Nb}_{3} \mathrm{Sn}$ formation increases up to this concentration. As may be seen from the phase diagram In Figure 10, concentration of tin exceeding 13.5 wt $\%$ at typical reaction temperature of $700^{\circ} \mathrm{C}$ to $800^{\circ} \mathrm{C}$ correspond to two-phased microstructures Including both the a phase and $\delta$ phase. If These duplex structures are usually avoided in gult1filamentary niablum/bronze composites because of their poot working propercles and the possibillty that $\delta$ phase interfetes with the growth of $\mathrm{kb} . \mathrm{Sn} .17$

Kinetic studies of Stuenaga et $\mathrm{al}^{15}$ suggest that the cate of $\mathrm{Nb}_{3} \mathrm{Sn}$ formation is severely reduced in the composition range corresponding to this two-phased atructure.* Whether this effect is the iesult of unfayorable kinetics of tin diffusion to the nlobium filaments in the formation of the A-15 phase or a thermodynamic effect irvolving the development of non $\mathrm{Nb}_{3}$ sn phases is not defiritely known. However, investigations of Zwicker and Rinderer ${ }^{18}$ have

*Recent work of $\mathrm{K}$. Ralls presented at the October 1976 AIME suggest that this is $n c:$ true of the entire composition range of this two-phased structure. 


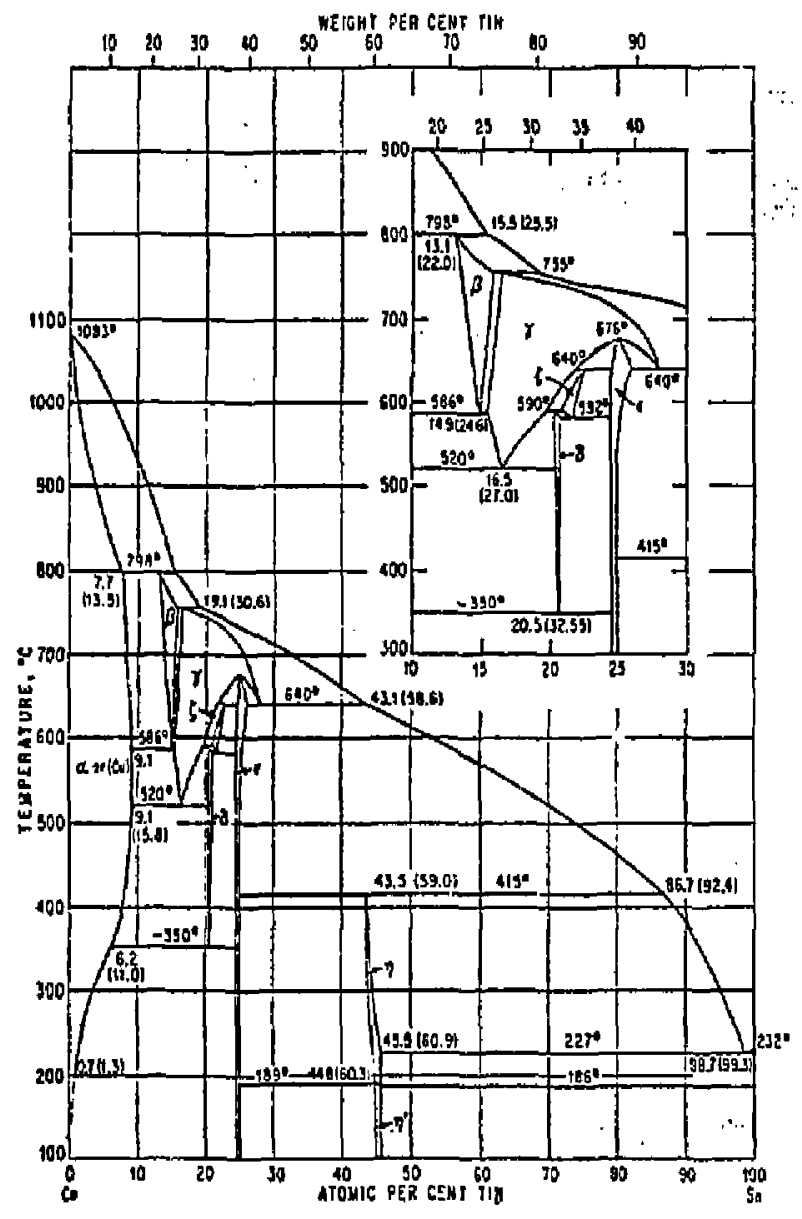

Figure 10. Phase diagram for the Tin-Copper system. 
clearly established that non $A-15$ phases are formed when nfobium reacts with $t$ in copper alloys having a hi:: = tin concentration than a-bronze.

There are several phases in the tin-copper system which are too britele to be worked. For example, the $E$ phase, characterized by a narrow cotposition range of hotrogeneity around the stolchiometry $\mathrm{Cu}_{3} \mathrm{Sn}$, has been shown to be extreme1y brittle. This is probably true as well of the other phase of narrow compositional range, the $n$ phase, which like the $\varepsilon$ is stable at room temperature. Alloys in equilibrium at room temperature which range in compogition from 45 wt $\%$ tin to 79 wt \% tin are characterlzed by e two-phased structure of the $n$ phase and a in solid solution saturated wth copper. These alloys are also characterized by a ductilfty roughly proportional to thelr tin concentration. In spite of the fact that alloys of this compositional range are not as ductile as atther pure copper or pure tin, composites Incl lding such al.loys as shown by Hashimoto et $\mathrm{al}^{3}$ can readily be drawn through significant redustions withost the need for Interpediate anneals. This is probably a consequence of two fortunate qualities of these tn-rich copper-tin alloys: they are softer than the copper matrlx and the hydrostatic stress provided by the matrix is sufficient to prevent fracture of the alloy phase.

In vtew of the suspected adverse effects of non $\alpha$-bronze copper-tin phases on the growth of $\mathrm{Mb}_{3} \mathrm{Sn}$ at the nlobtum filameuts we are taking the precaution in our proposed conductor designs of avolding the growth of such phases among the niobium filaments. Consequently, the composite must be optimized with proper regard to two conflicting considerations. On the one hand, one would like to eliminate as much of the copper matrix as possible to increase current density and, an the other hand, enough copper must be left as a buffer between the tin alloy regions and the nlobium filaments. 
The work of Kawakatsu et al ${ }^{18}$ provides some important information regardirg the growth of phases in a system consisting originally of pure copper and pure tin gaturated with copper. The phases appearing in diffusion couples generally include at least some of the phases appearting in the equilibrium phage diagram at the given temperature. As expected, the study of Rawakatsu et al ${ }^{10}$ showed the orderly development of only the $E$ and $n$ phases up to $410^{\circ} \mathrm{C}$. Unexpectedly, however, the $n$ phase still existed at $430^{\circ} \mathrm{C}$ when the phase diagram Indicates a maximum temperature of $415^{\circ} \mathrm{C}$ for the $n$ phase. The preferential growth of phases richer In tin such as $\eta$ is beneficial to the processing of the proposed conductor. The more concentrated the tin alloy resulting from heat treatment the more compact these non a phases which are detrimental to $\mathrm{Nb}_{3} \mathrm{Sn}$ formation. An optimal homogenization heat treatment involves the greatest confinement of the non $a$ phases which still permits the rapid diffusion of tin through a-bronze.

\subsection{Previous Work on Multifilamentary $\mathrm{Nb}$ Sn Composites Including Tin Rich}

The composite produced by Hashimoto et $\mathrm{al}^{3}$ involved pure copper, tin - 20 wt $\%$ copper and niobium in the ratto of $.673, .151, .176$ respectively. After reducing the compostte to about 0.00 " $^{\prime}(.127 \mathrm{am})$ diameter without a single anneal, the composite was heat treated at $720^{\circ} \mathrm{C}$ for 50 hours. The photomlcrograph of the composite following the heat treatment showed a cross section with no apparent vold formation. However, in view of the small number of niobium filaments compared to commercial conductors now avallable, the composite produced by these authors is far from optintzed. The development if a commercial process Eor this composite concept and the optinization of the overall current density in the composite is the goal of the present study. 


\subsection{ANALYSIS OF CONDUCTOR AND PROCESSING}

The present chapter will describe experimental and analytic studies performed to answer several critical questions in the design of composttes involving a reaction zatrix of pure copper and a tin rich copper-tin alloy. Among these critical aspects are the following:

1. The size and distribution of the $t$ in rich elements. Tin must be distributed sufficiently to allow diffugion throughout the reacting matrix. The size of the tin alloy elements and their proximity to niobium filaments is restricted by the need to prevent growth of non $\alpha$-phase copper-tin alloy phases among the niobium fllaments. The slze of the tin alloy elements will also determine the distribution of kirkendall volds. Present is all types of reacted multifilamentary composites, these vofds should not be so large or extenstve that they interfere with the transport of tin to the niobium filamente.

2. The heat treatment which will minimize the spreading of non a phases during the homogenization heat treatwent prior to reaction. The more compact the tin rich regions after homogenization of tin the larger the tin rich elements may be.

3. The procedure for producing elements for billet packing and billet extrusfon. Conductor fabrication usually begins with an extrusion of a composite billet made up of hexagonal cods conststing of the conductor elements. The number of extrusion stages, the nicure of the components at each stage of billet extrusion and the extrusion reduction ratio are all important to the cost of conductor fabrication and will therefore be considered in detail. The maximum extrusion ratio which may be accomplished by hydrostatic extrusion of billets containtag high tin alloy will be studied through several expertmental extrusions.

4. Control of billet heating during operaition. The mintoum billet extrusion cycle time will be determined by the likelihood of melting of the tin rich alloy. Ir. this study we have observed the effects of temperatute rise during the extrusion of a linited number of composite 
billets. By applying the foculation of Chapter 2 we will be able to extend our resultf to predict the heacing effects at larger billet diameters, arer a greater range '; ${ }^{c}$ speeds, and over a greatır range of reduct $\alpha$ or ratios.

The following chapter will taclude the description of four model conductors based on the Information we have assembled in this phase of the program. Each of the todel conductors will be capable of carrying 10,000 Amps at 12 Tesla and theit processing will be descrtbed in detall to facilitate the comparison of the economics of their production to that of a bronze composite.

\subsection{Drawing of Composites Including Tin or a Tin Rich Copper-Tin Alloy}

Figures 11 and 12 show the cross section of the composite used in our diffusion studies having been drawn to a $0.015^{\prime \prime}(.38 \mathrm{~mm})$ dameter and $0.008^{\prime \prime}(.20 \mathrm{~mm})$ diameter respectively. The composite consists " a core of a tin $1.7 \%$ copper alloy in a pure copper Jacket. As one tay see from the figures, the core exhlbits a duplex structure consisting of a matrix region of copper saturated tin and particles of $n$ phase as well as particles of $n$ phase urrounding cores of $\varepsilon$ phase. The existence of the $\varepsilon$ phas: is the result of coring during colidfication of the alloy. The cast structure of the starting tin alloy is shown in Figure 13. There as well we see the duplex structure which exists as a dendritic structure with regions of the copper rich phases consisting of cored regions having $E$ in the center and $\eta$ on the outside. A feature worthy of note is the constderable degree of refinement of the particles of the copper rich phases as one draws the composite from its original diameter of $0.500^{\prime \prime}$ to the final dlaneter of 0.008 " $(.20 \mathrm{mo})$. This refinement of the brittle phase apparent from Figures 11 and 13 represents an approxitate average of reduction. in cross sectional area of the grains by a factor of 200 . 


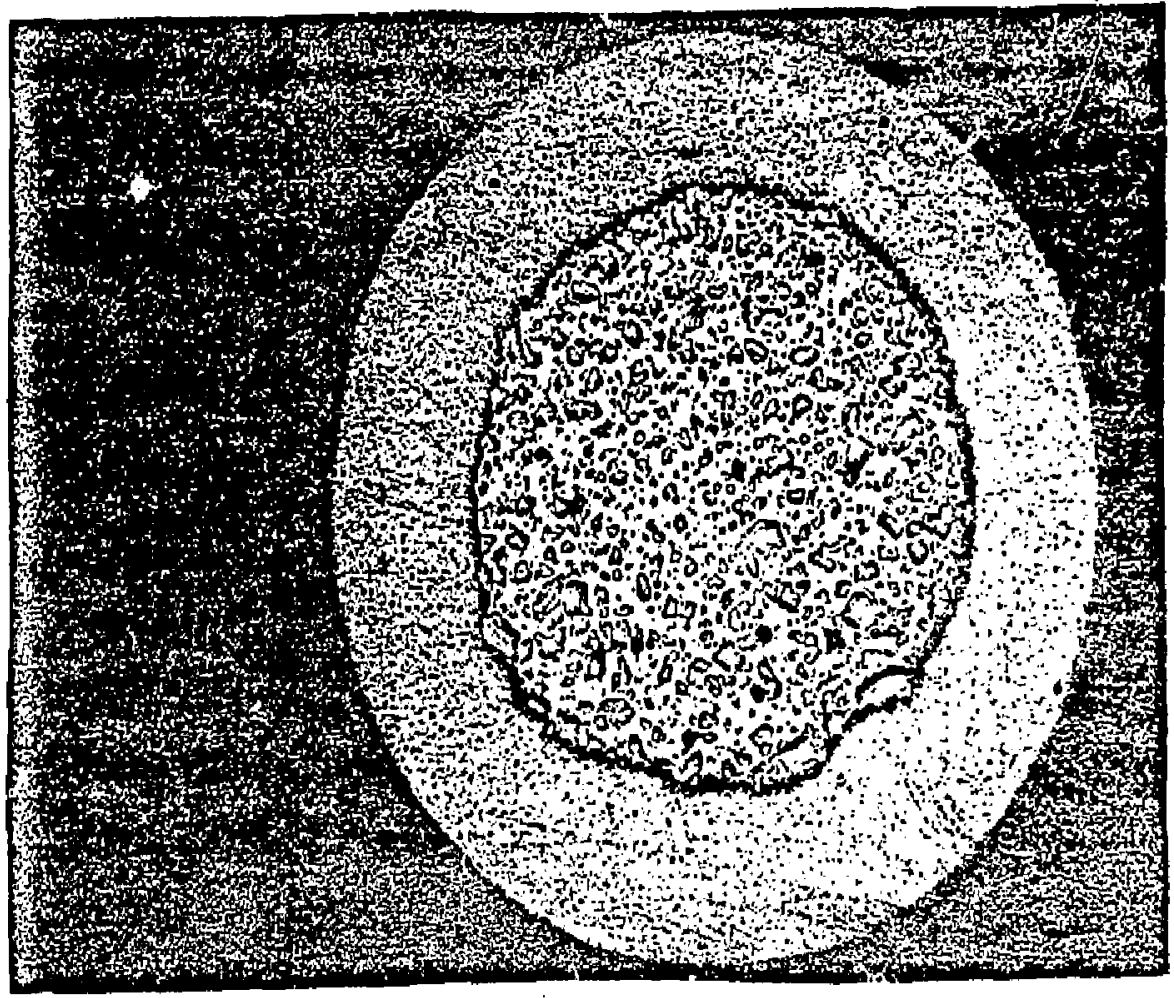

Flgure 11. Experimental composite used in diffusion studies consisting of a core of $\mathrm{Sn}-16.7 \%$ Cu within a jacket of pure copper composite diameter of $0.015 "$ (. $38 \mathrm{~mm})$. Magnification: $300 \mathrm{x}$ 


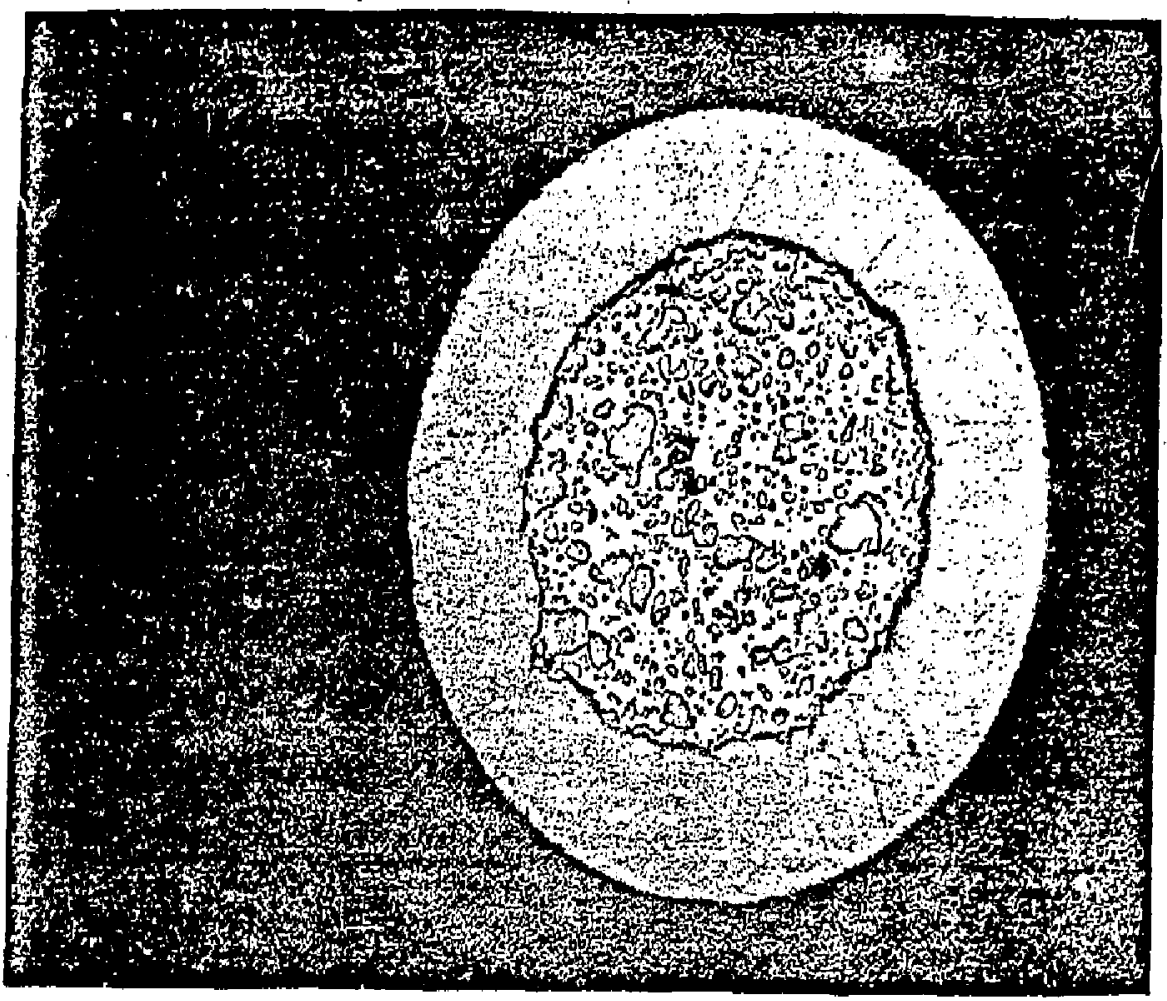

Figure 12. Same experimental composite as showl in Figure 11 but drawn to a diameter of $0.018^{\prime \prime}(.20 \mathrm{~mm})$.

Magnification: 500X 


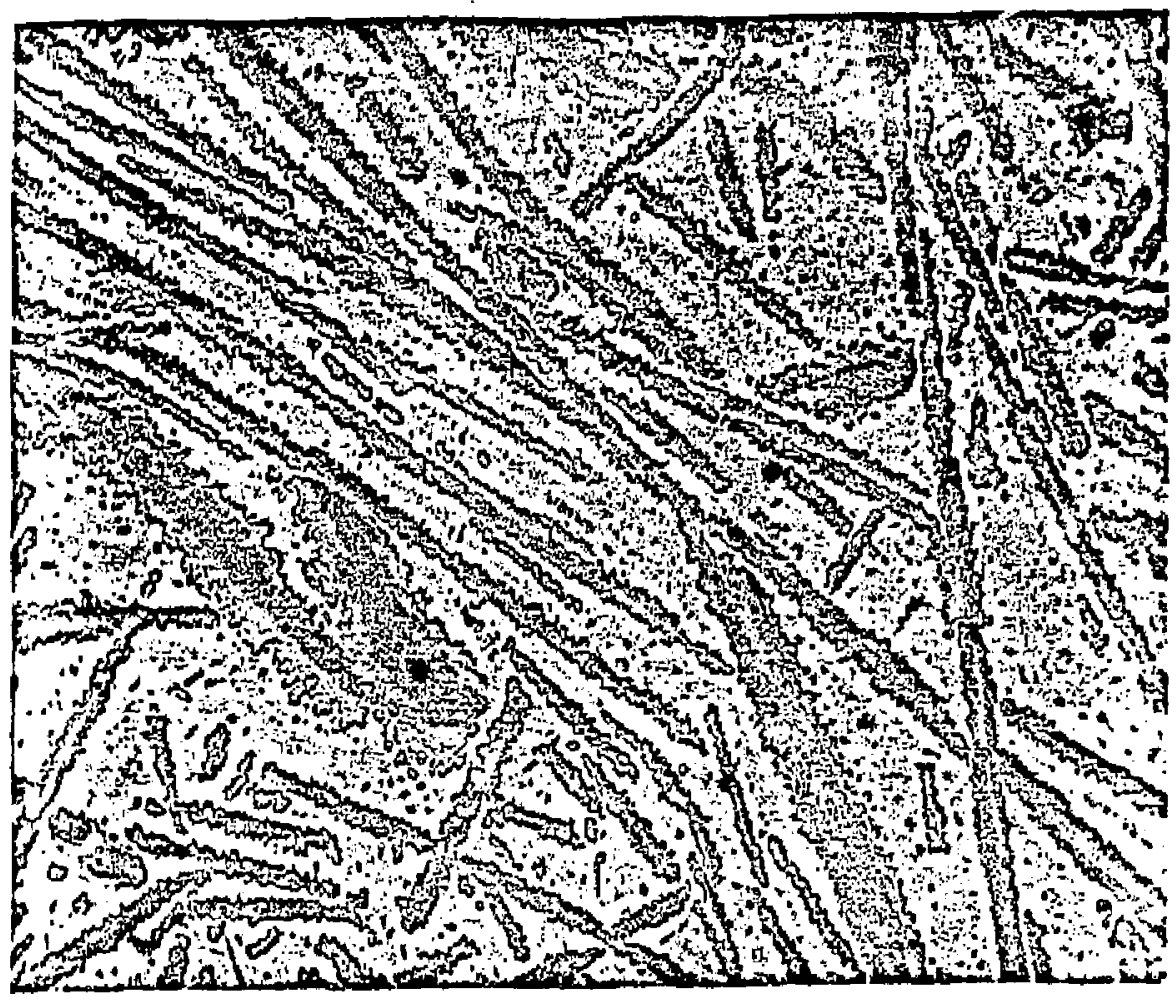

Figure 13. As cast structure of the $\mathrm{Sn}-16.7 \% \mathrm{Cil}$ alloy used to produce the composfte drawn in Figure 11 and 12. Magnification: $200 \mathrm{X}$ 
In spite of the existence of the brittle phase, the 16.7 wt $\%$ copper-tin alloy In a pure copper jacket may be drawn through slgnificant levels of reduction without the appearance of drawing defects such as chevroning which is characterized by vold regions near the center of an extrusion or drawn rod of a brittle matertal. The photonicrographs in FIgures 14 and 15 show sections along the length of the compostre having the cross section shown in Figure 11. Hot only 1s there no evidence of chevroning or other defects, there ts no disturbance of composite uniformity by the more brttele phase.

In our design of a composite including a tin rich region in the reaction matrix we have been more inclined towards a tin rich tin-copper alloy in the two phased region of the equilibrium phase diagram rather than pure tin. This preference is based on several considerations fnvolving orderly interdiffusion during homogenizacion heat treatment and the integrity of the composite. The work of Hashimoto et $\mathrm{al}^{3}$ Involving a composite including such an alloy (tin $20 \%$ copper) demonstrated the successful reduction of a composite with a two phased tin alloy constituent. The difference in hardness between pure tin and pure copper la large enough to lead to problemg during extrusion of a composite including both constituents. To avoid the distortion, which can occur when a softer constituent such as pure tin is drawn in a harder material such as copper, a small amount of copper (up to 20\%) nay be added to the tin to increase the hardness of this constituent. Another advantage of the tin-copper alloy over pure tin is that the gaterial can be contalned more readily if melting occurs during hydrostatic extrusion. Rather than melting entirely at a single temperature a tin rich alloy containing copper will begin to melt at slightly below the melting temperature of pure tin but whll exist below the 1iquidus temperature as a partly molten material with a distribution of a solid phase which impedes the flow of the molten portion of the alloy. A third possible ad'untage of the tin- 


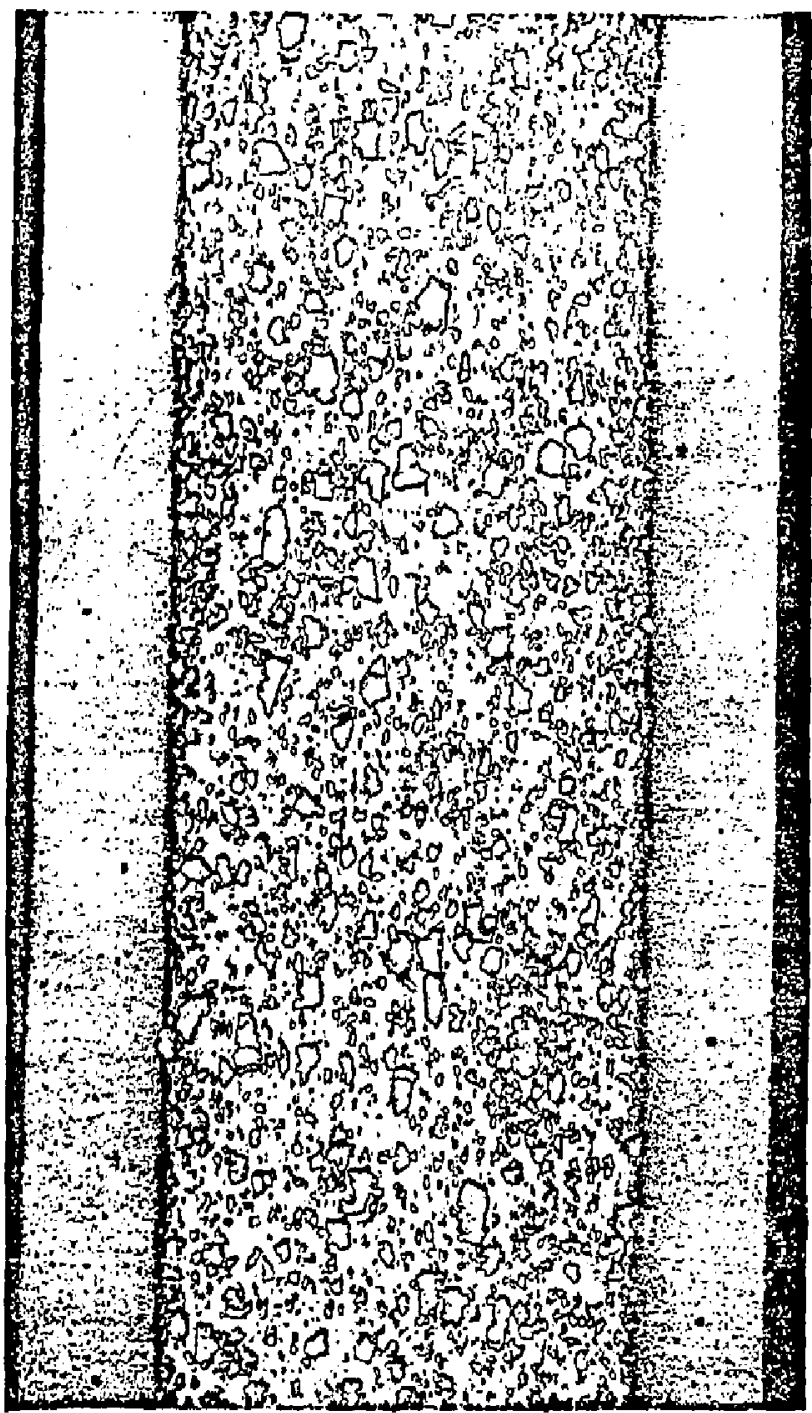

Figure 14. Photomicrograph of a longitudinal section of the composite shown in Figure 11. Magnification: $300 \mathrm{X}$ 


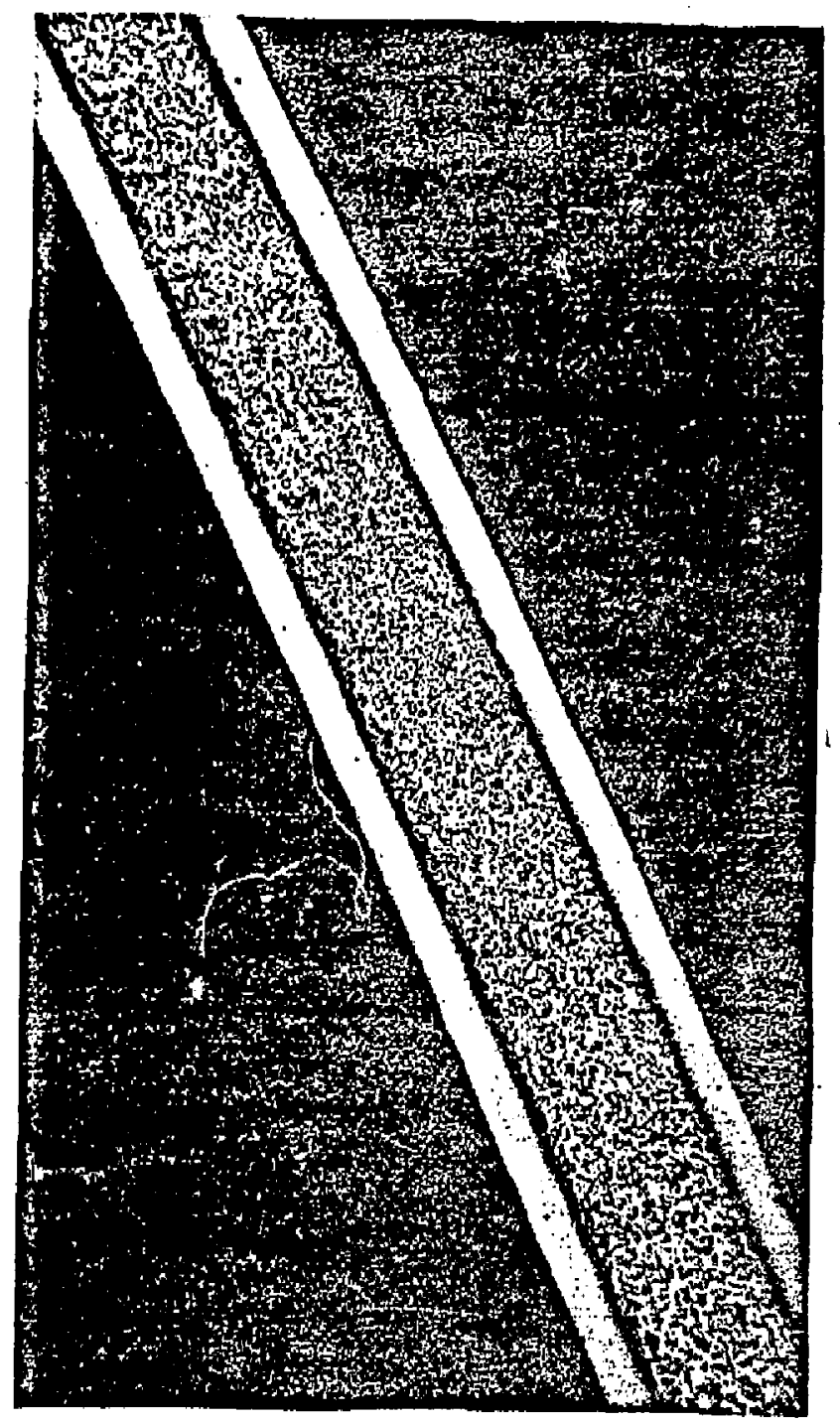

Figure 15. Photomicrograph of a longttudinal section of the composite as shown in Figure 11. Magnification: 90X 
copper-alloy ow:: pure tin is a wore orderly Interdifiusion resulting frow saturation of the tin solid solution phase w,th copper. When the gradient in concentration is reduced between two components of a diffuslon couple, genterally the degree of Xirkendall void formation near the original Interface is considerably reduced. Thts ts tmportant to our couposites because Kirkendall volds occurring near the original interface could concetvably interfere with diffusion of tin throughout the composite.

\subsection{Interdiffusion of Tin and Copper During Hamgenization of the Tin Rich Constituent}

The heat treatment of the proposed composite will have two stages. The first stage will a!low the homogenization of tin chroughout the reacting matrix in preparation for the reaction to be carrled out in the second stage of heat treatment. Since reaction should not occur in the first stage, th must be cartied out at a temperature below $600^{\circ} \mathrm{C}$. An igportant consideration in the selection of the heat treatment time and temperature is that at the chosen temperature the tin tust exhibit a sufficient rate of diffusion lil $\alpha$-bronze and the whole process must be completed with the greatest degree of confinenent of non a phases. The optimal homogenization heat treatment may involve two or more stages and w1ll be the subject of further Investigation. However, we have performed some experiments to determine the important features of che diffusion process.

\subsubsection{Diffusion in Ex erimental Composites}

The composite used in out studies is that shown in Figure 11. The overall diameter was $0.015^{\prime \prime}(.38 \mathrm{~mm})$ and the diameter of the tin rich regions wa $0.0092^{\prime \prime}$ $(.234 \mathrm{~mm})$. After a heat treatment $\cdot 400^{\circ} \mathrm{C}$ for 20 hours, the composite cross section had the configuration of phases shown in Figure 16 . The center region 1s the ordglnal two phase taiture of tin and $\eta$ phase. The next ring of material 


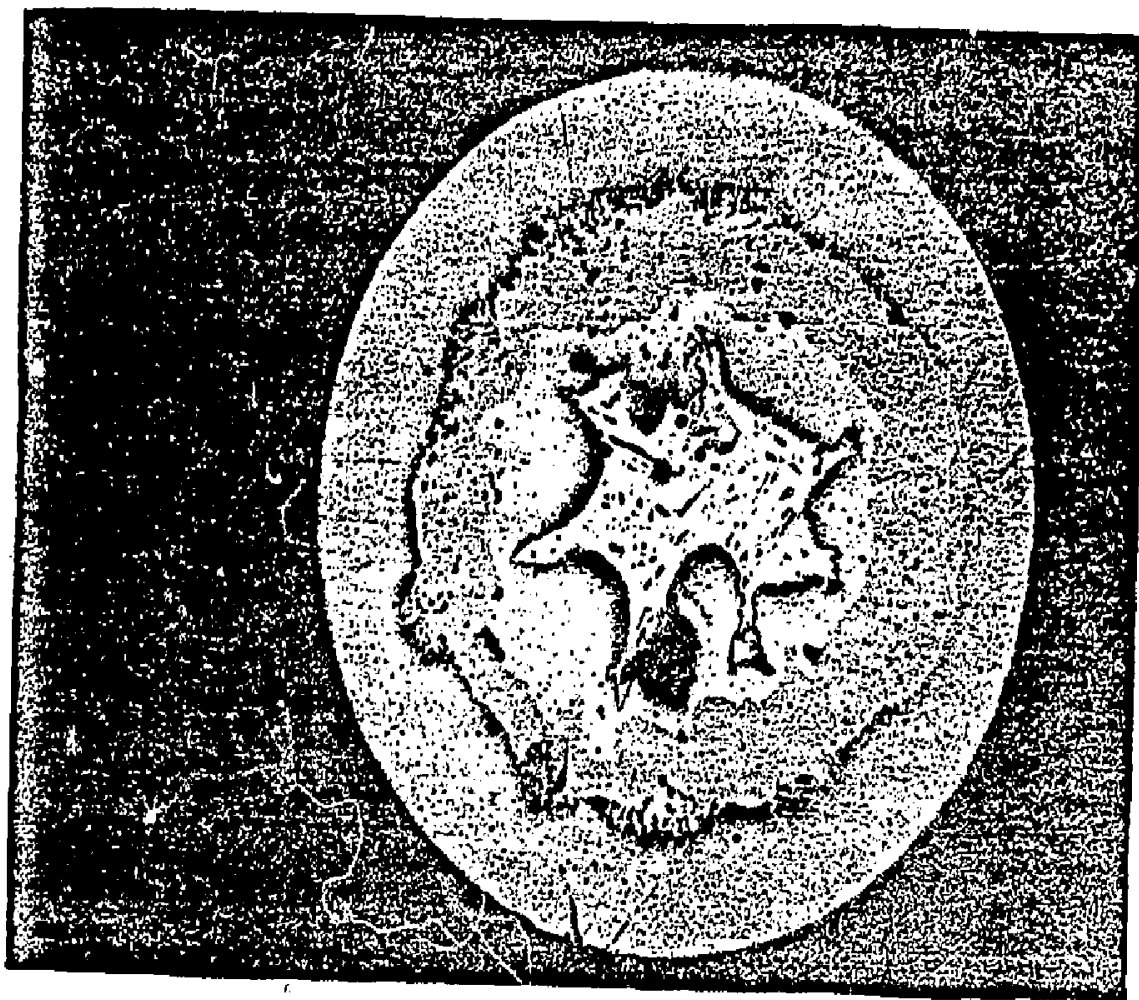

Figure 16. Photomicrograph showing the cross section of the composite wire after a heat treatment of 20 hrs. at $400^{\circ} \mathrm{C}$. Magnification: $300 \mathrm{X}$ 
going outward is pure $n$ phase followed by $\varepsilon$ phase and finaly the a phase. From the pinkish color of this phase one may conclude that at this temperature tin had not diffused to an appreciable extent in copper. The data of 0ikawa and Hosa ${ }^{19}$ incicating a deffusion distance for tin in copper of $4 \times 10^{-5}$ con after 20 hour', at $400^{\circ} \mathrm{C}$ confirms the sluggish diffusion of $i$ in in copper at this temperaturs. The heat treatment at $400^{\circ} \mathrm{C}$ was continued and the resuit is shown in Figure 17 . As this flgure shows, after 68 hours at $400^{\circ} \mathrm{C}$ all of the original tin rich phase mixture has been eliminated, the E phase has grow while the $\eta$ phase which now occuples the center has reduced. The outer region of almost pure copper still does not show any appreciable extent of tin diffusion into the copper. If the heat treatment at $400^{\circ} \mathrm{C}$ were allowed to continue, a'l the $\eta$ would probably be converted to $\varepsilon$ phase before even a small fraction of the tin could diffuse into the copper.

Figure 18 shows a sample of the composite shown in figure 11 after a heat treatment of 68 hours at $600^{\circ} \mathrm{C}$. Two phases are apparent in this photomicrograph. The yellowish phase near the outsdde is a bronze through which an appreciable amount of tin has diffused. The greytsh blue region with the specked appearance consists of the $E$ phase and small reglons of $\alpha$-bronze. The inner region has this phase mixture because it is the product of the decomposition of the $f$ phase which is formed at the heat creatment temperature $\left(600^{\circ} \mathrm{C}\right)$. Judging from the quant1ties of the two phases shown In this section, the congosite must be close to equtlibrium.

\subsubsection{Implications of These Diffusion Studies on Composite Design}

The distribution of the $\varepsilon$ phase shown in this photomicrograph is quite irregular most likely as a consequence of growth of the non a phases and subsequent decomposition of such phases as diffusion of tin into the copper is allowed to *Diffusion distance is defined as (diffusion coefficient $x$ time) 


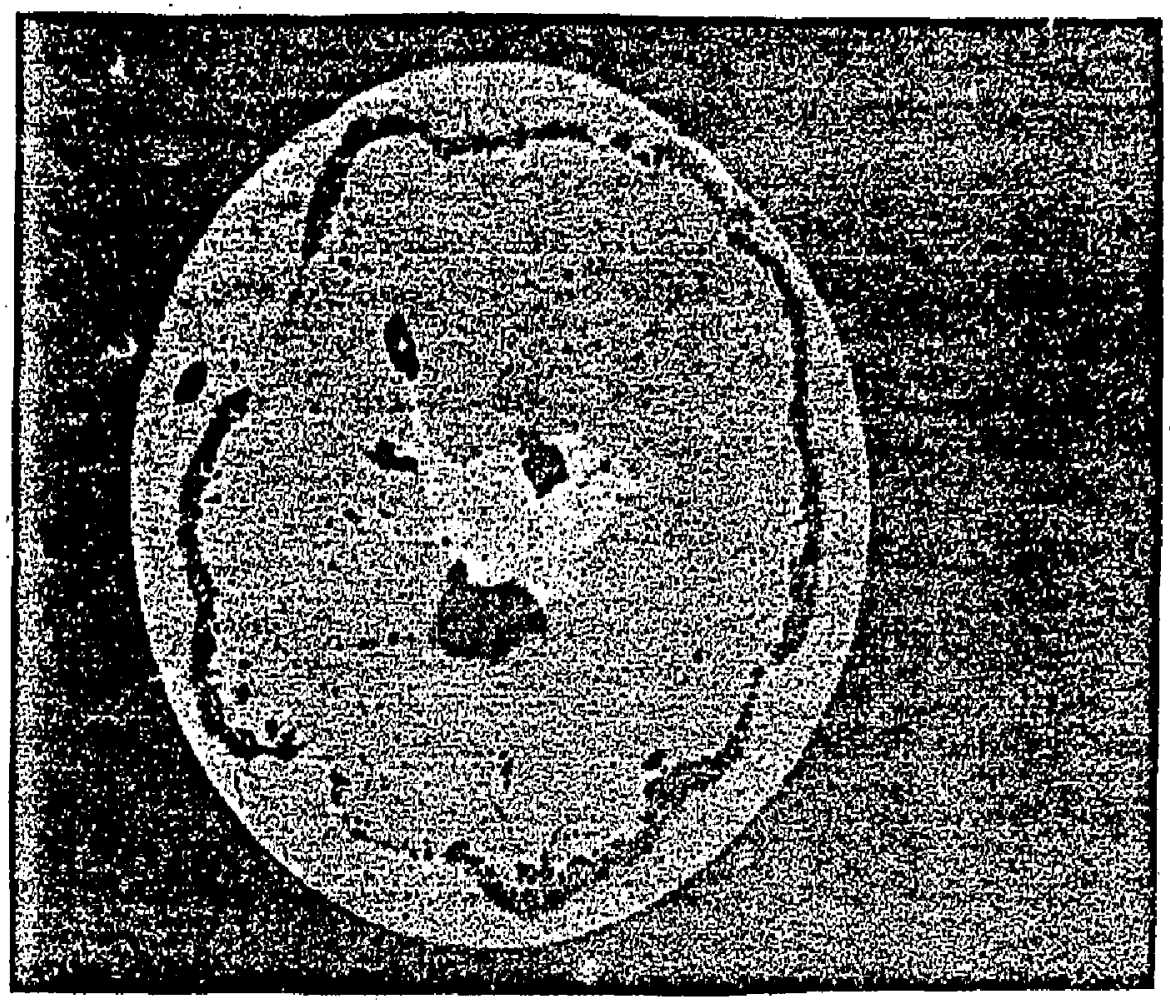

Figure 17. Photomicrograph showing the cross section of the composite wire after a heat treatment of $68 \mathrm{hrs}$. at $400^{\circ} \mathrm{C}$. Magnification: $300 \mathrm{X}$ 


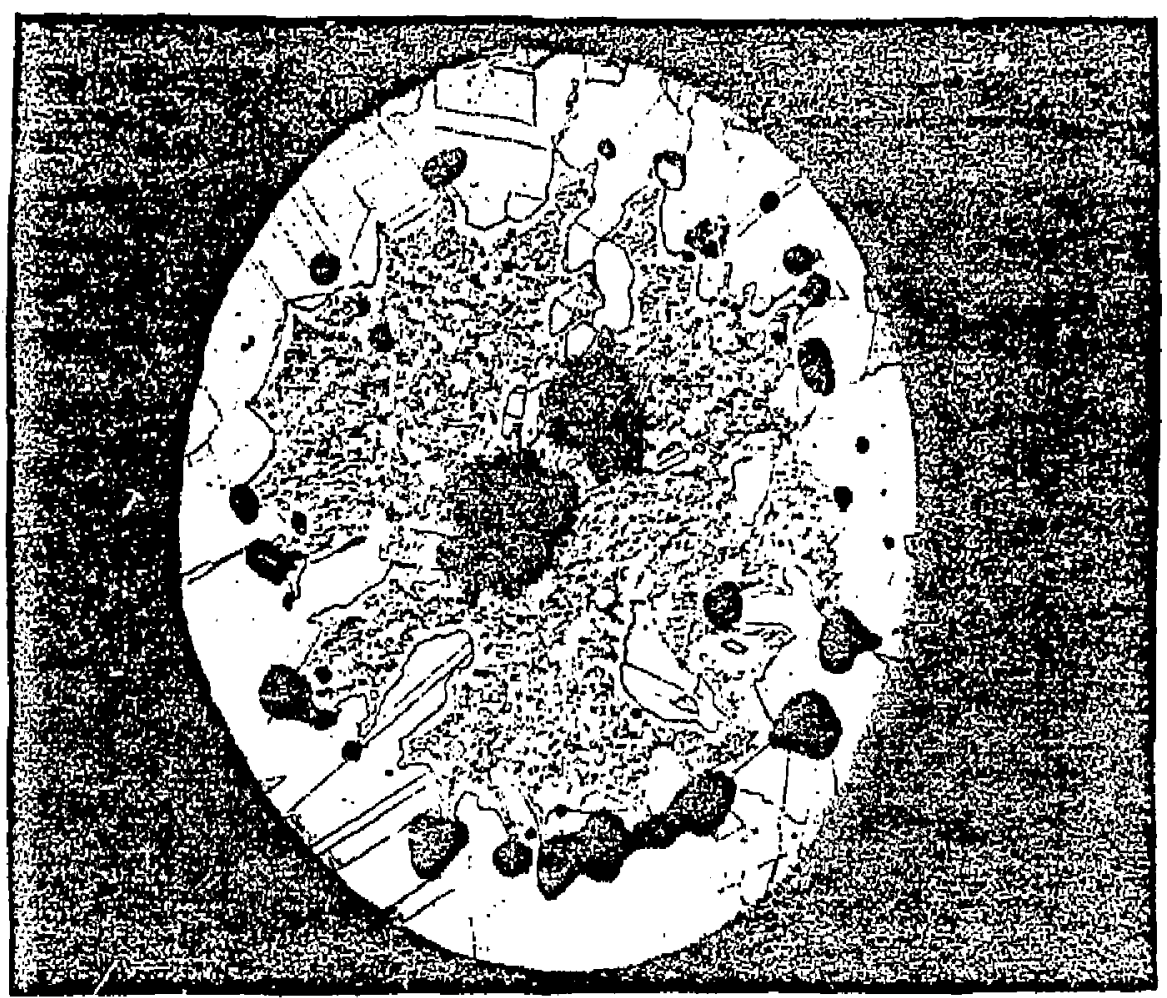

Figure 18. Photomicrograph of a sample of the composite shown in Figure 11 after a heat treatment of $61 \mathrm{hrs.} \mathrm{at}$ $600^{\circ} \mathrm{C}$. Maga iftcation: $300 \mathrm{X}$ 
proceed. The circle fully contafning the remanent $E$ phases is the region in which no nioblum filaments should exist in a superconducting cooposite including all three constituents. For the sake of solecting a heat treatment which will result In the greatest confinement of the $E$ phase, a comparison of the extent of $\varepsilon$ phase resulting from the two heat treatment temperatures will be useful. From the photonicrograph of Figure 17 we may calculate the rat lo of the diameter if the circle fully clrcumscribing the pon a phase zegion $\left(\mathrm{d}_{f}\right)$ to the diameter of the orfginal tin alloy filament $d_{1}$ :

$$
d_{f} / d_{j}=1.46
$$

(after a heat treatment of 68 hours at $400^{\circ}$ ). At this point in time during che fnterdiffusion of tin and copper the $n$ phase has not been completely crnverted to $\varepsilon$ phase. The final extent of the $\varepsilon$ phase is therefore expected to be worse than that indicated by expression (6). A sinflar ratio may be established for the heat treatment carried out at $600^{\circ} \mathrm{C}$ as represented by the photomicrograph of Figure 18:

$$
d_{f} / d_{i}=1.340
$$

(after a heat creatment of 61 hours at $600^{\circ} \mathrm{C}$ ). The results would tend to recommend the $600^{\circ} \mathrm{C}$ heat treatment over a lower temperature heat treatment such as one at $400^{\circ} \mathrm{C}$ for homogentaing the composite prior to reaction. The advantage of a higher temperature probably results from a high rate of diffusion of tin in copper occurring simultaneously with the growth of the other phases. A homogenization carried out at a temperature greater than $600^{\circ} \mathrm{C}$ Thay result in even greater confinement of the $E$ or $\delta$ phase but would present the danger of premature reaction and consequently a poor distribution of $\mathrm{Nb}_{3} \mathrm{Sn}$ over the groups of niobium fflaments. Mlthough the horogenization heat treatment is subject to 
further optimization, we will accept these preliminary results for the destgn of our composites. Accepting $600^{\circ} \mathrm{C}$ as the homogenization temperature, we vill use the relattonship of expression (7) as an Indication of the region fion which nlobium fliaments must be excluded.

Klckendall volds are always present after reaction of a multifilamentary $\mathrm{Mb}_{3} \mathrm{Sa}$ composite. However, bronze/Nb composites, externaliy tinned copper/niobium composites and copper/niobiun/tin alloy compsites differ in the nature and distribution of these yoids. In bronze/niobium composites volds generally become distributed throughout the niobiun filaments. In extemally tinned composites or composites containing a tin rich alloy In copper, Kirkendall void formation is usually restricted to the interface between the a regions and the of phase which forms early in the interdiffusion process. In the composite of Figure 18 these voids exist on or somewhat outside the ctrcle of diameter $d_{f}$. If in the design of a composite one distributes the nioblum filaments up to the circle of diameter $d_{f}$, one 1 s permitting only an insignificant fraction of the filaments to be affected by volds. The percentage of niobium Ellaments affected by voids in such a composite will mdoubtedly be less than that in a typical bronze/niobfum composite after reaction.

The Kirkendall volds aust not be extensive enough to interfare with the diffusion of tin throughout the composite. The observation of many sections of the composite of $F 1$ gure 18 revealed no void regions so extensive. Appendix $b$ of this report contains photomicrographs of several other sections of this heat treated composite. 


\subsection{Billet Construction}

The construction of billets in the production of large quantities of superconducting composite generally involves the stacking of hexagonal elements into 2. hollow cylindrical can. In the preparation of the billets used in the hydrostatic extruston experiments we therefore used such a stacking method. Hexagonal elements consisting of cores of pure $t$ in and a tin $-16.7 \%$ copper allog wete prepared. Both of these elemeats had cores accupylng $70 \%$ of their cross sectional area as thay be seen in Figures 19 and 20. Groups of seven hexagonal. elements were stacked into the billet shell as shown in the schematic representation of the billet cross section in Figure 21. The dimensions of the composite billet are shown in 31 gures 21 and 22 . The tail cap and nose of the billet were sacured to the body of che billet by electron bear welding. Photographs of these welds are shown in Figures 23 and 24.

A featore worthy of mentfoning is the very successful drawing of a comorite containing pure tin and copper. This may suogest that the precaution of alloying the tin with copper to increase its hardness is not necessary. If this is generalı: true, there would be much greater freedom in asigning composttes and undurbtedly a reduction in conductor cost.

The Important consideration with regarit to these composite billets is the maximum reduction ratio permlssible before some disruptive effect such as the melting of the $t$ in alloy accurs. The work of extrusion is converted almost entirely to heat which is partly dissipated and partly contributed to biljec heating. In order for the tin to melt ensugh of the mechanical energy of extrusion must be absorbed by the billet to ratse its temperature above the melfing point of tir. Also, the tin alloy must have time to absorb the Latent heat of fusion, With all these factors involved we cannot Innediately accept 


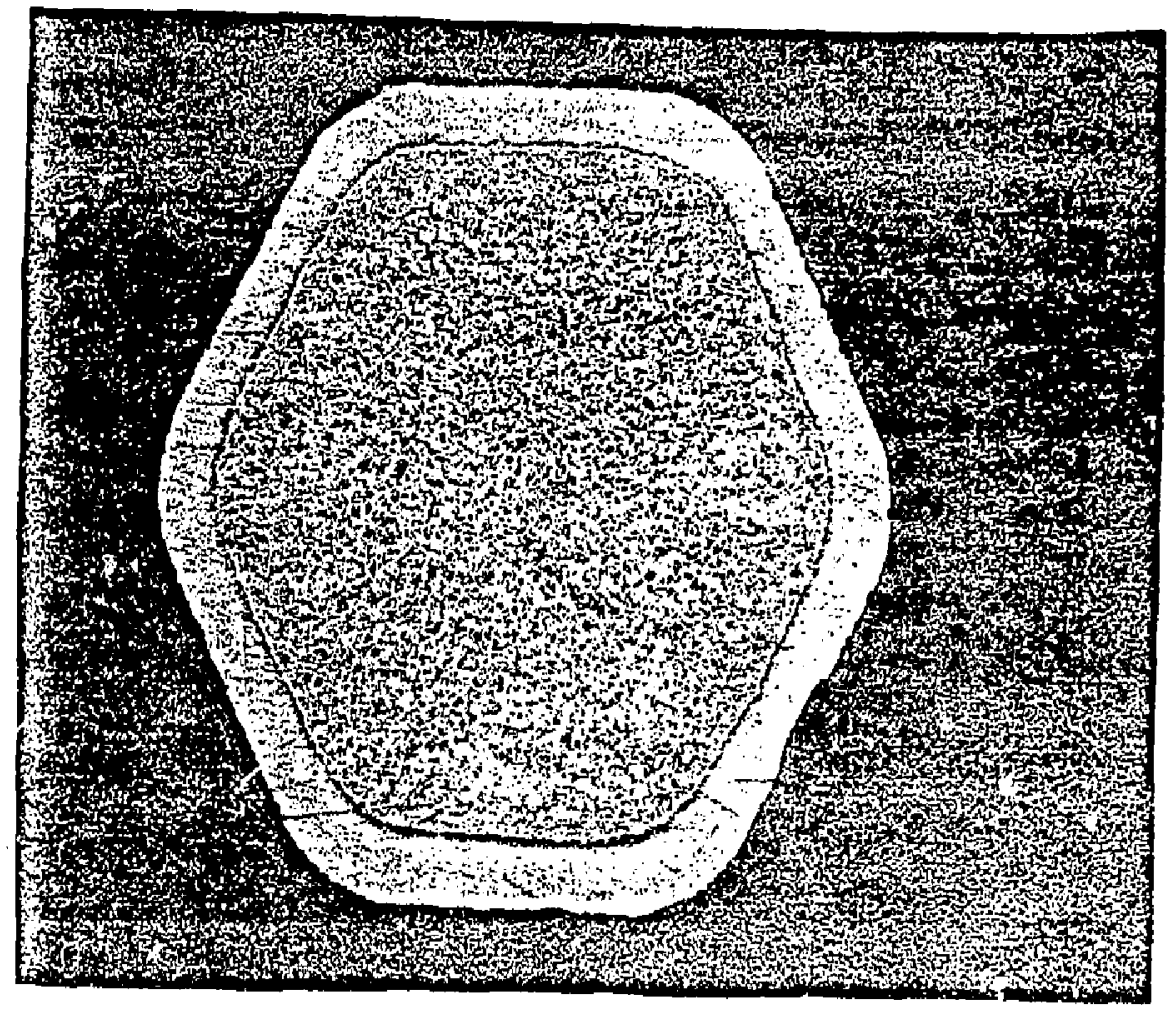

Figure 19. Cross section of the hexagonal elements used in packing the billets used in the study of hydrostatic extrusion. The dimensions of this hexagonal Iod is $0.177^{\prime \prime}(.450 \mathrm{~cm})$ side to side. The core, which is a $\mathrm{Sn}-16.7 \%$ C. alloy, occupies $70 \%$ of the cross section. 


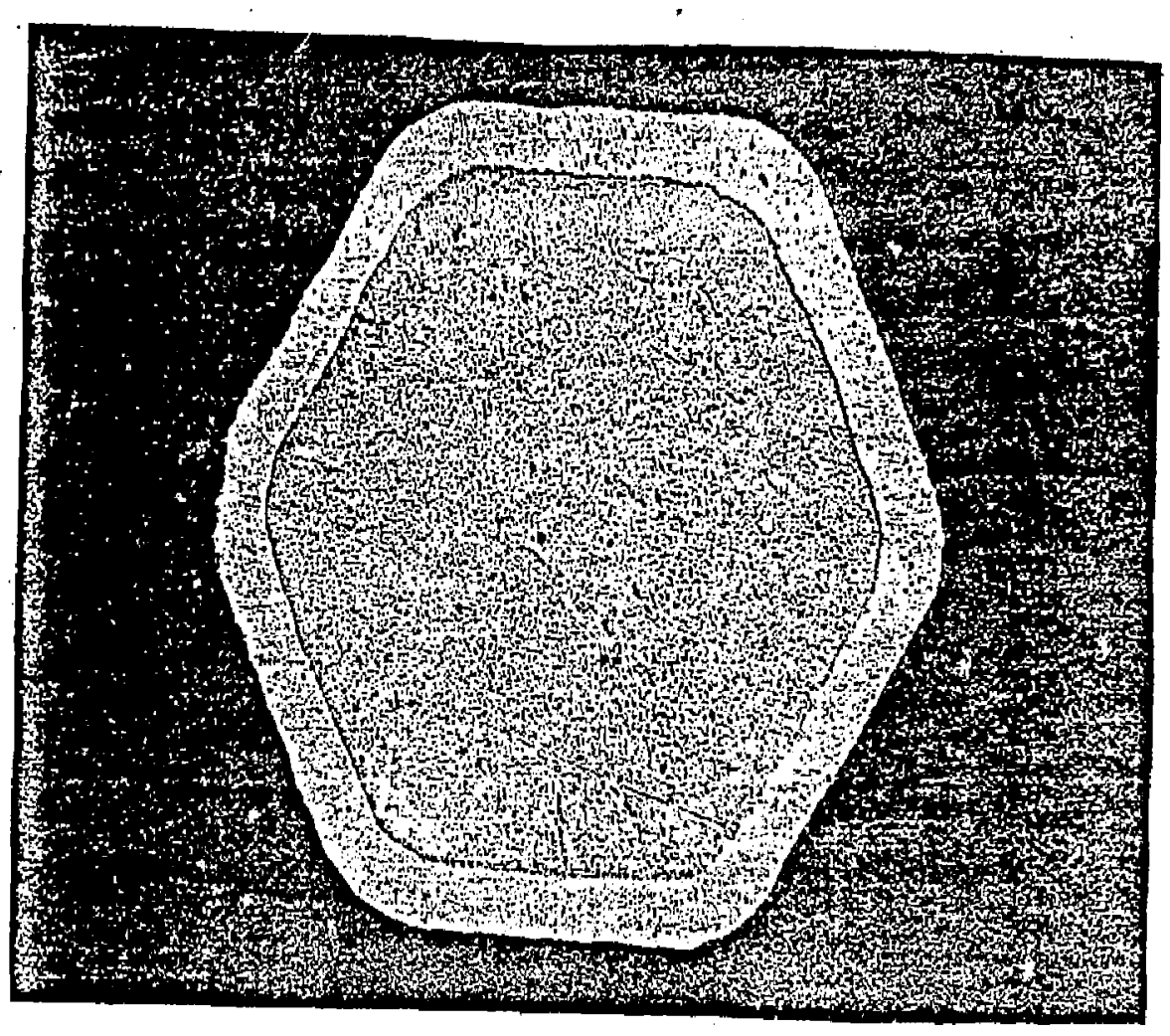

Figure 20. Cross section of the hexagonal element having as 1ts core pure tin. The dimension of the hexagonal rod is $0.177^{\prime \prime}(.450 \mathrm{~cm})$ ste to side. The core occupies $70 \%$ of the composite. 


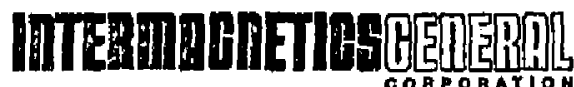

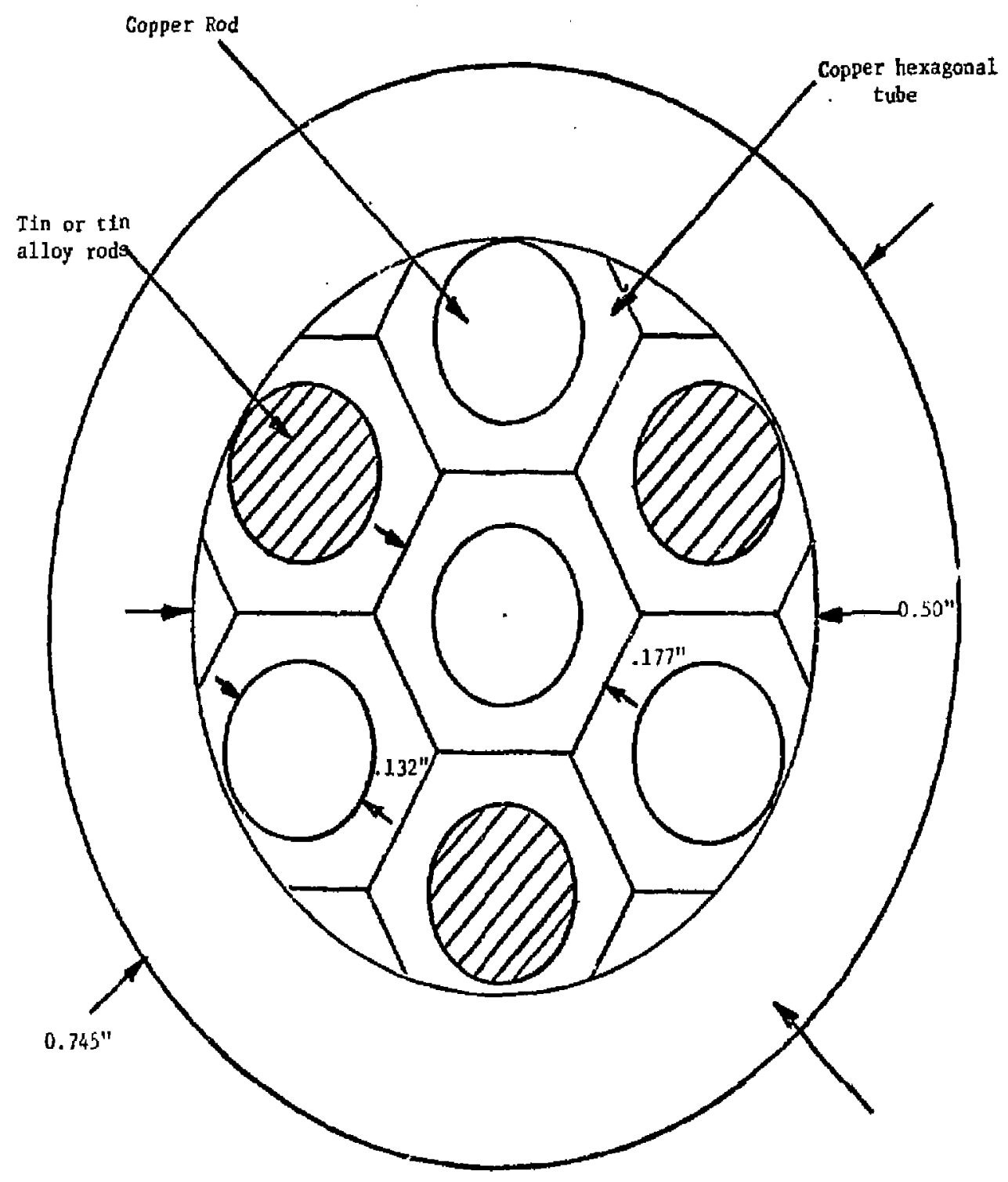

Figure 21. Cross section of billet showing the stacking of elements. 


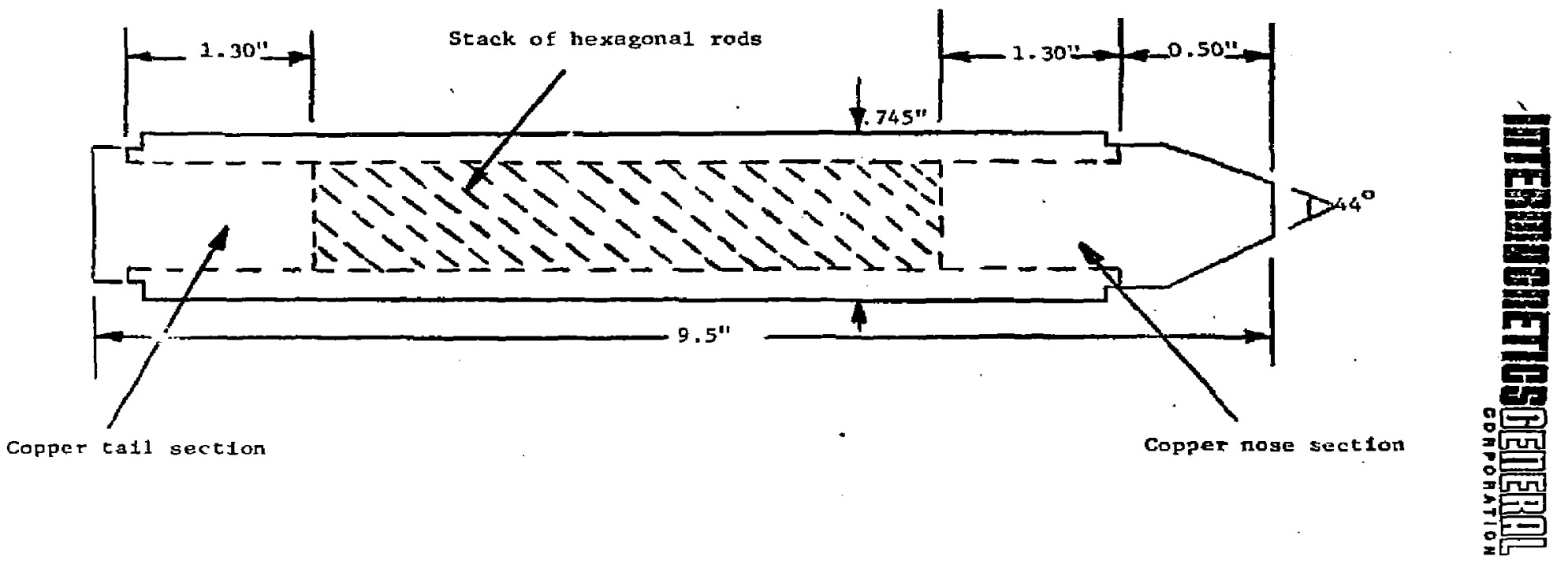

Figure 22, Drawing of the billet used in the bydrostatic extrusion experiments. 


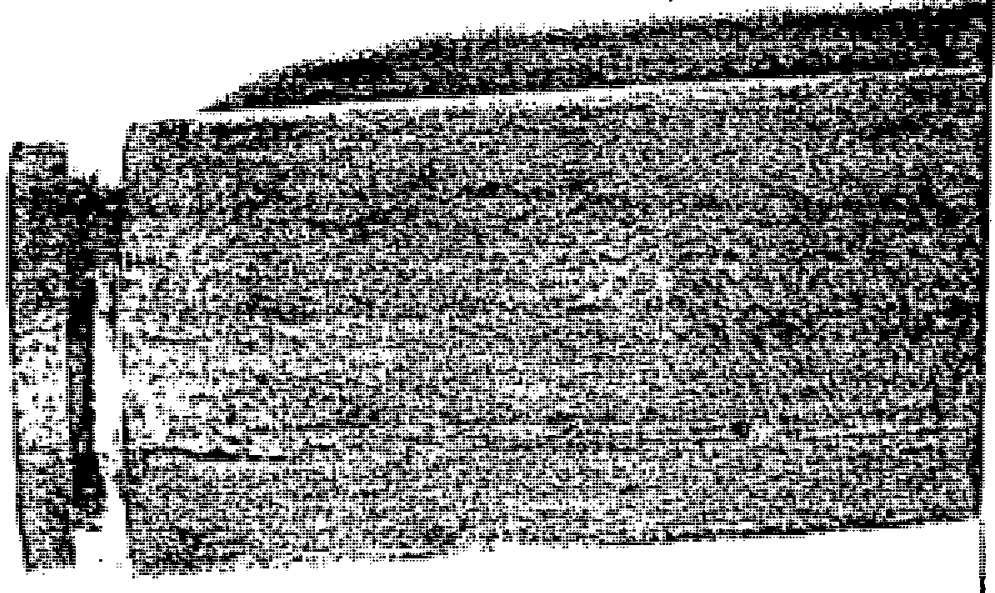

Figure 23. Photograph of weld at the tail section of the experimental billet.

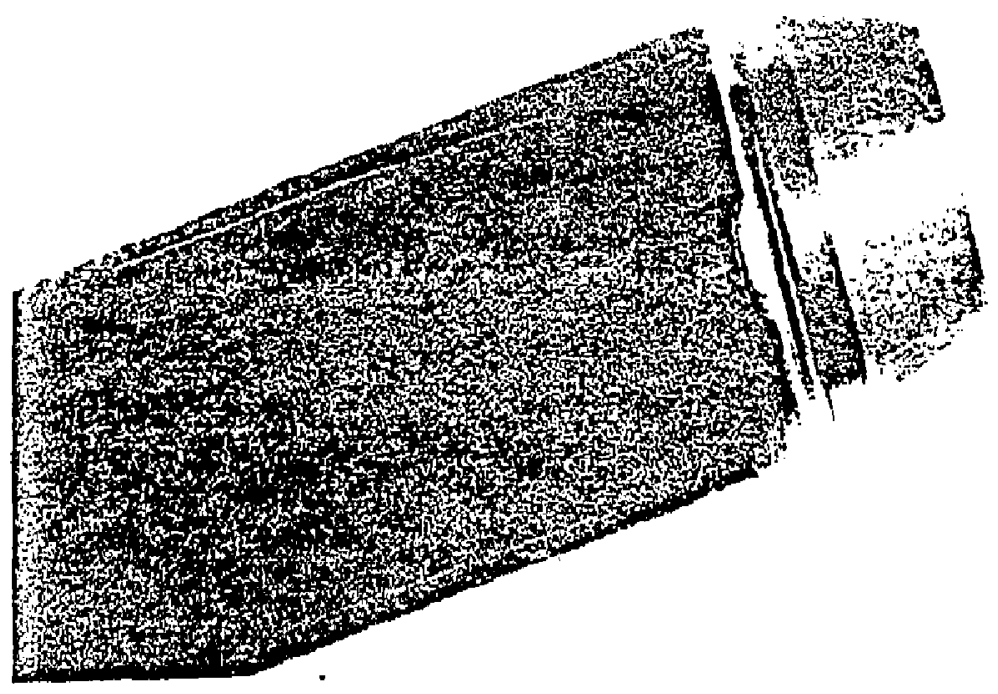

Figure 24. Photograph of the wald at the nose section of the experimental billet. 
the adtabatic temperature calculated from the extrusion presgure as an Indication of the temperature achleved by the billet and we cannot assure that merely reaching the melting point results in billet disrugtiou. HuL likely the billet temperature must exceed the melting polnt with a sufficient margin that the latent heat is accepted by the tin during the deformation of the composite.

A supercondurting billet contalning nloblum, tanialum, soft copper and the tin alloy will most likely, have a flow stress between hard and soft copper. To provdde a difference In component hardness not less than that existing in an actual composite bfllet, hard copper rather than soft copper was used in the experimental extrugions. The choice of hard copper also guaranteed that the calculated adfabatic temperature rise would exceed the relting point of the tin alloy for the extrusion ratios avallable to us. The purpose of these preliminary extrusions was to establish the possibility of producing a rotnd extrusion in a composite billet containing the tin alloy and to gain a rough Idea of the 1imitations on permissible extrusion ratio.

\subsection{Extrusion of Composite Btllets Contalning the Tin Alloy}

Because of the presence of the low melting point tin alloy the extrus:on must be carrted out with billets at room temperature or below. Because of the extremely high pressures associated wh the cold conventional extruston of copper and the other composite constituents, hydrostatic extrusion is absolutely essential. Although this extrusion method is not commercially practiced on large billets in the Onited States, the use of a converted conventional extruston press in the manner developed by investigations at Battelle seems to be a very practical possibtlity. 
The extrusion should reduce the billet to a dlameter less than 5 inches $(12.7 \mathrm{~cm})$ which is the limit of presently practical draw bench drawing. The higher the reduction ratto of the extruston the wore economical the process since higher extrusion ratios elfolnate more of the drat bench drawing which must be carried out in successive passes with liwited reductions per pass.

of the three extrusion ratios attempted only two 4.7 and 9.5 to 1 reduction in area could be accomplished because of the 1 - nitation in pressure $(235,000$ pst). The extrustons were interrupted when about $4 \mathrm{~cm}$ of the billet remalned. This allowed us to examfne the region remaining in the die. Figure 25 showing the billet excruded at $4.7 / 1$ reduction in area reveals some chatter as a result of meven and inadequate lubrication. The 9.5 to 1 reduction in area on the other hand I svealed a smooth surface at the die interface as shown in Figure 26. Apparently at the higher pressures necessary to carry out the higher reduction ratios, lubrication of the die/billet interface by the extrusion flutd is wore eifective. The cross section of the rod extruded at $4.7 / 1$ reduction ratio showed regions of nonbonding as did the rod extruded at 9.5/1. Cross sections of the two rods are shown in Figures 27 and 28 respectively. The 9.5 to 1 reduction resulted in melting and rupture of the billet. The results of the hydrostatic extrusions are swmarized in Table 3.1.

The extrusion pressures corresponding to the extrusion ratios of our composite bi.llets is shown in the graph of Figure 29 along with estimates of pressure for the extrusion of soft copper, The corresponding adiabatic temperature rises are likewise fndicated on the ordinate of this graph. The 4.7 to 1 reduction falls below the pressure corresponding to the melting temperature of tin. The 9.5 to 1 reduction, however, is signtficantly above this pressure. 


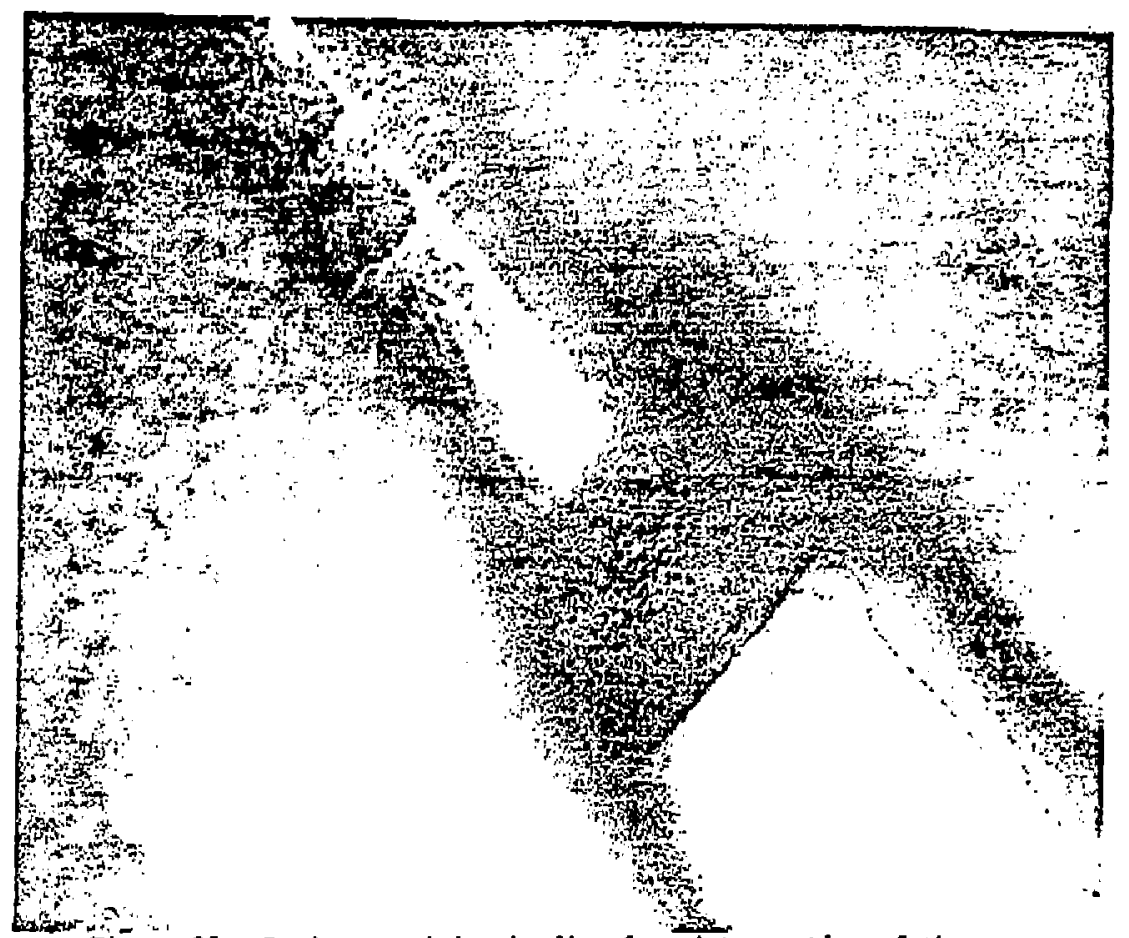

Figure 25. Region remaining in die after interruption of the 4.7 to 1 extrusion ( $6 \mathrm{ft} /$ gin billet velocity).

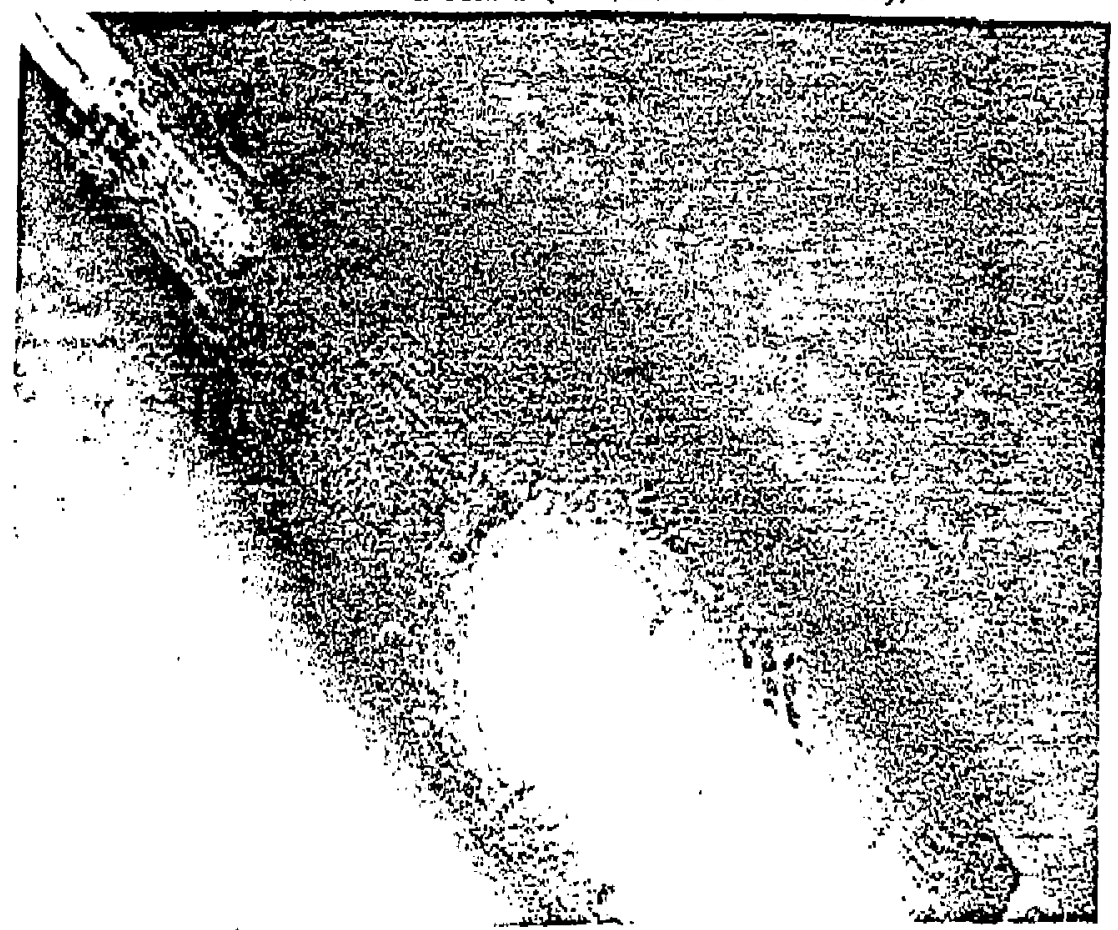

figure 26. llegion remaining in die after interruption of the 9.5 to 1 extrusion ( 3 [t/pin biliar velocity). 


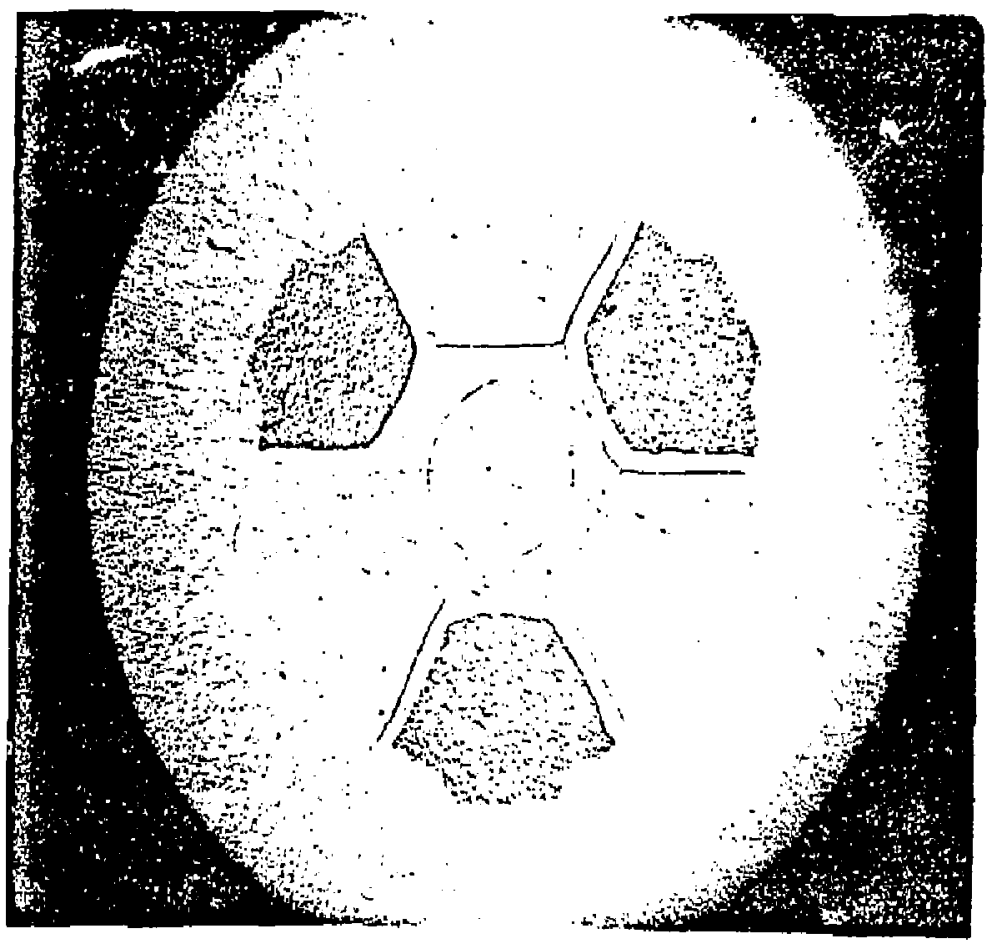

Figure 27. Cross section of rod extruded with a 4.7 to 1 reduction ratio and a billet speed of $6 \mathrm{ft}$, per minute. 


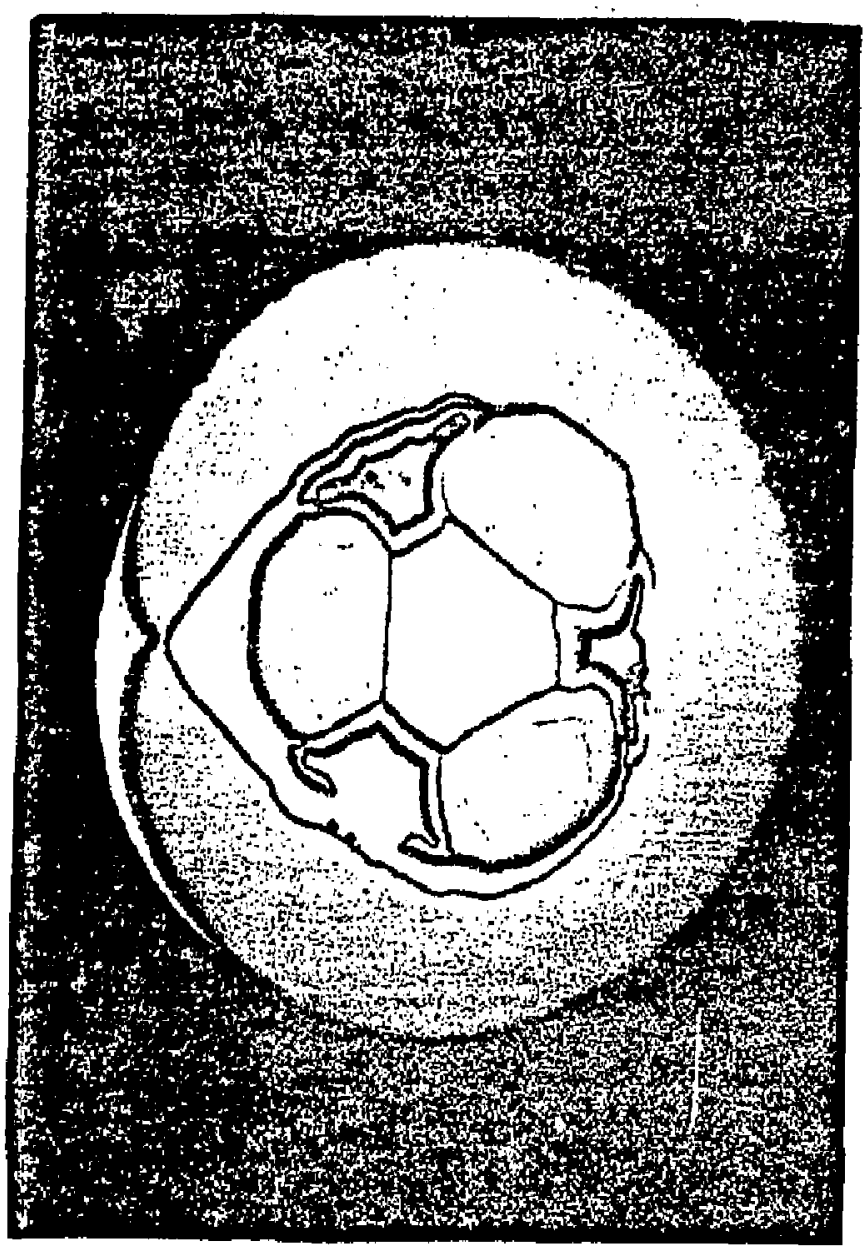

FIgure 28. Cross sect Ion of rod extruded with a 9.5 to 1 reduction ratio and a billet speed of $6 \mathrm{ft}$. per minute. 
Figure 29

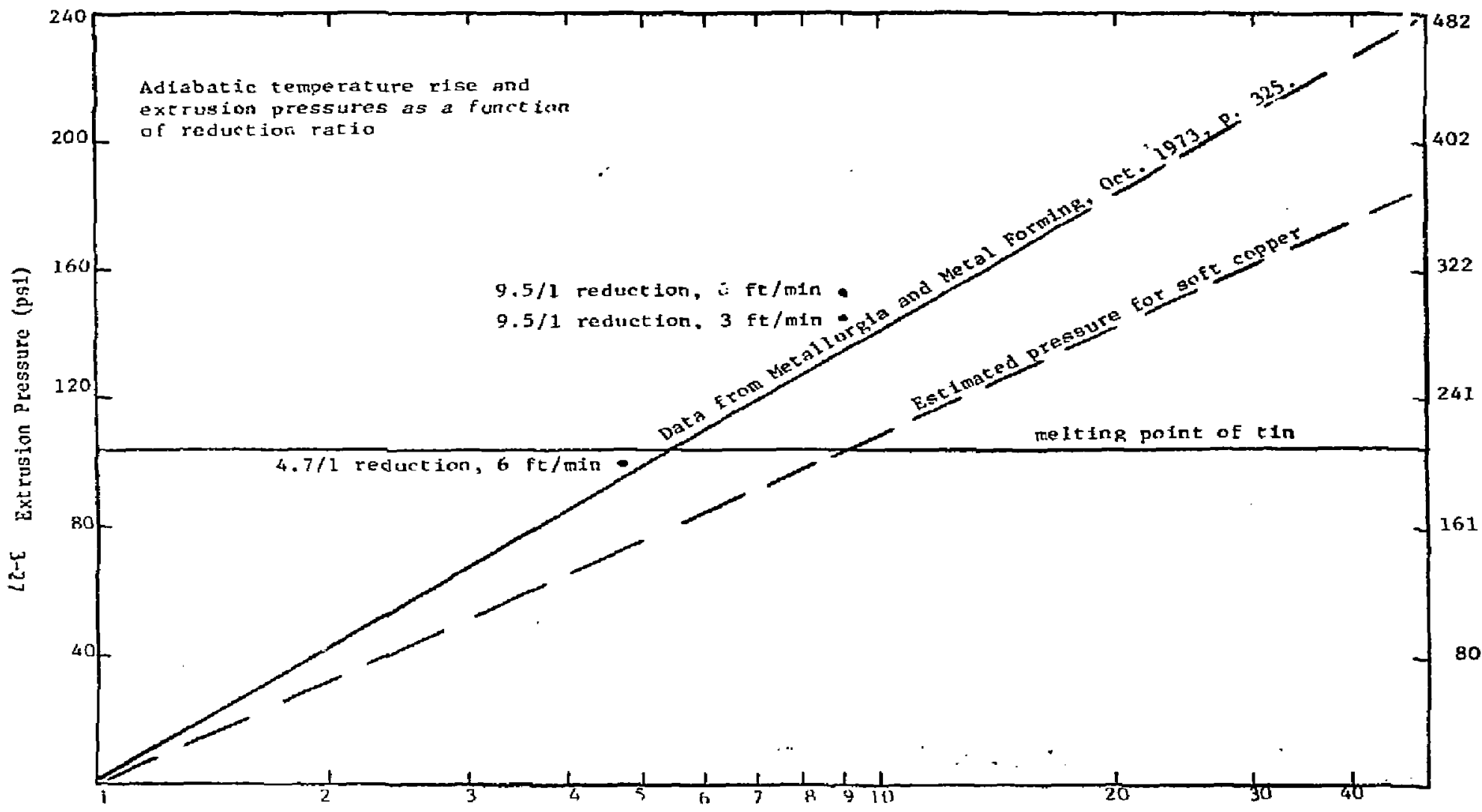

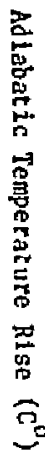

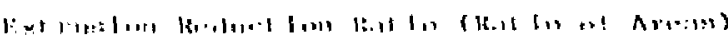


Table 3-1

SUMMARY OF HYDROSTATIC EXTRUSION EXPERTMENTS

Reduction in Arca Attempted

1. 4.7 to 1

2. 9.5 to 1

(melting)

3. 9.5 to 1

(IIelting)

4. 16 to 1
Peak Pressure at Beginning of Extruston

no peak

200,000 ps1

200,000 pst
BI11et Speed

$6 \mathrm{ft} / \mathrm{min}$.

$6 \mathrm{ft} / \mathrm{min}$.

$3 \mathrm{Ec} / \mathrm{min}$.
Estimated ndiabatic Tempereture Ribe*

\section{$200^{\circ} \mathrm{C}$}

$305^{\circ} \mathrm{C}$

145,000 psi

The Initial peak pressure prevented this reduction

*Th1s temperature 19 that occurring when no conduction of heat occurs along the billet or rod or to the tooling. It will be the peak temperature experienced by the material in the limt of high extruston speeds. 
In the extrusion of a superconducting corposite we can be sure of accomplishing at least a 4.7 to 1 repuction rat1o. This would correspond to a $10^{\prime \prime}(25 \mathrm{~cm})$ diameter biliet extruded to a $4.6^{\prime \prime}(11.7 \mathrm{~cm})$ diameter rod which can be readily handled by existing draw benches.

An alternative to accepting the 4.7 to 1 reduction ratio and continuing the reduction with bench drawing is carrying out the extrusion at a higher ratio with cooling of the extruded rod. The cruclal consideration in the evaluation of the possible economic advantage of the latter altemative is the required extrusion speed necessary to allow suffictent conduction of heat fros the deformation zone through the extruded rod to the cooling mediun. Using the forwulation of Chapter 2 with several simplifylng but conservative assumptions we arrive at the following expression for the maximum temperature achieved by the extruded billet:

$$
T_{\max }=\frac{D}{c}\left(\frac{1}{2}+\frac{1}{2}\left(1+\frac{8 h k}{c^{2} v_{R}^{2} a_{R}}\right)^{\frac{l}{2}}\right)^{1},
$$

where $\mathrm{C}$ is the heat capacity of the billet material (51 Btu/ $/{ }^{\circ} / \mathrm{ft}{ }^{3}$ for copper) $v_{R}$ is the velocity of the extruded rod

$a_{R}$ is the zadius of the extruded rod

$k$ is the therual conductivity of the composite material (219 Btu/hr ft ${ }^{\circ} \mathrm{F}$ for copper)

and $h$ is the surface heat transfer coefficient to the cooling medium.

Using values for pure copper we have calculated the temperature rise corresponding to the extruston of a billet at a speed of $.13 \mathrm{ft} / \mathrm{min}$ for a range of extrusion ratios. The extrusion pressure as a function of area reduction ratio used in the calculation are those corresponding to the trend followed by our composites consiscing of hayd copper and tin - $16.7 \%$ copper elements. The value of h was 
determined from the data for boiling water heat transfer of McAdams ${ }^{20}$ along with the assumption that the heat originates from a surface at half the radius of the extruded rod. The latter assumption approximately takes into account the volume of material that heat must conductor through to reach the cooling fluid. The retsulting value for $h$ was $2700 \mathrm{Btu} / \mathrm{Et}^{2}{ }^{\circ} \mathrm{F}$.

The results of these calculations ate shown in Figure 30 along with the data from the extrusion of our experimental composites. 
Temperature rise corresponding to water cooling at .12 ft/min blllet speed $\left({ }^{\circ} \mathrm{C}\right)$






\subsection{MODEL CONDUUCTOR AND ECONOMIC CONSIDERATIONS}

\section{I Design of a 10,000 Ampere (12 Tesla) Conductor Using the Proposed Technigue}

For the sake of making concrete economic cutparisons of the proposed technique to the conventional method of fabricating high current carrying capacity multifllamentary $\mathrm{Nb}_{3}$ Sn conductors, we are presenc1ag four coaductor examples all of which include a reactive matrix of pure copper and tin alloy. These conductors, designed to carry 10,000 Amperes at 12 Tesla, $4.2 \mathrm{~K}$, w111 be based on information gathered in the present study as well as previous experience with bronze bearing and externally diffused composites. Among the considerations in the design of a composite using the proposed method are the following:

1. The tin rich filaments should be distributed and of such size as to avoid the engulfing of nlobium filaments by alloy phaseg such as $\varepsilon$ or $\delta$ resulting from the homogenization heat treatment. The diffusion experiments described in the previous section will provide a guide in selecting the proper tin alloy filanent size. Assuming a heat trealment at $600^{\circ} \mathrm{C}$, the growth factor in expresston (7) may be used. I.tcreasing the surface to volute of the tin alloy filament by reducing its size is expected to enhance the tate of transport of tiu by diffusion into the copper relative to the rate of growth of the other tin alloys. Consequently, we expect the growth factor (1.e. the ratio of expression (7) to reduce with decreasing tin Alloy filament diameter. Since the tin alloy filaments in the model conductors are sjaller than those of the diffusion study, we expect expression ( 7 ) to be a conservative estimate of the act cal growth factor.

2. The tin rich filaments should be distributed $\varepsilon^{-}$as to allow homogenation of $t$ in throughout the reaction mat $f x$ in a reasonable time. Our past experience with external diffusion indicates that homogenizaticn ray occur in a reasonable time at $600^{\circ} \mathrm{C}$ 'if all niobiut filaments are within 5 mils (.127 of the tin region. Such a distribution of tin would allow sufficient homogenization to occur In a period less than 100 hours. 
3. The nlobium filaments should be sufficiently spaced from one another to nllow diffusion of tin between the fllagents and prevent welding betwen the nlobium fllainents as the composite is drawn to its final diameter. From previous experience we have selected a minimum spacing between the niobium filaments of one half the filament diameter.

4. High conductivity (OFHC) copper distributed throughout the conductor is useful in providing stability by slowing down flux jump thereby allowing wore time for the heat generated to diffuse away. A rule of thumb proposed by W118on ${ }^{21}$ for the distribution of the copper is that no $\mathrm{Nb}_{3} \mathrm{Sn}$ filament in the bronze should find itself more than $200 \mathrm{p}$ away from a regton of pure copper.

The four conductors presented w1ll involve two stages of extruston, when a conduccor with such high curreot carrying capacity is constructed with a bropze matrlx, three extrusion stages are generally adviseble. However, because fabrication of hexagonal rod or tube elements of OFHC copper is widely practiced by existing manufacturers, we may eliminate this first extrusion by using comercially fabricated elements and increasing the number of elements stacked in the two extrusions. There are at least three advantages of such an approach:

1. The cost of the extrusion of a specially prepared bronze enmposite billet is replaced by the use of more efficiently produced standard commercial nexago.al copper rods and tubes.

2. The loss of material in a first composite extrusion stage due to the typical $80 \%$ billet yleld is eliminated.

3. The amount of matrix material in the final conductor can be reduced.

offsetting these advancages, however, is the increased expense of fabricating the sialler and wore numerous elements for the remaining stages. 
A11 of the proposed model conductors wlll contatn h1gh conductivity copper occupying about $30 \%$ of the cross section and will fulfill all four of the requirements mentioned above. Stace the first model conductor includes the tin alloy in the second stages only, the first stage may be carrled out elther by bydrostatic extrusion or conventional extrusion. On the other hand the second model ca.juctor factudes the $t$ in alloy in both stages and therefore both stages tust be carried out by hydrostatic extrusion. The advantages and disadvantages of the two approaches will be discussed. In order to produce a sufficient quantity of $\mathrm{Mb}_{3} \mathrm{Sn}$ of high eritical current density, filawents on the order of $4 p$ dianeter $w 111$ be included in the destgn. From the value of critical current for $\mathrm{Nb}_{3} \mathrm{Sn}$ at $12 \mathrm{Tesla}$ and $4.2 \mathrm{~K}$ :

$$
\mathrm{J}_{\mathrm{c}}\left(\mathrm{Nb}_{3} \mathrm{Sn} ; 12 \mathrm{~T} ; 4.2 \mathrm{~K}\right)=2.02 \times 10^{5} \mathrm{~A} / \mathrm{cm}^{2}
$$

we may readily calculate the total cross sectional area of $\mathrm{Nb}_{3}$ Sn necessary in the conductor

$$
4.95 \times 10^{-2} \mathrm{~cm}^{2} \text { of } \mathrm{Nb}_{3} \mathrm{Sn}
$$

From this value and the size of the filaments we find that we will require on the order of 500,000 filamencs for the conductor. This is not an unreasonable figure for packing ta two stages.

The proposed conductor models are not intended to represent optimal conductors but rather good candldates based on careftil consideration of design restrictions. Furthernore, they sufficiently represent the advantages of the proposed metnod to be compared to conductors prepared by conventianal means. 


\subsection{Mode1 Conductor I}

This conductor is produced in two stages:

First stage: Elements of nioblum cores in copper with a composition ratio of $2 \mathrm{Cu}$ to $1 \mathrm{Nb}$ and facluding on the order of $500 \mathrm{Nb}$ filaments are produced. This ratio of copper to niobium takes into accout the minimus spacing mectioned previously as well as the need for a copper car which oecupies $15 \%$ of the crosssectional area of the billet, Containing no tin alloys, these elements can be prepared by conventional extruston of composite blllets. Hexagonal elements of cantalum protected copper must also be prepared for the second billet stacking. These elements may be prepared efther by the coextrusion of tantalum sheathed copper or by the insertion of hexagonal copper cods into hexagonal tantalum tubes. Also needed for the second stage billet are copper clad tin or copper tin alloy hexagonal rods for stacking finto the second stage billet. These elements may be prepared either by drawing a composite rod produced simply by inserting a tin alloy rod into a copper tube up to $2^{\prime \prime}(5 \mathrm{~cm})$ outside diameter or by hydrostatically extruding a billet of larger diateter.

Second stage: The hexagonal rod elements produced in the first stage for second stage packing will be about $0.22 "(.56 \mathrm{~cm})$ side to side. The tin alloy cores of the copper clad tin alloy rods are of largest size possible but not large enough to allow non a tio-copper phases to engulf the niobium filaments during the homogentzation heat treatment. This consideration dictates that the Sa $-16.7 \%$ Cu cores not be greater in are a than $68 \%$ of the copper clad hexagonal element. The billet can will consist of a tantalum tnner sheath protecting an outer shell of ofHC copper. The second stage billet cross section is represented schemstically in Figure 31 . The regions of tantalur protected copper distributed throughout the conductor and on the outside totals about $35 \%$ of the cross- 
sectional area. A unit cell of the packing is represented in Figure 32 . This unft ceIl contains 6 units of tantalum protected copper, 6 units containing the tin allog filaments and 24 elements of the $\mathrm{Wb} / \mathrm{Cu}$ composite.

The details of billet packing and the characteristics of the final conductor for Model Conductor I are sumarized in Table 4,1. In calculating the quantity of $\mathrm{Nb}_{3} \mathrm{Sn}$ resulting from reaction we have assumed a residual $4 \% \mathrm{Sn}$ in the reactive matrix and a $40 \%$ growth of the original $\mathrm{Nb}$ as a result of reaction to $\mathrm{Ab}_{3} \mathrm{St}$.

\subsection{Kode1 Conductor II}

First stage: Rather than producing the nlobium/copper and copper/Sn $-16.7 \% \mathrm{Cu}$ composite elements separately in the first conductor, a single billet containing, all three elements is extruded in the first stages of Model Conductor II. Unlike the first conductor, the slze of the tin alloy filawent is not restricted by the region of non a phase resulting from homogenization but rather by the : requirement that all hexaganal elements be of the same size. The copper clad tin alloy elements used In the first stage billet w11l have $80 \%$ of their cross section occupied by the $t$ in alloy. A schematic representation of the first stage packing is shown in Figure 33. A unit cell of the first stage billet hexagonal rod stacking is shown in Figure 34.

Second stage: The second stage billet represented schematically fn Figure 35 has a pure copper can with a tantalum sheath serving as a diffusion barrier in the ffual conductor. Within the ewo concentric cylindrical tubes is the group of tantalum clad copper and $\mathrm{Nb} / \mathrm{Cu} / \mathrm{Sn}-16.7 \% \mathrm{Cu}$ hexagonal elements. A unit cell of the packing in the second atage billet is shown in Figure 35.

\subsection{Nodel Conductor III}

This conductor is likewlse produced in two stages. In the first stage as shown In Figure 37 a niobium/copper composite is produced having 735 niobiut cores. 
The ratio of copper to niobium of this first stage composite is 1.5 . This composite is drawn tc a hexagonal rod and clad with pure tin. The clad rods are redrawn through a hexagonal die and stacked in the second stage billet along with hexagonal rods consisting of tantalum clad copper as shown in Figure 37. The billet packing and conductor characteristics are sumarized in Table 4-3.

\subsection{Model Conductor IV}

In this conductor the superconducting fllaments consist of niobium tubes each Irrounding a regtion of the tin alloy and pure copper. The first stage billet shown In Figure 38 consists of 735 niobium tubes in a copper matrix. This bil.let is extruded hydrostatically and dram to a hexagonal rod for restacking into a second stage billet as shown in Figure 39. This billet is dram to the conductar whose characteristics are sumartzed in Table $4-4$.

\subsection{Processing of Conductors}

Calculations in the previous chapter indicate that some increase in extrusion ratio is gained by cooling the extruded rod. However, in order for the raasure to be effective the extrusion speed must be substantially reduced. By applying cooling and reducing the extruston speed to $.13 \mathrm{ft} / \mathrm{min}$, the extruston ratio of an 8 " diameter billet can be increased from 4.7 to about 9 (assuming the properties of hard copper). The option of extrusion with a ratio of 4.7 and continuing the reduct ion to total ratio of 9 to 1 by drawing would probably be more expensive In view of the considerable amount of handling involved. In any event the difference between the two options would have little impact on the total cost of the processed conductor In view of the many other processing steps involved. 
There may be more effective means of removing heat from the extruding billet. One may be by the direct cooling of the dfe region but this would undoubtedly Involve the design of a spectal press. Another means thay be to reduce the billet temperature below room temperature prior to extruslon. These measures should be congldered in the optimization of the extrusion.

The use of a hydrestatic extrusion press such as that budlt by ASEA with a chamber of about 50" length would be preferred. However: since none presently exist in this country, the use of a converted extrusion iess in the manner developed by Battelle is the most likely altemative. The cost of converting such a press is a vexy small fraction of the total conductor cost for such a large device as FERF, The cost of operating such a press will tost Iikely be Less than for a conventional press in view of the reduced die wear because of the cold extruston.

The extruded rod is drawn on a conveational draw bench to either a hexagonal Iod if an intermediate stage 1s involved or to the final conductor. No anneals are requilred and reduction will proceed with much fewer problens than with either NbTi/Cu composites or bronze/Nb composites because of the higher ductility of the components in the proposed design.

\subsection{Compartson of Conductor Designs}

The ftrst two model conductors show Immediate fabricability based on our experiments. The third could undoubtedly be made with some modification of this design if not by the specific procedure outlined. The fourth is an adaptation of a design presently under development. 
The first model conductor involving only one hydrostatic extrusion appears to have at least two advantages over the second. One advantage ts that the first model conductur involves only one hydrostatic extrusion whereas the second involves two, In view of greater complexdty of the hydrostatic reduction process, one pay speculate that there is an economic advantage to the process relying the least on hydrostatic extrusion. Another fmortant advantage of the first model conductor is that it requires less reactive matrlx for the production of a given quaritity of $\mathrm{Nb}_{3} \mathrm{Sn}$ than the second model conductor. This is due to the fact that the second model conductor requires more superfluous copper sheathing in the construction of the first blliet. However, innovations in billet prepatation techniques may eliminate this disadvantage. An advantage of the second model conductor however is that because of the reduced tin alioy filament size a reduction in the homogenlzation heat treatment time would be realized.

The most interesting of these conductor options is the fourth. An obvious advantage of this approach is the significant reduction tn the quantity of reactive matrix over a bronze composite. Other advantages relate to the larger area ratio of the niobium tube to the reactive matrix as compaced to an analogous composite using 13 wt \% Sn bronze. Construction of billet elements Involve the use of niobium tubes with a larger wall thickness to dlameter ratio than that which would be used in a similar compasite involving a $13.5 \mathrm{wt} \%$ Sn bronze. The use of heavles walled tubes considerably reduces the likelihood of tube fraction which could be a considerable problem in view of the fact that 0500,000 tubes are used. In addition to this the cost of nioblum tube on a per pound basts would be cheaper for heavier walled tubling. 
Table 4-1

SUMARY OF WODEL CONDUCIOR I

FIRST STAGE

1. No/Cu elements drawn to a hexagonal cross section for stacking into the second stage billet have a $\mathrm{Cu}$ to $\mathrm{Nb}$ ratio of 1.9 to 1 and a total of 750 nlobium filaments.

2. $\mathrm{Cu} /(\mathrm{Sn}-16.7 \% \mathrm{Cu})$ bexagonal comosite rods having $68 \%$ of their cross section occupied by the tin alloy core prepared for the second stage billet.

3. Hexagonal tantalum clad copper elements having $80 \%$ of thefr cross section occupled by copper are prepared for the second atage billet.

4. If the second stage billet is $8^{\prime \prime}(20.32 \mathrm{~cm})$ diameter, the hexagonal elements produced in the first stage will have the dimensions $0.216^{\prime \prime}$ $(.549 \mathrm{~cm})$ side to side.

SECOND STAGE

5. Percentage of the cross sectional area of the second stage billet occupied by copper can: $18 \%$

6. Percentage of cross sectional area occupled by tantalum sheath: $5 \%$

7. Number of $\mathrm{Nb} / \mathrm{Cu}$ elements in the second stage packing: 576

8. Number of tantalum protected copper regions in the second stage: 144

9. Number of copper/(Sn $-16.7 \% \mathrm{Cu})$ rod elements: 144

CONDUCTOR CHARAGTERISTICS

10. Total number of niobium f1laments: 432,000

11. Nominal diameter of fllaments: $4,0 \mu$

12. Critical current at $12 \mathrm{Tesla}, 4.2 \mathrm{~K}: \quad 10,000 \mathrm{Amps}$

13. Percentage of cross sectional area which is tantalum protected high conductivity copper: $35.8 \%$

14. Percentage of area which is $\mathrm{Nb}: 17.7 \%$

15. Percentage of area which is reactlve matelx: $46,5 \%$

16. Area of niobiun prtor to reaction: $5.44 \times 10^{-2} \mathrm{~cm}^{2}$

17. Area of $\mathrm{Nb}_{3} \mathrm{Sn}$ following reaction: $4.95 \times 10^{-2} \mathrm{~cm}^{2}$

18. Percentage of ort!jual niobium fllament reacted: $65 \%$

19. Cross sectional area of final conductor: $.3073 \mathrm{ctr}^{2}$

20. Cross sectional dianeter of round conductor: $.626 \mathrm{~cm}$

21. Cross sectional. dimenstons of conductor with $2: 1$ aspect ratio:

$.784 \mathrm{~cm} x .390 \mathrm{~cm}$ 
Table 4-2

SIMMARY OF MODEL CONDUCTOR II

FIRST STAGE

1. Cross sectional area of first stage composfte billet occupled by copper can: $1 \mathrm{j} \%$

2. Percentage of cross sectional area occupied by $\mathrm{Nb}$ in the first stage composite btllet: $25 \%$

3. Percentege of first stage billet occupled by $\mathrm{Sn}: 16.7 \% \mathrm{Cu}$ alloy: $22 \%$

4. Per:entag: of first stage billet occupied by Cu: $63 \%$

5. Number of niobium fllaments in the first stage billet: 745

SECOND STAGE

6. Number of hexagonal elements contafning $\mathrm{Mb}, \mathrm{tin}$ alloy and copper: 630

7. Number of hexagonal elements containjog tentalum protected copper: 105

8. Percentage of cross sectional area occupled by copper can: $18 \%$

9. Percentage of cross sectional area occupied by tantalum sheath: 5\%

CONDUCTOR CHARACTERISTICS

10. Area occupied by tantalum protected copper: $34 \%$

11. Area occupied by nlobium filaments: $16,5 \%$

12. gercentage of area occupied by react Ive matrix: $49.5 \%$

13. A.ud of reactive matrix to area of nioblum filament: $3.0 / 1$

14. Area of $\mathrm{Nb}_{3} \mathrm{Sn}$ after reaction: $4.95 \times 10_{\mathrm{q}}^{-2} \mathrm{~cm}^{2}$

15. Percentage of nlobium fllament reacted: $60 \%$

16. Critical current at 12 Tesla, 4.2 K: 10,000 Amps

17. Nominal diameter of filaments: $4.0 \mu$

18. Nubber of filaments: 469,000

19. Area of nioblum prior to reaction: $5.89 \times 10^{-2} \mathrm{~cm}^{2}$

20. Conductor cross sectional area: $.357 \mathrm{~cm}^{2}$

21. Dimensions of tound conductor: .574 en diameter

22. Dimenstons of conductor of $2: 1$ aspect ratto: $.845 \mathrm{cto} \times .422 \mathrm{~cm}$ 


\section{Table 4-3}

SURMARY OF YODEL CONDUCTOR III

\section{FIRST STAGE}

1. Construction of composite b11le including 745 nloolum cores having a copper/niobium ratio of 1.5 to 1 .

\section{SECOND STAGE}

2. Number of tin clad Mo/Cu hexagonal elements: 630

3. Number of hexagonal elements contafniug tantalum protected copper: 105

4. Percentage of cross sectional area occupied by copper can: $18 \%$

5. Percentage of cross sectional area occupied by tantalum sheath: $4 \%$

\section{CONDUCTOR CHARACTEY ISTICS}

6. Area occupled by tantalum protected copper: $34 \%$

7. Area occupled by niobiun filaments: $23 \%\left(5.89 \times 10^{-2} \mathrm{~cm}^{2}\right)$

8. Percentage of area occupled by reactive gatr1x: $43 \%$

9. Area of reactive matrix co atea of niobium filaments; 1.87

10. Area of $\mathrm{Nb}_{3} \mathrm{Sn}$ fater reaction: $4.95 \times 10^{-2} \mathrm{~cm}^{2}$

11. Percentage of niobium filament reacted: $60 \%$

12. Critical current at 12 Tesla, $4.2 \mathrm{~K}: 10,000$ Amps

13. Nominal dameter of filaments: $4,0 \mathrm{\mu}$

14. Number of fllaments: 469,000

15. Area of aiobium prior to reaction: $5.89 \times 10^{-2} \mathrm{~cm}^{2}$

16. Conductor cross sectional area: .256

17. Dimensions of round conductor: .571 con diameter

18. Dimensions $c$ conductor of $2: 1$ aspect ratio:, $715 \times .358 \mathrm{~cm}$ 
Table 4-4

SUMMARY OF MODEL CONDUCTOR IV

\section{FIRST STAGE}

1. Number of nlobium tubes: 745

2. Percentage of first stage billet occupled by nioblum tubes: $48{ }^{\circ}$

3. Percentage occuplert by pure copper outside nioblum tubes: $10 \%$

4. Percentage occupled by tin $-16.7 \%$ copper: $18.6 \%$

5. Percentage accupfed by pure copper inside niobium tubes: $23.4 \%$

SECOND STAGE

6. Percentage of area occupied by nioblum: $38.4 \%$

7. Percentage occupled by copper outside tubes: $28 \%$

8. Percentage occupled by copper instde tubes: $18.7 \%$

9. Percentage of area occupied by $t i n-16.7 \%$ Cu: $14.9 \%$

\section{CONDUCTOR CHARACTERISTICS}

10. Ratio of reactive matrix to niobium: .875

11. Area of $\mathrm{Nb}_{3} \mathrm{Sn}$ after reaction: $4.95 \times 10^{-2} \mathrm{~cm}^{2}$

12. Percentage of nlobium tube reacted: $60 \%$

13. Number of tubes: 469,000

14. Area of niobium prior to reaction: $5.89 \times 10^{-2}$

15. Conductor cross sectional area: $.153 \mathrm{~cm}^{2}$

16. Dimension of round conductor: $.443 \mathrm{~cm}$ diameter

17. Digensions of conductor of $2: 1$ aspect ratio: $.277 \times .553 \mathrm{~cm}$ 




Nobium/copper composite

elements produced in the

first stage

$\xi$

8

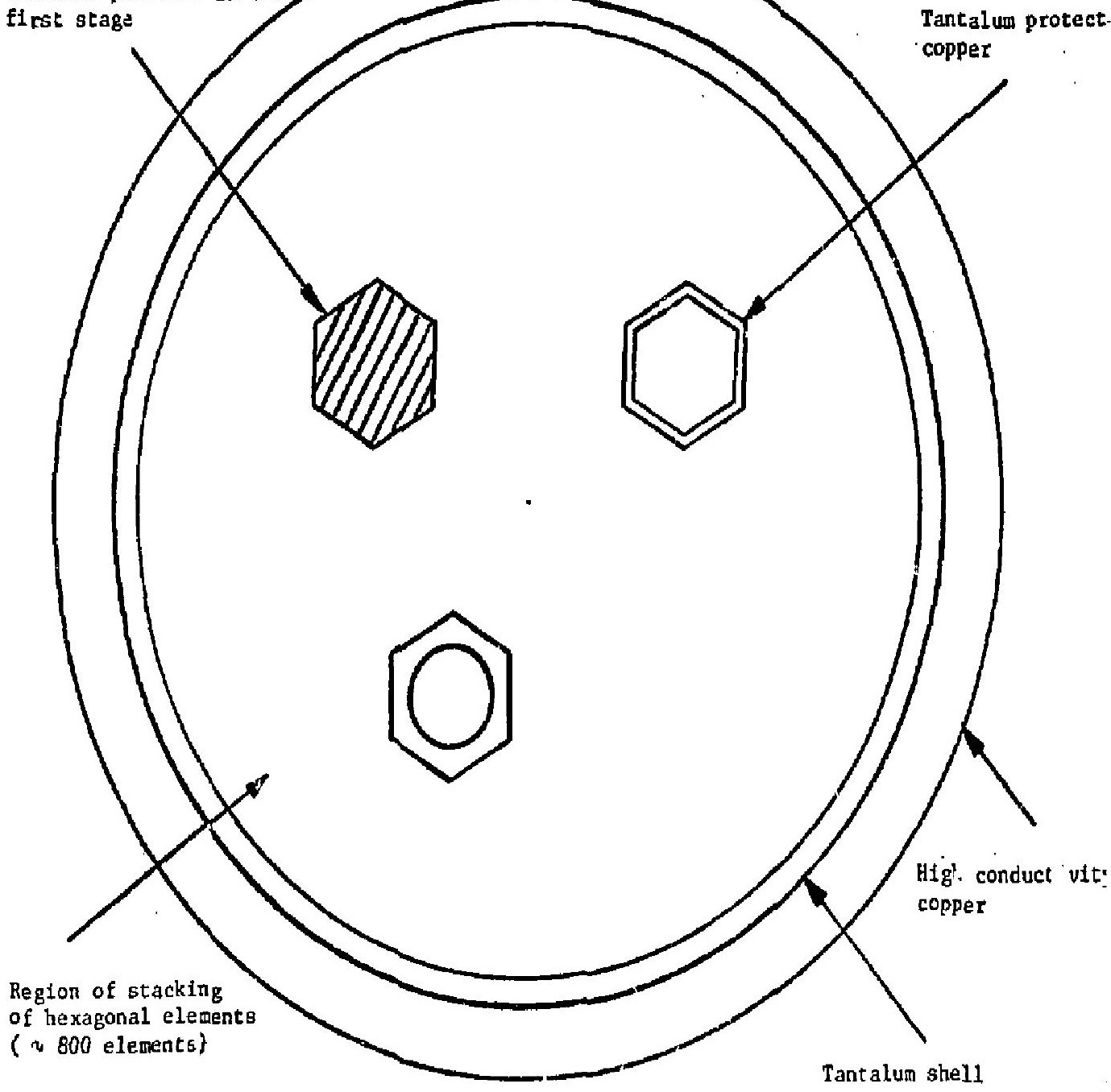

7

Figure 31. Schematic representation of the second stage of billet packing for Model Conductor I 


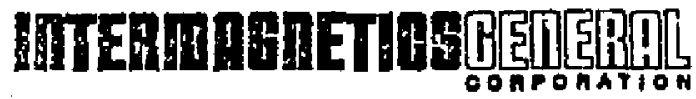
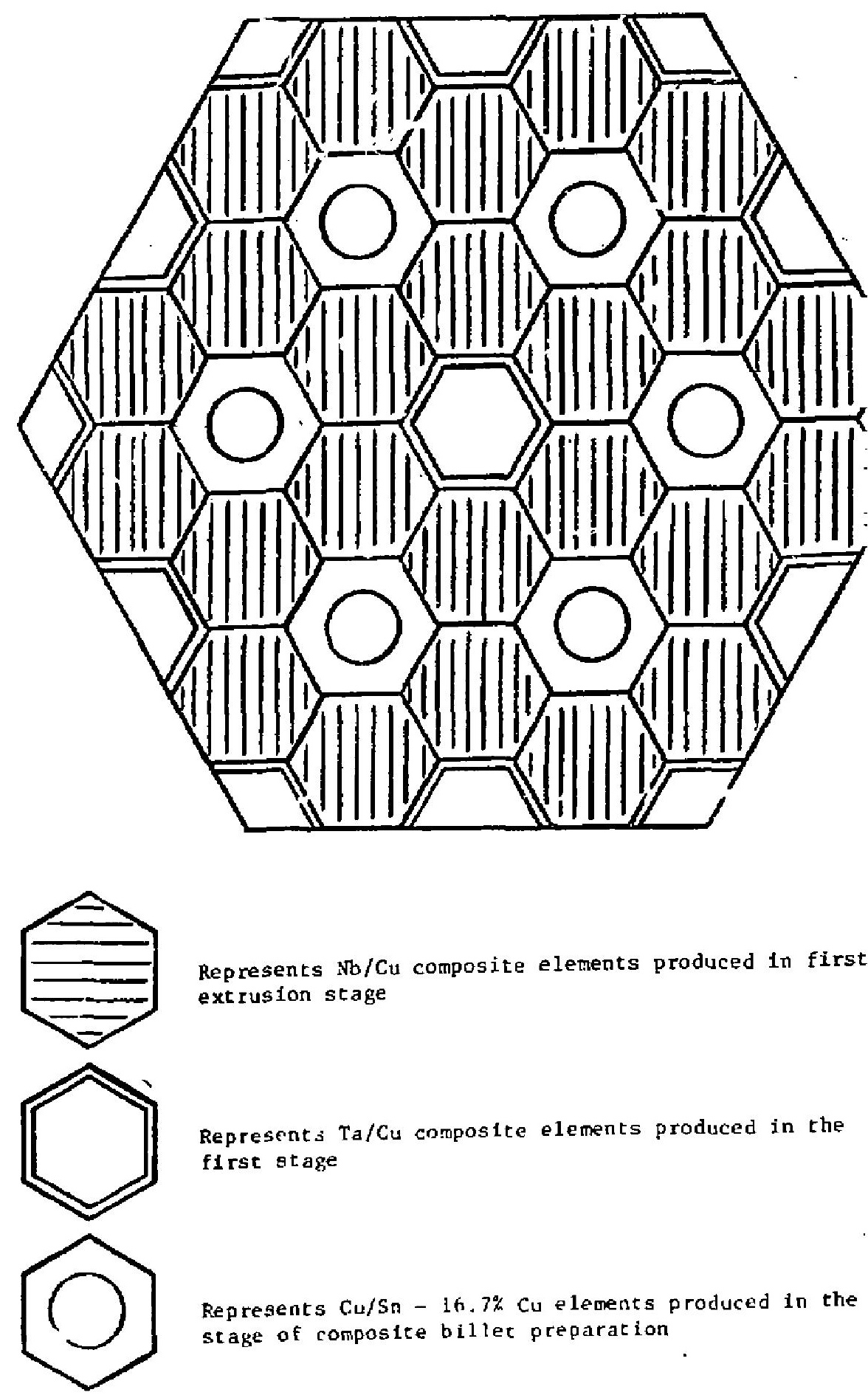

Represents $\mathrm{Nb} / \mathrm{Cu}$ composite elements produced in first extrusion stage

Represent: Ta/Cu composte elements produced in the first atage

Represents Cu/Sn - $16.7 \%$ Cu elements produced in the stage of composite billet preparation

Figure 32. Untt cell of billet stacking for stcond stage extrusion of todel conductor I

$$
c-4
$$




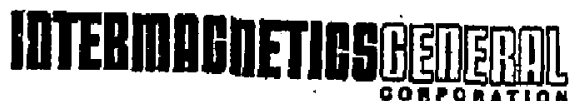

Nobium fllament in a copper sheath
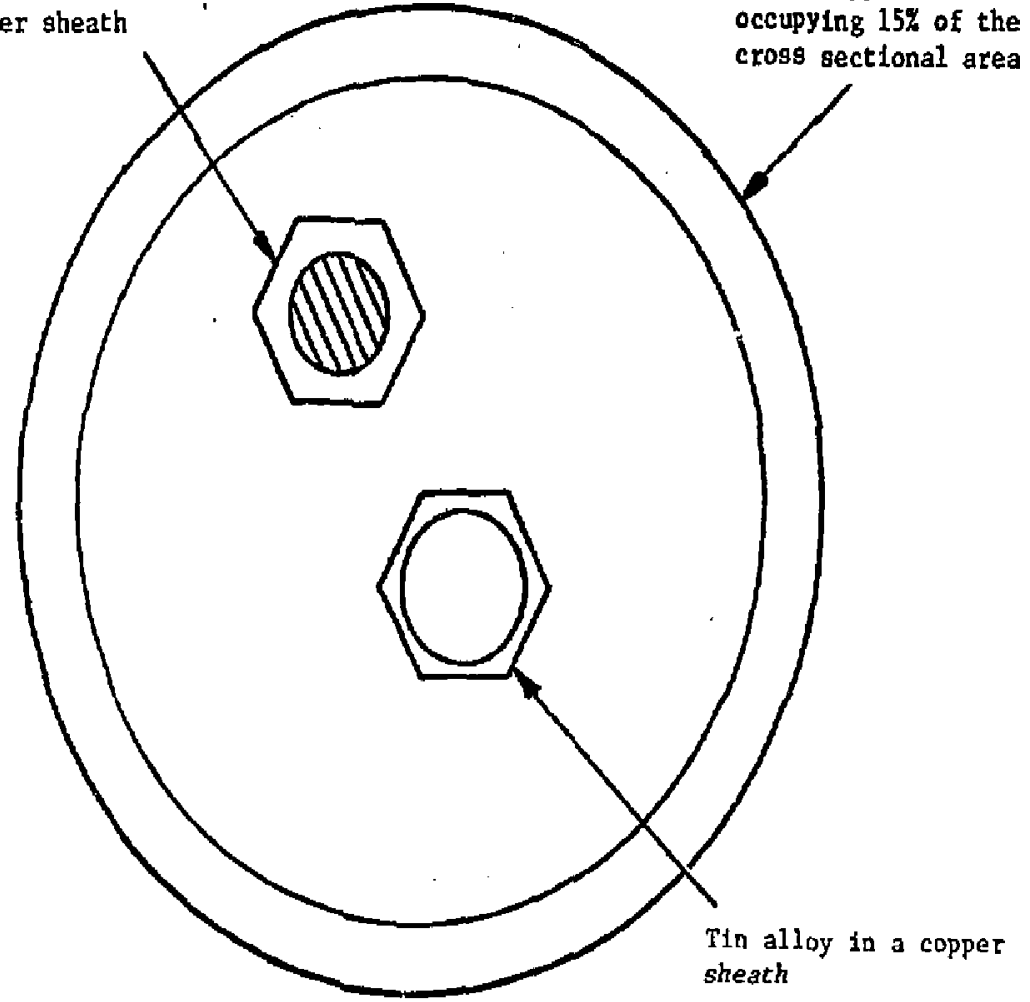

Figure 33. Schematic representation of the first stagt of billet packfag for Model Conductor II 


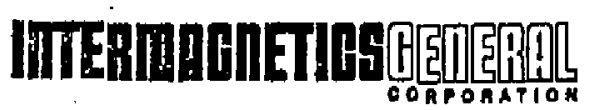
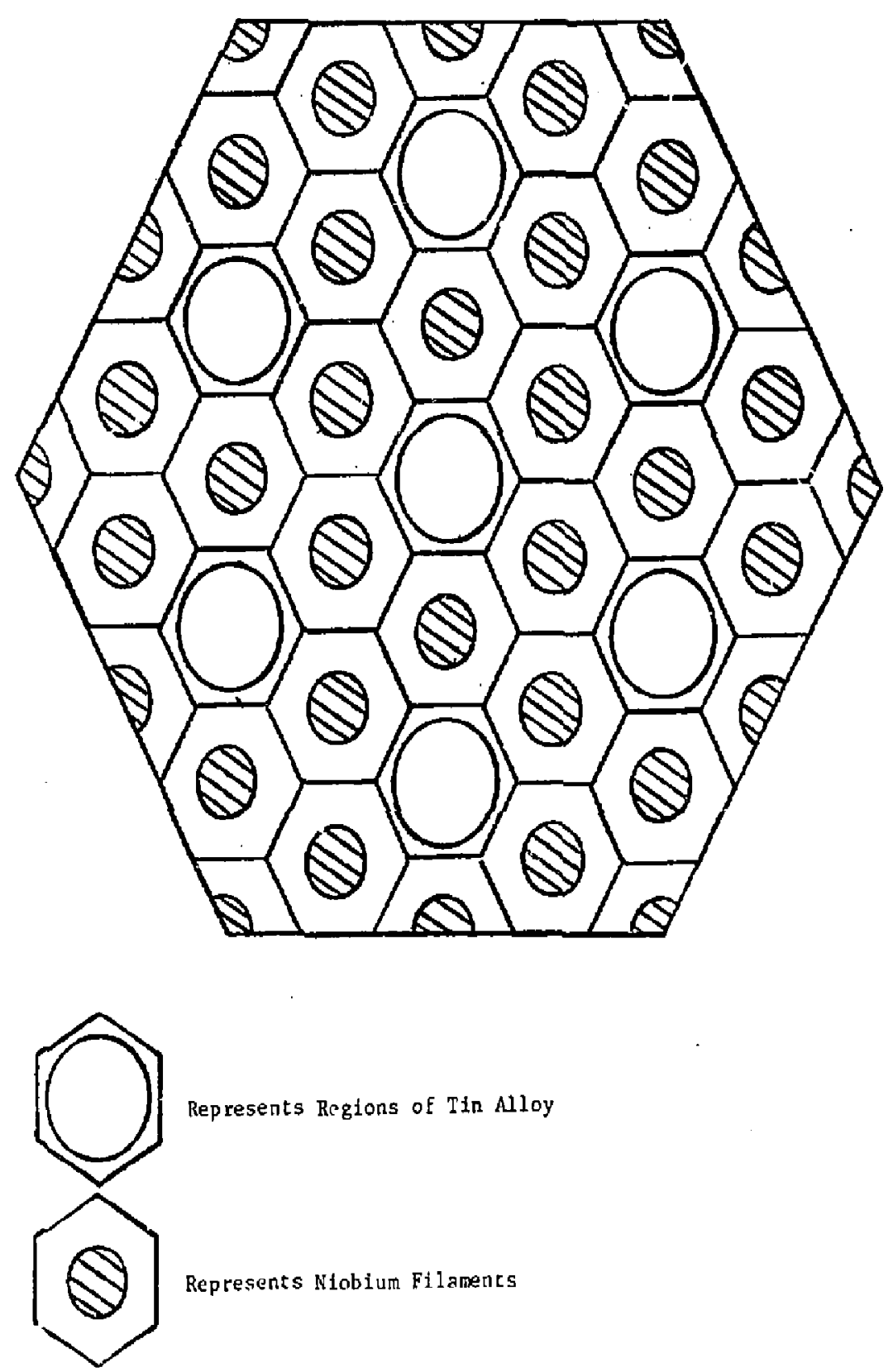

Figure 34. Unit cell of the first stage of packing of Model Conductor II 


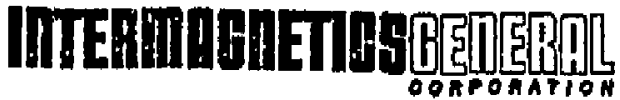

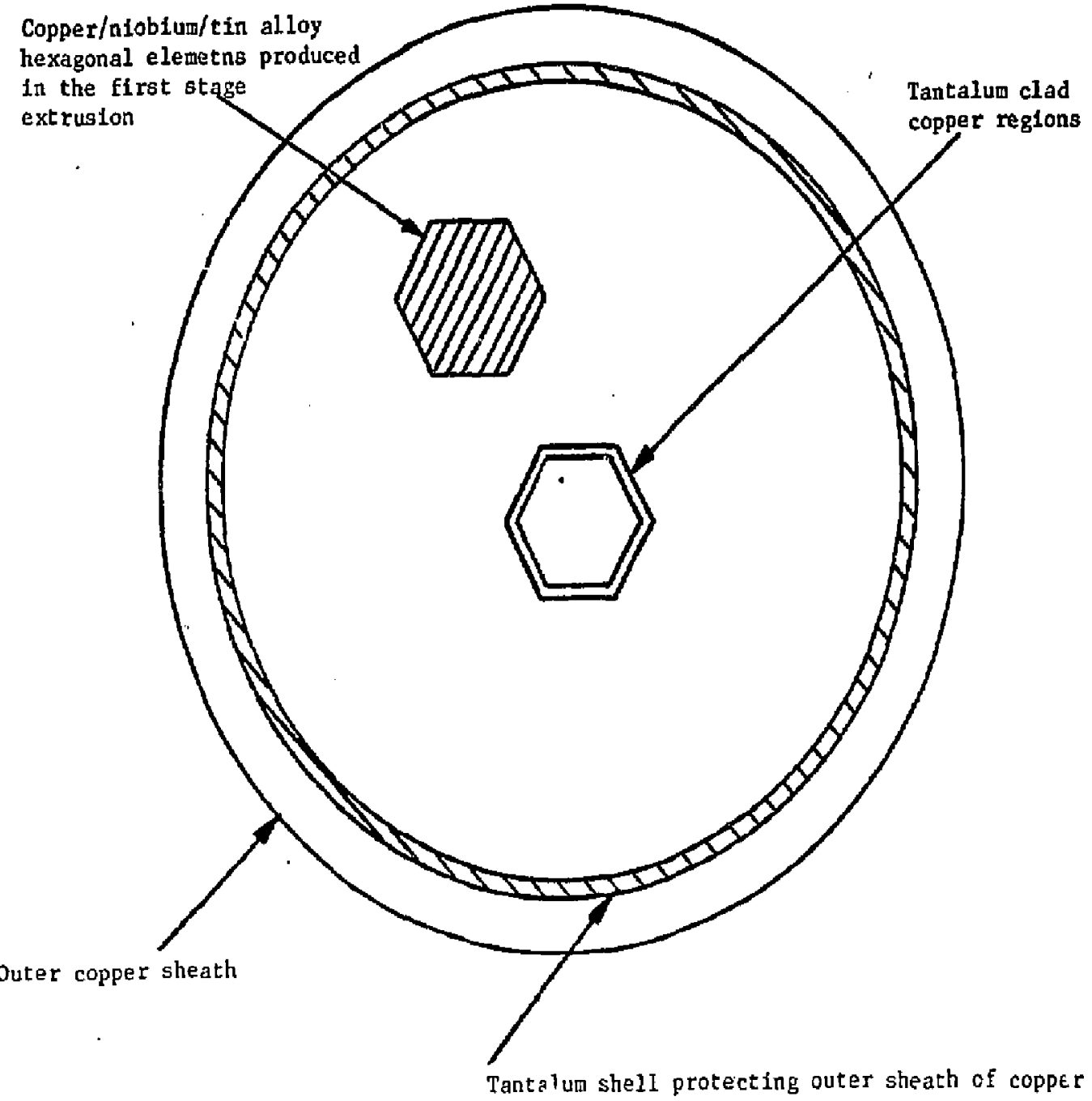

Figure 35. Schematic representation of the second stage billet of Model Conductor $T$ ? 

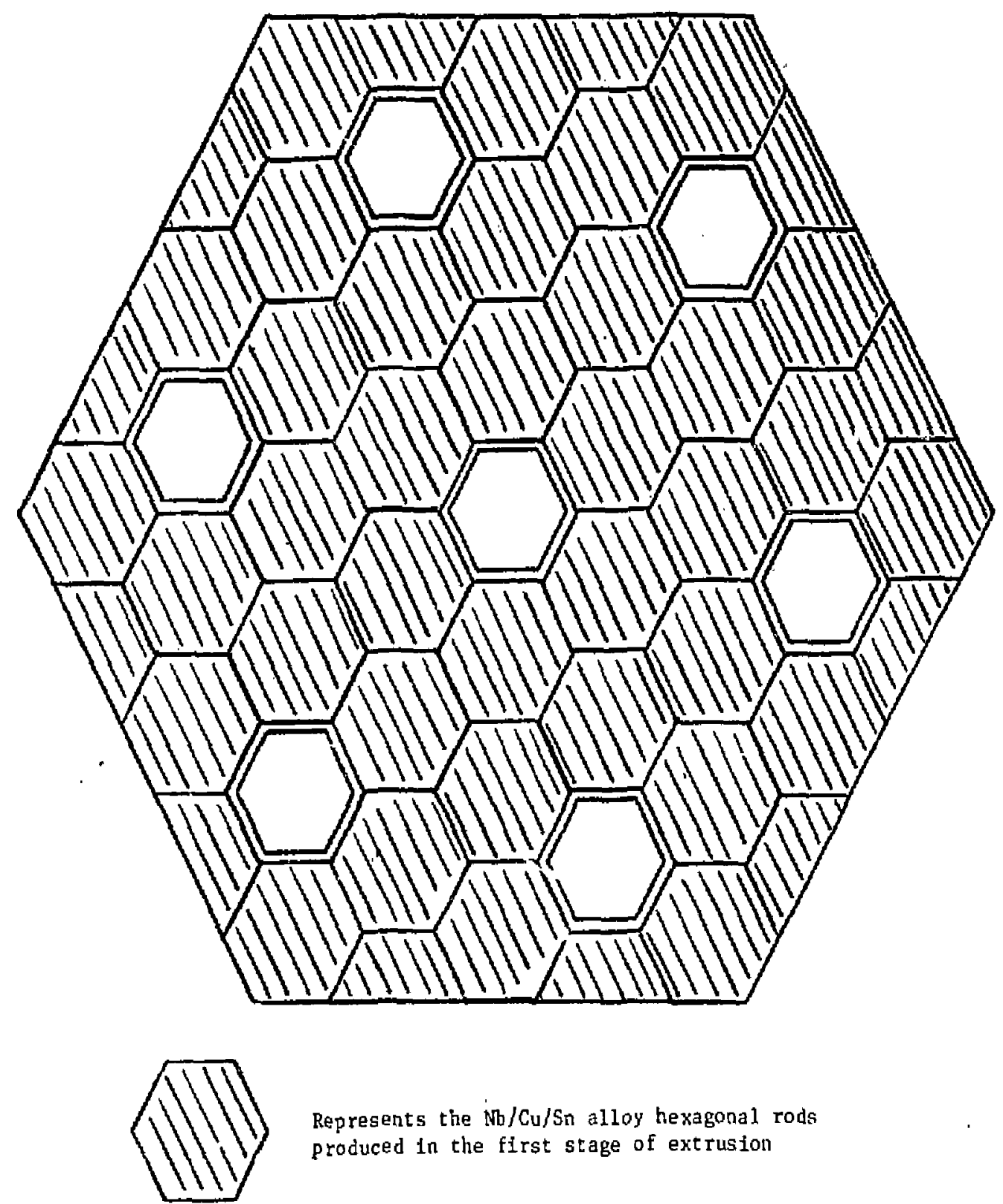

Represents the $\mathrm{Mb} / \mathrm{Cu} / \mathrm{Sn}$ alloy hexagonal rods

produced in the first stage of extrusion

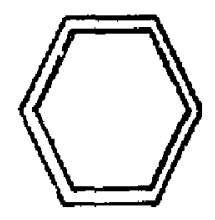

Represents the la clad coppit elements included

for stabilization.

Figure 36. Unit cell of stacking of hexagonal elenents in

the second stage billet of Model Conductor II 


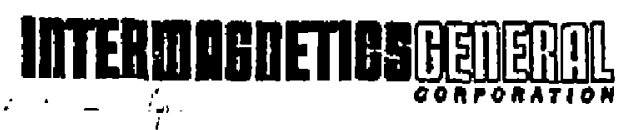

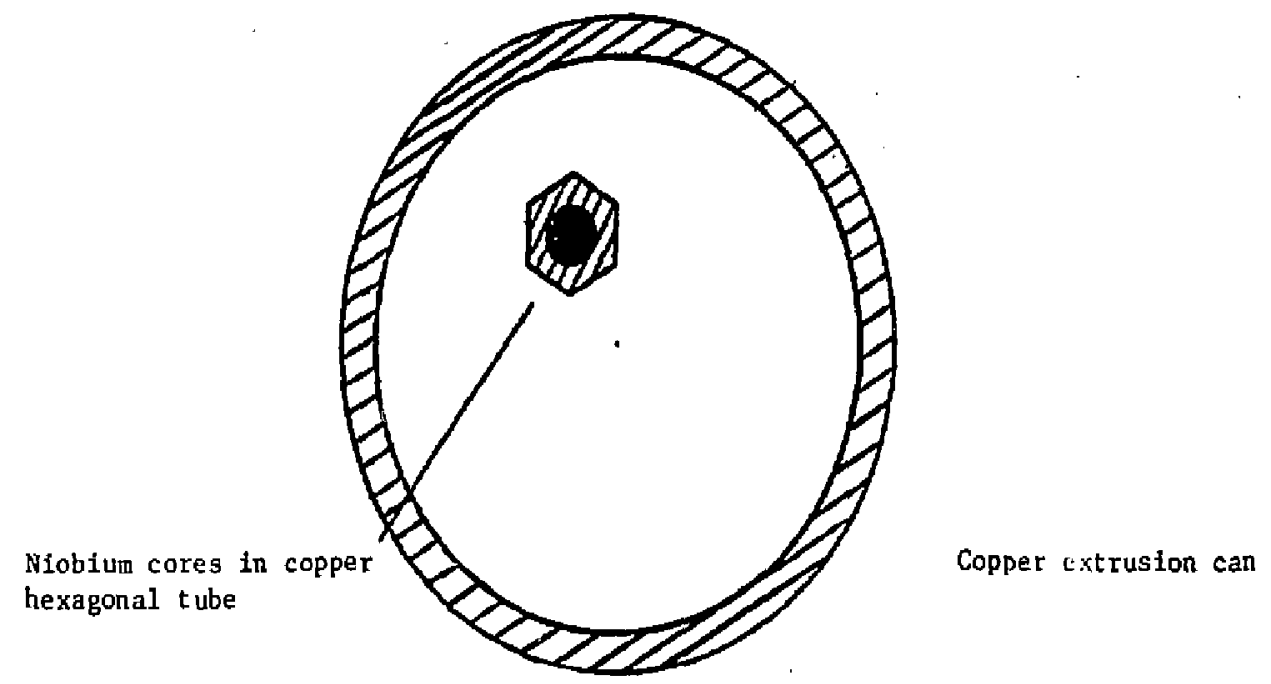

Fitst Stage Billet

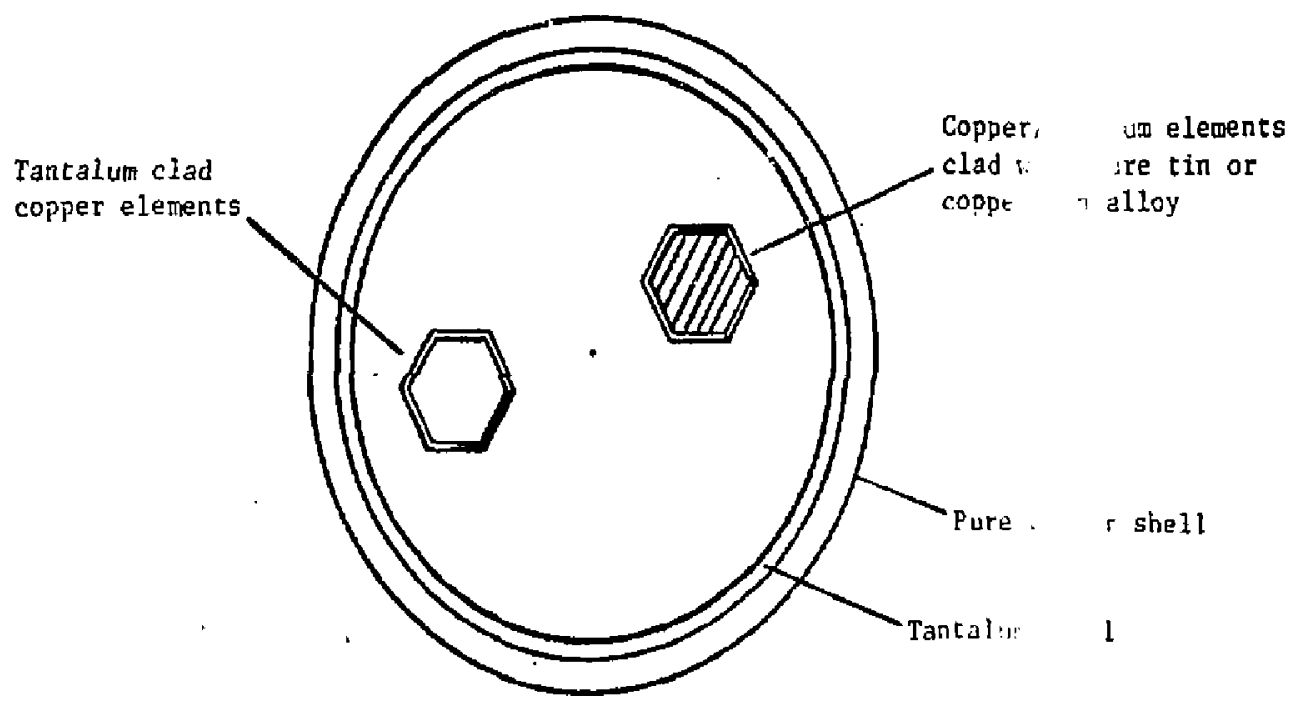

Second Stage Brllet

Flgure 37. Conductor III: First stage and second stage parkinu 


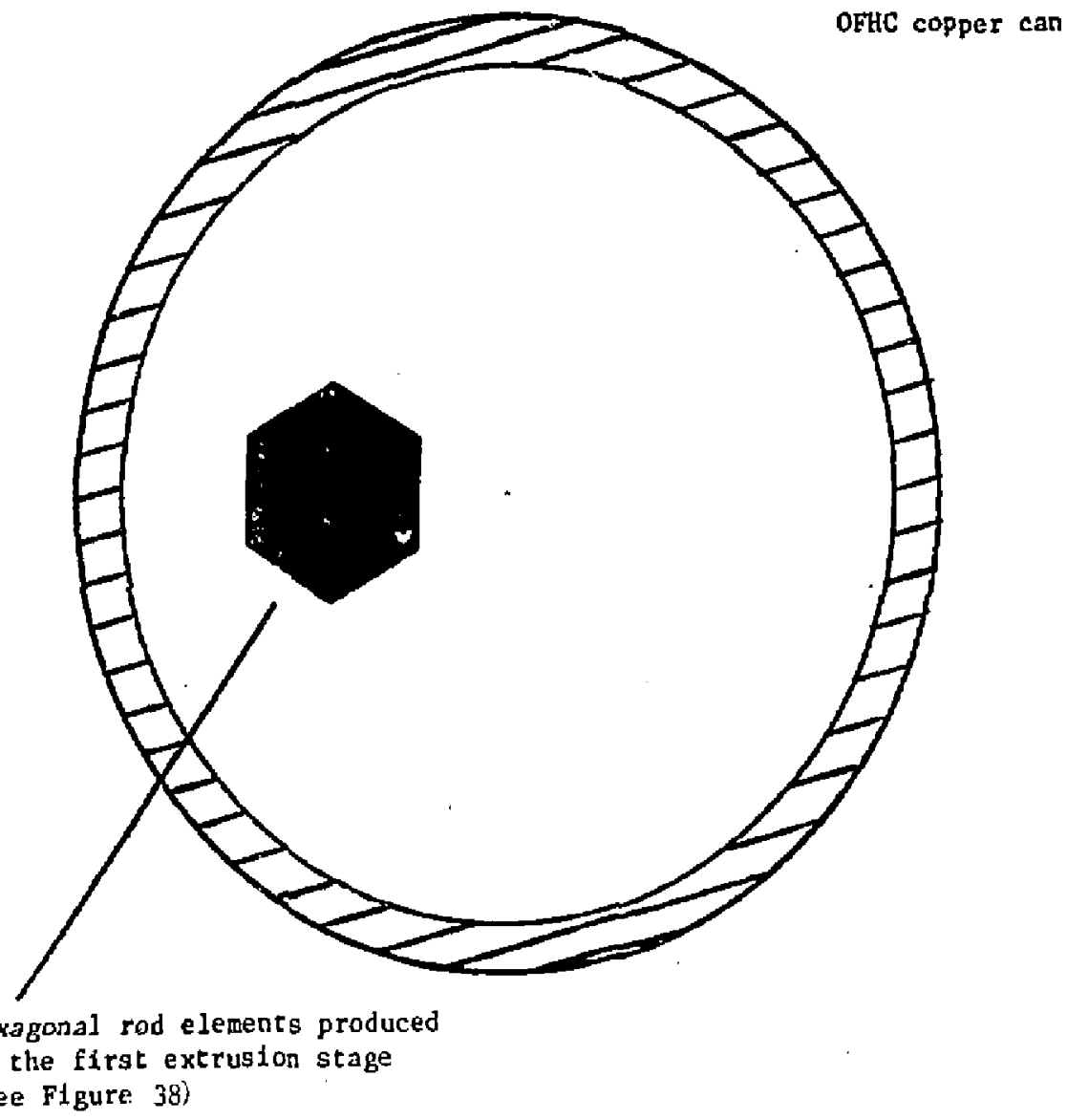

Figure 39. Conductor IV: Second stage billet preparation. 


\subsection{ECONOMIC CONSIDERATIONS}

There are several factors which affect the cost of a multifliamentary $\mathrm{Nb}_{3} \mathrm{Sn}$ conductor, Among these are:

1. The amount of reactive matrix necessary to produce a given quantity of $\mathrm{Nb}_{3} \mathrm{Sn}$. The bronze in conventional compoite serves only to carry the tin which is uged to react the aiobfim filaments. Followiag the reaction the depleted bronze serves tho useful purpose. The use of a tin Ifch alloy in copper provides hope of reducing the voluio of this reactive matrix thereby reducing the awount of materlal which wust be carried through the processing to produce a glven quantity of $\mathrm{Nb}_{3} \mathrm{Sm}$ superconductor.

2. The critical current denstty of the $\mathrm{ib}_{3} \mathrm{Sn}$. Increasing the critical current density of $\mathrm{kb}_{3} \mathrm{Sn}$ also increases the amp-meter yleld per pound of material processed.

3. The cost of the Individual processing steps.

4. The yield per extrusion.

In this chapter we w111 evaluate these aspects of the conductor designg described in Chapter 4.

\subsection{Quantity of Reactive Matrix Necessary to React the Niobium Filaments}

The most tangible Increase da conductor yield results from the feduct ton of matrix required tc produce a given quantity of $\mathrm{Nb}_{3} \mathrm{Sn}$. To factlitate tne comarison of the conductor models with a composite Including a 13.5 wt $\%$ bronze, Table 5.1 has been constructed. This table lists the matrix to nfobfum rat to for $60 \mathrm{z}$ and $100 \%$ reaction of each of the model composites and a 13.5 wt \% bronze composite.

For $60 \%$ reduction only conductors 3 and 4 provide a reduction of conductor size over a 13.5 wt $\%$ Sn bronze composite for the same current carry'ig capacity. For $100 \%$ reaction all if the model conduetors provide a it luciton of conductor 
stze from a 13.5 tt $\%$ bronze. This reduction ranges from $17 \%$ to $64 \%$ for podel conductors 2 and 4 respectively.

Since the cost of the conductor per pound is roughly the save for all of these conductors and since the cost of processing is considerably wore per pound than the raw materials, the cost reduction is roughly proportional to this reduction in conductor volume.

\subsection{Cost Differences Resulting From Modiftcations of the Processiag}

The processing of the model conductors differ in geveral significant ways from that of a composite consisting of brodze, nioblum and puze copper protected by a diffusion barrier. Each of the model ccnductorg of Chapter 4 Involve at least one and in some cases two hydrostatic extrustons. Fabrication of a comosite Including a 13.5 wt $\%$ brotize Itust be carried out in these conventional extrusions. Since the rodel conductors are all primarily copper, the frequent anneals required for bronze composites are elininated. Model Conductor IV has two spectal features which affect its cost of fabrication. It involves aioblum tubes which are more costly to fabricate than nioblum rod and it has no tantalum sheathing which usually compises about $7 \%$ of the composites. Table 5.2 summarizes the processing differences from the 13.5 wt $\%$ Sn bronze for each of the model conductors and the Ir fopact on the cost of processing per pound of conductor.

\subsection{Other Factors Affecting Condurtor Cost}

In addition to the two factors discussed, there are at least two other factors which may result in a cost advantage of the proposed conductora over a bronze composite. One is the result of higher critical current densities of $\mathrm{Nb}_{3} \mathrm{Sn}$ resulting from improved reaction teinetics and the other results from the Improved billet yield possible with hydrosiatic extrusion. 
There has been speculat lon that reaction of the nfobium fllaments should be carried out to only a linited extent such as $60 \%$ or less because beyond that the strain corresponding to an unacceptable level of degradation may be too low. For this level of reaction conductors 1 and 2 provide no reduction in reacrive matrix from that in a 13.5 wt of Sn bronze. However, as a result of the aúlilty to inctease the quantity of tin avallable witb the relatively small increase in the volume of the reactive watrix, one maj maintain tin concentrations close to the maximum solubility of tin in copper over most of the reaction. In a bronze composite, however, the tin concentration decreases from its saturation level as the reaction proceeds. The result is a generally lower rate of $\mathrm{Nb}_{3} \mathrm{Sn}$ formation for the 13.5 wt I $\mathrm{Sn}$ composites. Lower rates of $\mathrm{No}_{3} \mathrm{Sn}$ formation meat longer reaction times and consequently lower critical current densities in the $\mathrm{Nb}_{3} \mathrm{Sn}$ for the bronze composites. The gield per unit of nfoblum or per unit of material processed is therefore expected to be lower for 13.5 wt I sn comosites even for limited ataction of the th filaments.

As discussed in Chapter 2, redused extruded rod discard is expected per extrusion for hydrostatic extrusion because of the reduced die angles posstble. This reduction in discard may be as much as $10 \%$ per extrusion which result in a cost savings of as much as $17 \%$. 
Table 5.2

PROCESSING MODIFICATIONS FOR THE MODEL CONDUCTORS

AND THE RESULTLNG PERCENTAGE CHANGE IN

COST OF PROCESSING PER POUND OF MATERLALI

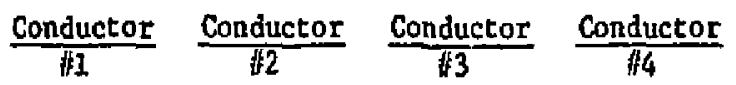

1. Cost change regulting from seduction of the number of extrustons. (Including the consideration of the increased yleld from the starting materials).

$$
-14 \%
$$$$
-14 \%
$$$$
-14 \%
$$

2. Cost change resulting from differences in raw waterlals.

$0 \%$

$0 \%$

$+7 \%$

$+21 \%^{2}$

3. Cost reduction resulting from the elfmination of intermedtate anneals.

4. Cost increase resulting from the small extrusion ratio which necessitates additi c al rod drawing

$+5 \%$

$+5 \%$

$+5 \%$

NET CHANGE

'Compared to a 13.5 wt $\%$ bronze/niobium composite de:igned 5 a $60 \%$ reaction.

${ }^{2}$ Includes the addition due to cost of nioblum tubes and the reduction due to the elimination of the tantalum 


\subsection{SUMMARY \& CONCLUSIUNS}

\subsection{Economlc Advantages}

1. Four pract lcal. conductor configurations containing a $\mathrm{Sn}-16.7 \%$ Cu high tin bronze reactive matrix were designed and analyzed to assess the potential economlc advantege offered by the high tin bronze compared to a conventional multifilament $\mathrm{N}_{3} \mathrm{Sn}$ conductor produced with a $\mathrm{Cu}-13.5 \%$ sn low tin bronze.

2. The most afgnificant cost advantage of the $h t g h-t$ in bronze is assoctated with the reduction in the area of the conductor cross section, and consequently in che conductor welght, required to produce a specified critical current. The reduction in welght of materlal per ampare meter is a direct consequence of the utilization of a much smaller overall quantity of bronze to provide roughly the same apount of $t$ For reaction to form $\mathrm{ND}_{3} \mathrm{SD}$.

3. Although only two of the four designs showed a potentlal 1mprovement in amp-meter yield per pound over conventional composite for $60 \%$ reaction of the $\mathrm{Nb}$ fllaments, all of them showed an fmprovement for 90\% reaction.

4. Conductor 4, the econonically most attract fie of the four conductors has the potential for providing a $40 \%$ cost savings per ampere meter of conductor when compared to the conventional composite. This cost reduction 1 s the net difference between a cost Increase of 87 (per pound of conductor) and an approximate factor-of-two reduction in the area of conductor crass section requited to produce a spectfled critical current. The $8 \%$ cost tncrease $1 \mathrm{~s}$ assoct.ated with the added cost of fabricating with expensive No tubes. The cost comparison is made between conductors which contain 1slands of bronze and $\mathrm{Mb}_{3} \mathrm{Sn}$ within copper, where the minimum awomt of copper that permits fabrication, about $30 \%$ of the overall cross gection, has been utilized in each case. Reaction of $60 \%$ of the $\mathrm{Nb}$ has been assumed, and the fraction of the cross section which is $\mathrm{Nb}_{3} \mathrm{Sn}$ is consequently higher for condcutor 4 . The influences of increased $\mathrm{Mb}_{3} \mathrm{Sn}$ fraction and fllament configuration upon the mechanlcal propertles of the conductor hâs not bee assessed. 


\subsection{Bydrogtatic Extrustion}

1. Because the high tin bronze is relatfvely soft and may become liquid during extruston, fabrication by hydrostatic extrusion and drawing are required to process conductor from this materlal.

2. The economics of high tin bronze processing is therefore related to the availability of hydrostatic extrusion facilitieg and the capabtlities of those facilities by comparison with processing by convelitional means.

3. Although four hydrostatlc extrusion facllities capable of axtruding $7^{\prime \prime}$ dlameter blllets have been produced in Sweden, none of these presses are 10 the United States. However, an altemative to the purchase or construction of hydrostatic presses is available by the conversion of a conventional press in the manner developed at Battelle Laboratory. For example, the cost of conversion of a conveutional press to a hydrostat ic extrusion press capable of extruding billets of 8-10 inch diameter would be about $\$ 100,000$. This represents 1ess than $1 \%$ of the cost of the $7 \times 10^{4} \mathrm{~kg}$ of multifilamentary conductor to be used in FERF.

4. Additional potential e. onomic benefits resulfing from the high tin bronze hydrostatic extruston process are reduced discard of the extrusion product and elimination of costly anneals characteristic of processing bronze composttes.

\subsection{Advancages For Co11 Construction}

The largest single length of conductor which can be manufactured is very important to the construction of a coll. The shorter the conductor lengths the more frequently foints must be made and the more frequently foints are made the more difficult coll construction becomes. Increasing the unit lengths of ronductor can be accomplished either by increasing the critical current density of the composite or by Increasing the volutre (1,e. billet size) of the single unit. 
The maximum volume of the single unit 18 determined by the largeat avallable draw bench and the same limitation exigts for both conventionally and hydrostaticaliy extruded composites. Therefore, the use of a bigh tin bronze nultif1lameptary $\mathrm{Nb}_{3} \mathrm{Sa}$ composite, which results in an 1mprovement in current density over a low tin bronze composite, wt1l lead to greater untt lengths of conducror, and advartages in coil construction.

\subsection{Experimental Results}

1. The prelitinary compost te bfllet extrustons carried out In this study Indicate that sound extruston of a hard copper and tin alloy compostes can be accomplished at billet speeds of $6 \mathrm{ft} / \mathrm{min}$ and an extrusion ratio of 4.7 to 1 . Higher reduction ratios w11 require lower speeds and fluid cooling of the tooling and extrusion product or the replacement of hard copper with annealed copper.

2. Our experiments Indicate that sound comosites congloting of at least 70\% tin of efn-copper alloy can be produced for billet stackfng.

3. We also vertfied the work of Hashimoto et $a^{3}$ showing that a composite containing a tin rich copper tin alloy can be drawn to amall diameters $(2.2 \mathrm{~mm})$ without disturbing the tin alioy fllaments, 


\subsection{RECOMMENDATIONS}

Having shown that wultifilamentary composites containidg a reactive watrix of pure tin or tin - $16.7 \%$ copper has a considerable potential for reducing conductor cost and having demonstraced the ability to fabticate billet components, we recommend that as the next stage in the study of this type of composite IGC continue with the construction of $2^{\prime \prime}-3^{\prime \prime}$ diameter full compostte billets. The recommended degtgns are those of Model Conductors 3 and 4 which provide the greatest potential reduction in conductor cost.

Surcegsful fabrication of a 10,000 anp conductor from the $2^{\text {" }}$ to $3^{\prime \prime}$ diameter billets would then be followed by scale up to a conmercial sized billet is cooperatton with either Battelle Laboratory or the National standard Comany which presently operates a hydro extrusion press in Scotland. 


\subsection{REFERENCES}

1. Ziurys, E. J., "Supercanducting Magnet Development Program for Fusion Power Application", Proceedings of the Fifth International Magnet Technology Conference, Rome; Italy, April 1975.

2. Hansen, M., Congt1tution of Binary Alloys, McGraw-H1ll Book Co., Inc., New Lork, 1958.

3. Hash1moto, Y., Yosh1zaki, K., Tanaka, M., Proc. Fifth Int. Cryo. Bagr. Conference, Kyoto, 1974.

4. Anon., "Aydrostatic Bxtrusion - A Viable Hethod of Metal Forming, Metellurgia and Metal Eorming", October 1973, p. 325.

5. Bridgeman, P. W., Studies in Large Blastic Flow and Fracture, MeGtaw-H111 Book Co., Inc., New York, 1952 .

6. Avitzur, B., Metal Forming: Processes and Analysis, McGraw-Bill Book Co., Inc., New York, 1972 .

7. A.S.E.A. Pamphlet :AQ14-102E, "Quintus, Bydrostat1c Extrus1on Press Type Q.E."

8. Pfeffer, J. B., "Bydrostatic Extrusion - Now a Production Process", Soclety of Manufacturfng Engtneerg Technical Paper 1f74-209.

9. Bobrowsky, A. R., "Augrented Hydrostatic Extrugion", presented at the Manufacturing of $\mathrm{H}$ tr: Sonference of the Soctety of Shanufacturing Engineers, February 1976, Philadelphia, Penneylvanla.

10. Alexander, J, M., Lengyel, B., Hydrostatic Extrusion, Mills and Boon, London, 1975 .

11. Andrus, P., Schmehl, G., "Westem Electric Company Continuous Hydrostatic Wire Extrusion", Manufacturlag of thire Conference of the Soctety of Manufacturing Engineers, Eebruary 1976, Philadelphia, Pennsylvania.

12. Altan, T., Kobayashi, S., "A Numerical Hethod for Estimating the Temperature Distribut Ion in Extrusion Through Conical Dies", Joumal of Engineering for Industry, February 1968, p. 107.

13. Guha, R. M., Lengyel, $3 .$, "Temperatures in Aigh Speed lydrostatic ExtrusionDrawing with FrIction", Vol, 54, p. 117, January 1974.

14. Singer, A.R.E., Al-Samarra1, S. H. K., "Temperature Change Associared W1th Speed Varlation During Extrusion", Joumal Institute of Metals, Vol. 89, p. 225.

15. Suenaga, M., Horigani, O., Luhman, T. S., "Effects of Sn Concentration on the Critical Current Density of $\mathrm{Nb}_{3} \mathrm{Sn}$ Formed at the $\mathrm{Nb}-(\mathrm{Cu} \mathrm{Sn}$ Alloy) Interface", Applled Physics Letters, 25, 624 (1974). 
16. Lee, J. A., Olds, C. F,, Larbalagtier, D., "Some Aspects of Multifllamentary Wo 3 Sn Production", Colloques Internationaux, C.N.R.S. No. 242 - Physique cous Chamg Magnetique Interses.

17. 2wicker, V., Rindeter, I., "Uatersuchmgen zur BL1dung der $\mathrm{Nb}_{3} \mathrm{Sn}-\mathrm{Al} 5$ Phase bei Temperaturen unter $800^{\circ} \mathrm{C}, \mathrm{z}$. Netallktnde, Vol. 66, $312,4.739$, (1975).

18. Kawakatsu, I., Osawa, T., Yanaguchi, H., "On the Growth of Alloy Layers Between Solid Copper and Liquid Tin", Trans. T.I.M., 1972, Vol. 13, P. 436.

19. Oikawa, H., Hosol, A., "Interdiffusion in Cu-Sn Solid Solution - Confiruation of Anomalously Large Xirkendall Effect", Scripta Metallurgica, Vol. 9, pp. 823-828, (1975).

20. McAdams, W. H., Kennel, W. F., Minden, C. S., Rudolf, C., Plcornell, C., and Dow, J, E., "Heat Transfer at High kates to Hater with Surface Bolling", Ind. Eng. Chem., 41, September, (1945); Rohsenow, W. M., Cho1, H., Heat, Mars and Momentum Transfer, Prentice-Ha11, Inc., (1961).

21. Hilson, N. M., "Superconducting Materials: Some Recent Developments", presented at the 5th International Nagnet Technology Conference, Frascati, Italy, April 21-25, 1975.

22. Intermagnetics General Corporacion, "Cabled Multifilamentary Mb Sa Superconductar Development for the LLL-CTR Program", Flnal Report to Lawrence Liverwore Laboratory, Contract 16840305. 
APPENDIX A

\section{ZACTLTIES FOR HYDROSTATIC EXIRUSION}

The largest hydrostatic extrusion presses in existence are those produced by ASEA of Sweden. Although four of these large presses are now in exfotence, nore have been Installed in the United States. One of the presses is located in Scotland and operated by a subsidiary of the Amerlcan firm, Mational Standard Company. On a billet of $7 "$ (17.8 cm) diadeter and $50^{\prime \prime}(127 \mathrm{~cm})$ this press is capable of providing over 200,000 psi extrusion pressure. Doyle Rausch of the National Standard Company informed us that the press could be made avallable for the hydrostatic extrusica of superconducting composites. National Standard Company would also gladly respond Informally to requegts for extrusion cost Information on specific biliet sizes and extruston parameters.

Hydrostatic extrusion could also be accomplished through the conversion of a conventional ext.rtision press in the manner Investigated at Battelle. Individuals at Batcelle indicate that the conversion of a press for the hydrostatic extrusion of a billet 7" $(17.8 \mathrm{~cm})$ diameter at a pressure on the order of 200,000 psi would cost in the order of magnitude of $\$ 10^{5}$. There are several conventional presges In this comtry which could be converted for the hydrostatic extrugion of byllets of this size. The Battelle technique has been demonstrated by the conversion of a 2500 ton conventional press to a bydzustatic press capable of extruding 5" (12.7 c⿴囗1) diameter, $16^{\prime \prime}(40.6 \mathrm{~cm})$ leagth billete.

In addition to these full scale facilities there exist several experimental extruston presses whth might concelvably be used for the extrusion of auperconducting compostte billets. Several of these facilities are sumarized in Table A-1. 
Table A-1

SOME HYDROSTATIC EXTRUSION FACILITTES EXISTING IN THE UNITED STATES

\section{Location}

1. Westinghouse RED Center Pictsburgh, Pennsylvanla

2. Battelle Laboratory Colmbus, Ohto

3. Battelle Laboratary Columbus, OhIo

4. Stanford Univergity

5. Henet Weapo.ts Laboratory Hatervilet Argenal Watervilet, New York

\section{B11let Diametex}

$1.5^{11}(3.8 \mathrm{~cm})$

B11let Length

$8^{\prime \prime}(20 \mathrm{~cm})$

Preasure At

Given Diameter

150,000 pet

at 1.5.

300,000 peI

at i"

5" $(12.7 \mathrm{~cm})$

$16^{\prime \prime}(40.6 \mathrm{~cm})$

250,000 pa1

2 3/8" diameter

$12 "(30.5 \mathrm{~cm})$

300,000 pEL

(700 ton press)

$0.75^{\prime \prime}(1.91 \mathrm{~cm})$

$8^{12}(20 \mathrm{ct})$

250,000 pa1

at $0.75 " \mathrm{dia}$

500,000 peI

ac $0.375^{\prime \prime}$ dis

$1.0^{\prime \prime}(2.54 \mathrm{~cm})$

6" $(15.24 \mathrm{~cm})$

No Informacion avallable
300,000 pet ar $1.0 \mathrm{~W}$ de
Comment

Converted 2500 ton conventionel press

Vertical extrusion preas 


\section{APPENDIX B}

TOID FORMATION IN INTERDIFEUSED COPPER/TIN-16.7\% COMPOSTTES

Chapter 3 includes a photograph of a $0.015^{\prime \prime}$ diameter composite consisting of pure copper and tin - $16.7 \%$ copper after interdiffusion at $600^{\circ} \mathrm{C}$ for 60 hours. The photomicrograph showg soine degree of vold formation. The vold formation after interdiffusion should not be of an extent whicr. prevents the diffusion of tin Into the filament region. Several additional photomicrographs were taken of uther diffused composite cross sections and are shown in Figures B-1 to B-3. As indicated by the miform yellow color in the a-bronze region, the diffusion of tin at $600^{\circ} \mathrm{C}$ was not hincered by the roid formation. 


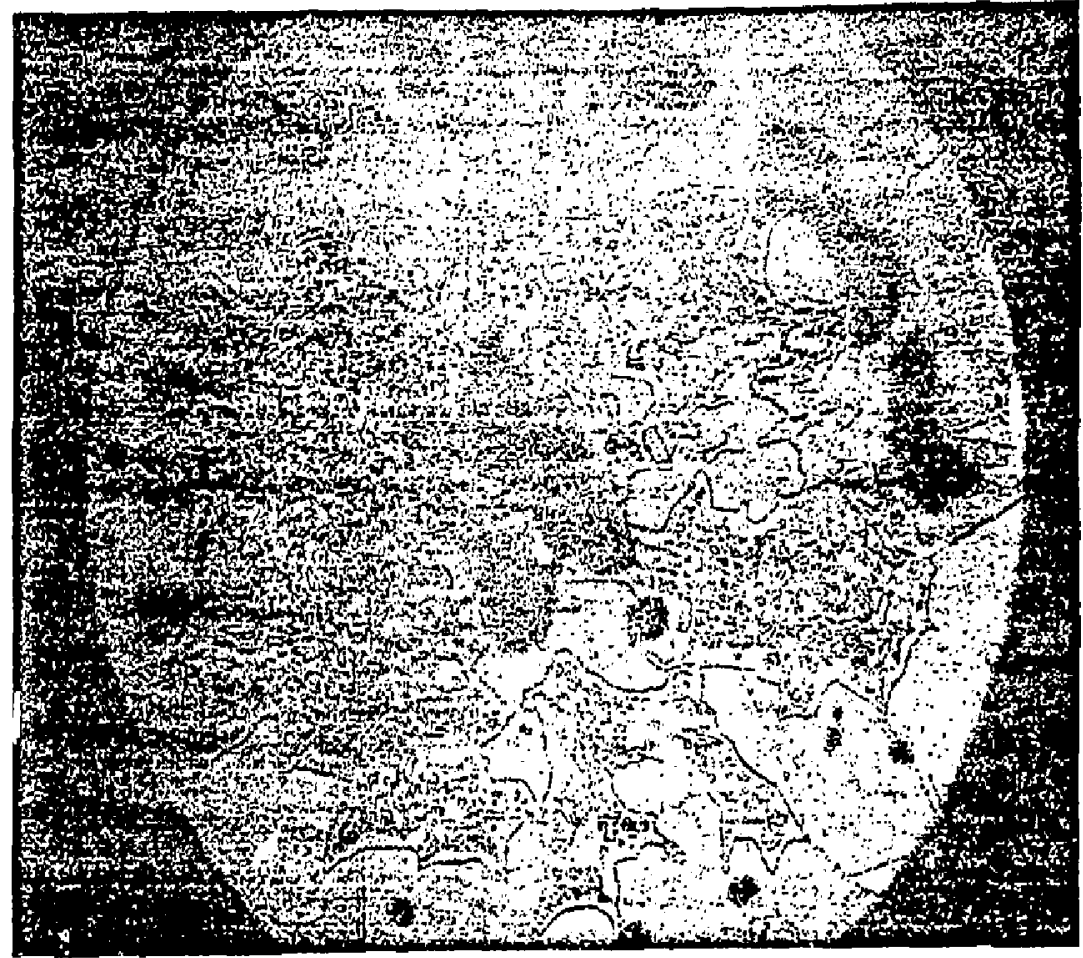

FIgute B-1

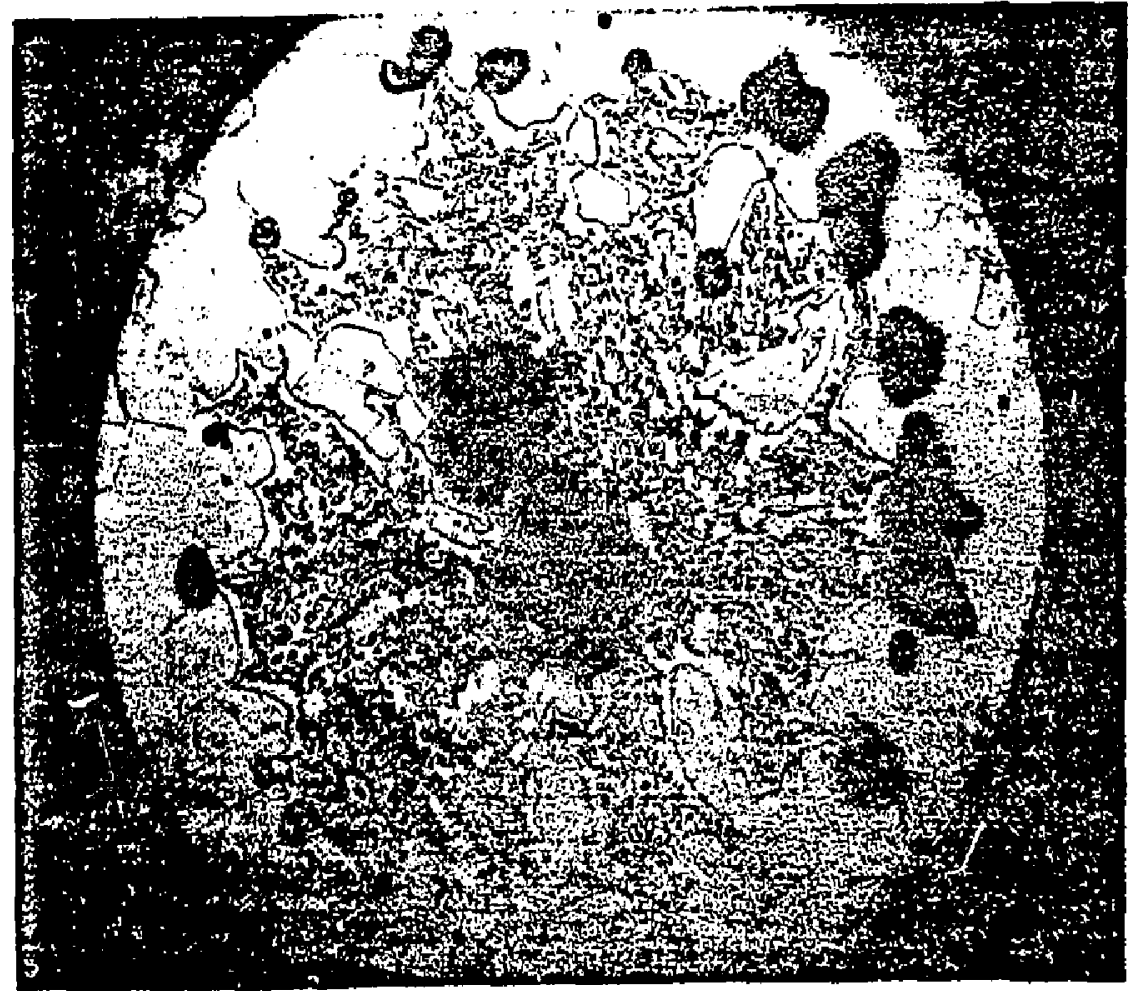

Figure B-2 


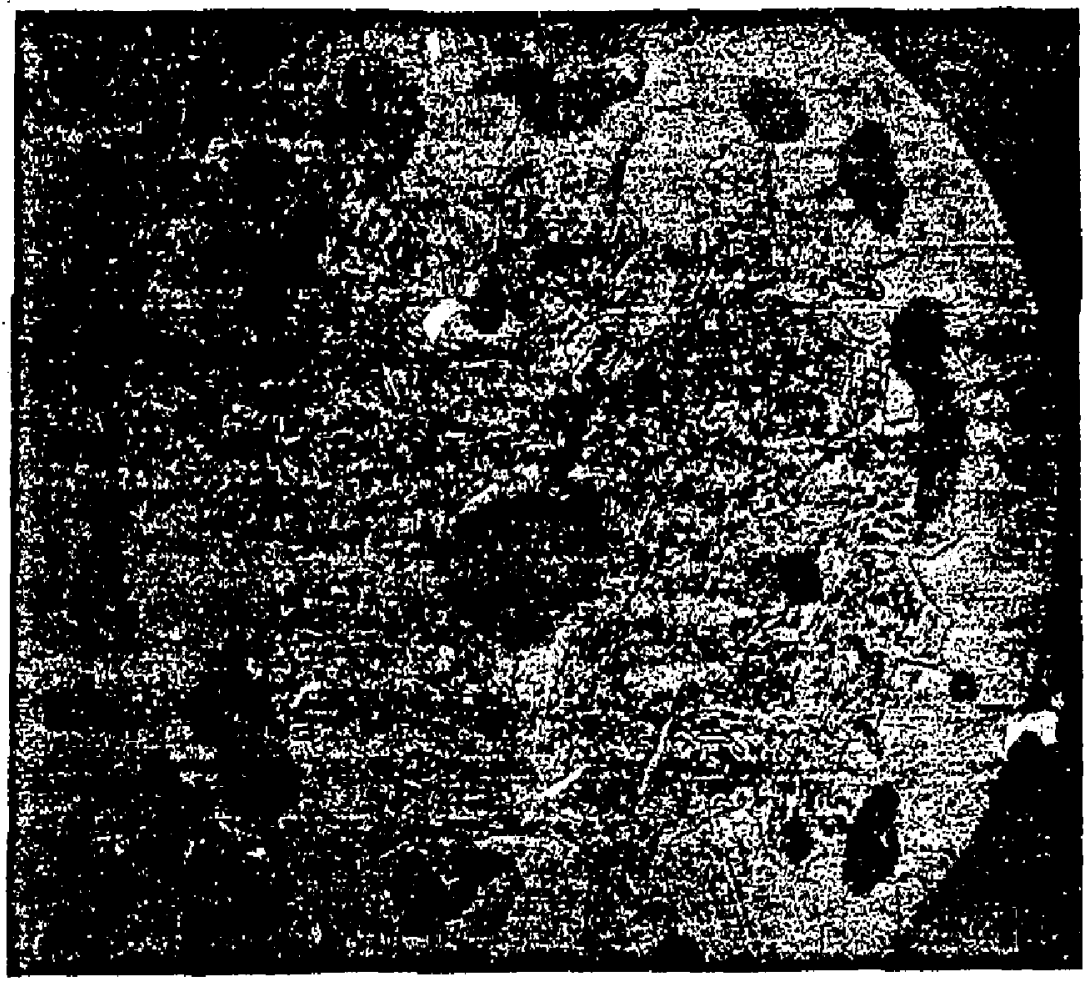

Figure B-3

Figures B-1 to B-3. Photomicrograph of a $0.015^{\prime \prime}$ dianecer copper/Sn $-16.7 \%$ Cu couposite interdiffused at $600^{\circ} \mathrm{C}$ for 60 hours.

'This report whs prepared an accousl of work the Unsored $y$ the United States Goretnment. Fieliher the Uniled Staies nor the United Stotes Energy Research \& Derslopment Administration, nor any of their emplojees, nor any of their antsoctor subeontraclots, of the dny of their canisoctors, wartanty, axpres or employees, makes any lebbllity or or implied, of assumics any legal conpistenoss or ustulisy for the dectrocy, apparatus, roduct of process disformstion, roptestents or process disclosed, or privplaly-otwred rights," 